Keywords: Concrete Cracking Transport Through Cracks Concrete Performance

Retention: Permanent

\title{
Transport Through Cracked Concrete: Literature Review
}

Christine A. Langton

April 2012

Savannah River National Laboratory Savannah River Nuclear Solutions, LLC Aiken, SC 29808

Prepared for the U.S. Department of Energy under contract number DE-AC09-08SR22470.

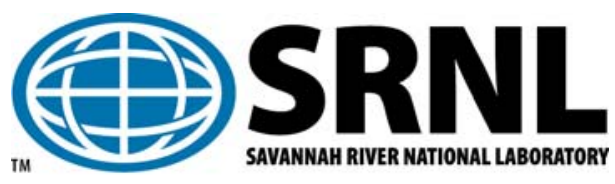




\section{DISCLAIMER}

This work was prepared under an agreement with and funded by the U.S. Government. Neither the U.S. Government or its employees, nor any of its contractors, subcontractors or their employees, makes any express or implied:

1. warranty or assumes any legal liability for the accuracy, completeness, or for the use or results of such use of any information, product, or process disclosed; or

2. representation that such use or results of such use would not infringe privately owned rights; or

3. endorsement or recommendation of any specifically identified commercial product, process, or service.

Any views and opinions of authors expressed in this work do not necessarily state or reflect those of the United States Government, or its contractors, or subcontractors.

\section{Printed in the United States of America}

Prepared for

U.S. Department of Energy 


\section{REVIEWS AND APPROVALS}

AUTHOR:

C. A. Langton, E\&CPT Research Programs

Date

TECHNICAL REVIEW:

G. A. Taylor, Radiological Performance Assessment / SRNL

Date

APPROVALS:

H. H. Burns, E\&CPT Research Programs Project Manager / SRNL

Date

K. M. Fox, E\&CPT Research Programs, Manager

Date

S. L. Marra, E\&CPT Research Programs, Manager

Date

K. H. Rosenberger, Waste Determinations, SRR

Date 


\section{ACKNOWLEDGEMENTS}

The study was funded by SRR Waste Determinations, Closure and Waste Disposal Authority to support SRS Performance Assessments. The literature review was performed by Professor Jason Weiss, Professor and Associate Head School of Civil Engineering Purdue University in response to SRR0000678 (RFPRQ00001029-WY). 


\section{TABLE OF CONTENTS}

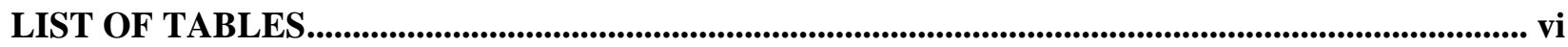

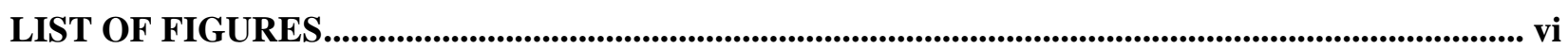

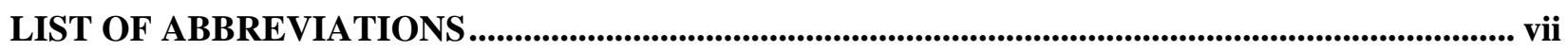

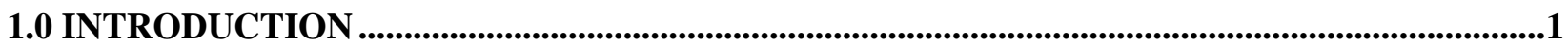

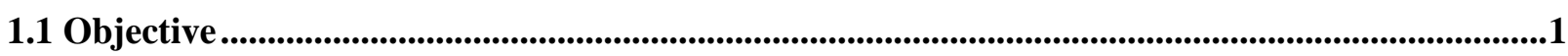

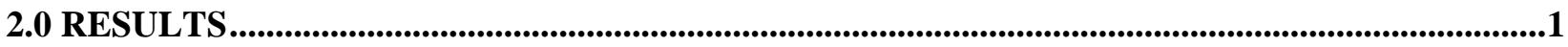

2.1 Size of Cracks Important For Moisture Transport and Frame Work for Describing Cracks....2

2.2 Framework for Describing Cracks in Concrete with Respect to Transport Modeling................2

2.3 Relationship Between Pore/Crack Size, Saturation and Relative Humidity .................................4

2.4 Depth to which concrete is influenced by surface drying ........................................................4

2.5 Time Required to Saturate Concrete in Soil with 100\% Relative Humidity.................................5

2.6 Relationship Between Rebar Corrosion and Cracking and Spalling..............................................5

2.7 Methods for Measuring Transport in Partially Saturated Concrete .................................................6

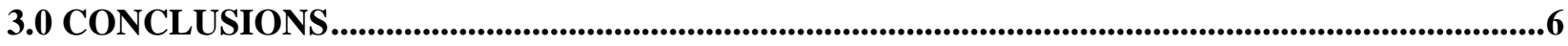

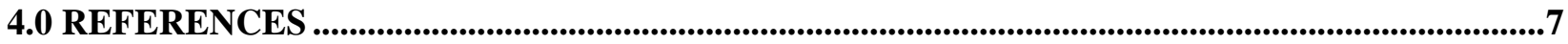

ATTACHMENT 1. Literature Review: Transport Through Cracked Porous Media with Emphasis on Concrete. 


\section{LIST OF TABLES}

Table 2-1. Framework for characterizing concrete cracks..................................................................3

\section{LIST OF FIGURES}

Figure 2-1. Effect of Drying on a Cured Concrete Wall as a function of Environmental

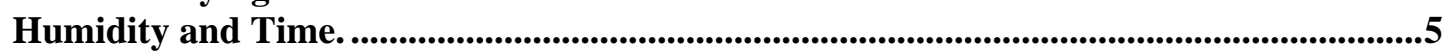




\section{LIST OF ABBREVIATIONS}

$\begin{array}{ll}\text { ASR } & \text { Alkali Silica Reaction } \\ \text { DOE } & \text { US Department of Energy } \\ \text { PA } & \text { Performance Assessment } \\ \text { RH } & \text { Relative Humidity } \\ \text { SLA } & \text { Service Level Agreement } \\ \text { SRNL } & \text { Savannah River National Laboratory } \\ \text { SRNS } & \text { Savannah River Nuclear Solutions, LLC } \\ \text { SRR } & \text { Savannah River Remediation, LLC } \\ \text { TTR } & \text { Technical Task Request } \\ \mu \mathrm{m} & \text { Micrometer }\left(10^{-6} \mathrm{~m}\right)\end{array}$




\subsection{INTRODUCTION}

Concrete containment structures and cement-based fills and waste forms are used at the Savannah River Site to enhance the performance of shallow land disposal systems designed for containment of low-level radioactive waste. Understanding and measuring transport through cracked concrete is important for describing the initial condition of radioactive waste containment structures at the Savannah River Site (SRS) and for predicting performance of these structures over time.

This report transmits the results of a literature review on transport through cracked concrete which was performed by Professor Jason Weiss, Purdue University per SRR0000678 (RFP-RQ00001029-WY). This review complements the NRC-sponsored literature review and assessment of factors relevant to performance of grouted systems for radioactive waste disposal [1]. This review was performed by The Center for Nuclear Waste Regulatory Analyses, San Antonio, TX, and The University of Aberdeen, Aberdeen Scotland and was focused on tank closure.

This work was performed as part of SLA-WSTD-00023 Revision 6 [1].

\subsection{Objective}

The objective of the literature review on transport through cracked concrete was to identify information in the open literature which can be applied to SRS transport models for cementitious containment structures, fills, and waste forms. In addition, the literature review was intended to:

1) Provide a framework for describing and classifying cracks in containment structures and cementitious materials used in radioactive waste disposal,

2) Document the state of knowledge and research related to transport through cracks in concrete for various exposure conditions,

3) Provide information or methodology for answering several specific questions related to cracking and transport in concrete, and

4) Provide information that can be used to design experiments on transport through cracked samples and actual structures.

\subsection{RESULTS}

The literature review prepared by Professor Jason Weiss, Purdue University, is included as Attachment 1. In summary, nomenclature for describing cracks, discrete (localized or localized through wall) and distributed (bulk or progressive damage originating on an exposed surface) was provided. Causes of the discrete and distributed cracks were provided in addition to general time of formation (early, during service, and severe loading events) for the various types of cracks. Modeling approaches documented in the literature for describing transport through discrete and distributed cracks were also summarized. Most of the data on transport through cracked concrete applies to saturated samples although a few reports on gas transport through partially saturated cracks were identified. Very limited information has been published on transport of moisture in cracked unsaturated concrete. The literature review by R. T. Pabalan, et al., provides some information on transport through partially saturated cracked media [2].

Information provided in this literature review was used to answer the following questions that relate to understanding the role of cracks with respect to gas and liquid transport.

1) Influence of crack size on moisture transportation under saturated and unsaturated conditions;

2) Framework for considering cracks when modeling transport; 
3) Relationship between pore/crack size, pore/crack saturation and relative humidity in the exposure environment;

4) Depth to which concrete is influenced by surface drying as a function of conditions and time;

5) Time required to saturate concrete in water or soil with a high relative humidity;

6) Relationship between rebar corrosion and concrete cracking/spalling;

7) Methods available for characterizing transport in partially saturated concrete.

\subsection{Size of Cracks Important For Moisture Transport and Frame Work for Describing Cracks}

In general very small cracks (10 microns) in concrete occur typically at the interface of the aggregate and paste. These cracks tend to be disconnected and are taken into account in the majority of transport property measurements of intact material. Consequently, these small interfacial cracks do not need to be modeled separately [3].

Discrete Cracks - Cracks with openings larger than $100 \mu \mathrm{m}$ (visible), discrete cracks, are not likely to be saturated unless the material is in water or exposed to very high relative humidity ( $>95 \%)$. These cracks have the potential to greatly influence fluid transport (permeability and diffusion) at high RH conditions. For saturated conditions flow through discrete cracks can be modeled as flow between parallel plates which correlates to the width cubed. However, the roughness of the crack necessitates a factor to reduce the effective crack width. At lower relative humidities, gas transport becomes more significant. In addition, the thickness of the fluid film on the surfaces on partially saturated pores and cracks in rocks is related to surface roughness of the pore/crack surfaces. However this relationship does not appear to have been widely adopted in the concrete literature.

Distributed Cracks - Some forms of physical and chemical damage result in a coalesced crack network (freeze-thaw, alkali silica reaction (ASR), sulfate damage). Flow through this network can be simulated using a "smeared" approach in which the fracture network is treated as a continuum and the fractures are not simulated independently. Rather, transport parameters are "averaged" to reflect the response of the damaged material. Property gradient as a function of distance from the surface due to the severity of cracking and location of the reinforcing steel are relevant for cracking related to exposed surfaces. The degree of saturation will influence 1) whether the cracks are saturated or empty based on the principles as mentioned above and 2) the potential rate of damage development as many reactions are related to the relative humidity and availability of water.

\subsection{Framework for Describing Cracks in Concrete with Respect to Transport Modeling.}

For this discussion on transport through cracks (discontinuities), cracks are defined as having one dimension of at least 40 to 100 micrometers which is in the size range of large unhydrated cement grains and an aspect ratio of $>1: 3$. Defects in concrete smaller than this are considered as part of the matrix and the impact of these discontinuities is accounted for in the properties of the undamaged material. In other words, the smallest crack that would be differentiated from a cement paste matrix for the purpose of describing transport phenomena would have dimensions of approximately 40 x $120 \mu \mathrm{m}$. Microcracks can be considered as having apertures of less than 70 to $100 \mu \mathrm{m}$ and lengths of at least $300 \mu \mathrm{m}$. Macrocracks are usually associated with visible cracks which typically represent cracks that are greater than 100 microns in width. Common causes of cracking in concrete are listed in Table 2-1. 
Table 2-1. Framework for characterizing concrete cracks.

\begin{tabular}{|c|c|c|c|c|c|}
\hline \multirow[b]{2}{*}{ Cause of Cracking } & \multirow[b]{2}{*}{$\begin{array}{c}\text { Crack } \\
\text { Distribution }\end{array}$} & \multicolumn{3}{|c|}{ Spatial Configuration } & \multirow[b]{2}{*}{$\begin{array}{c}\text { Transport modeling } \\
\text { Approach }\end{array}$} \\
\hline & & Localized & $\begin{array}{l}\text { Through } \\
\text { wall }\end{array}$ & $\begin{array}{l}\text { Advancing } \\
\text { from surface }\end{array}$ & \\
\hline Mechanical Loading & Discrete & Microcracks & Macrocracks & NA & \multirow{3}{*}{$\begin{array}{l}\text { Microcracks: Accounted } \\
\text { for in material properties } \\
\text { Coalesced Microcracks: } \\
\text { Averaged or smeared } \\
\text { approach } \\
\text { Macrocracks: Flow } \\
\text { through rough parallel } \\
\text { plates or Dual porosity } \\
\text { flow (discrete fractures } \\
\text { and porous material) }\end{array}$} \\
\hline $\begin{array}{l}\text { Temperature Gradient, } \\
\text { Movement Against } \\
\text { Restraint }\end{array}$ & Discrete & Microcracks & Macrocracks & NA & \\
\hline $\begin{array}{l}\text { Moisture Gradient, } \\
\text { Movement Against } \\
\text { Restraint } \\
\text { (Drying Shrinkge) }\end{array}$ & Discrete & Microcracks & Macrocracks & NA & \\
\hline $\begin{array}{l}\text { Inherent Sulfate } \\
\text { Attack }\end{array}$ & $\begin{array}{l}\text { Distributed } \\
\text { through bulk } \\
\text { material } \\
\end{array}$ & Microcracks & Macrocracks & NA & \multirow{3}{*}{$\begin{array}{l}\text { Modify transport } \\
\text { parameters of the as } \\
\text { designed concrete to } \\
\text { reflect transport through } \\
\text { the damaged } \\
\text { layer/material. } \\
\text { (progressive damage) }\end{array}$} \\
\hline $\begin{array}{l}\text { Alkali Aggregate } \\
\text { Reaction }\end{array}$ & $\begin{array}{l}\text { Distributed } \\
\text { through bulk } \\
\text { material } \\
\end{array}$ & Microcracks & Macrocracks & NA & \\
\hline Freeze-Thaw Cycling & $\begin{array}{l}\text { Distributed } \\
\text { through bulk } \\
\text { material } \\
\end{array}$ & Microcracks & Macrocracks & NA & \\
\hline $\begin{array}{l}\text { Plastic Shrinkage } \\
\text { (surface drying) }\end{array}$ & $\begin{array}{l}\text { Distributed } \\
\text { in surface } \\
\text { layer }\end{array}$ & Microcracks & Macrocracks & No & $\begin{array}{l}\text { Modify transport } \\
\text { parameters of the as } \\
\text { designed concrete to } \\
\text { reflect transport through } \\
\text { the damaged surface } \\
\text { material } \\
\text { (damage not progressive) }\end{array}$ \\
\hline $\begin{array}{l}\text { External Sulfate } \\
\text { Attack }\end{array}$ & Distributed & Microcracks & Macrocracks & $\begin{array}{l}\text { Progressive } \\
\text { from surface } \\
\text { into bulk } \\
\text { material }\end{array}$ & $\begin{array}{l}\text { Modify transport } \\
\text { parameters of the as } \\
\text { designed concrete to } \\
\text { reflect transport through } \\
\text { the damaged material. } \\
\text { (progressive damage) }\end{array}$ \\
\hline Carbonation & None & None & None & $\begin{array}{l}\text { Progressive } \\
\text { from surface } \\
\text { into bulk } \\
\text { material }\end{array}$ & $\begin{array}{l}\text { None } \\
\text { Material specific data are } \\
\text { required to modify the } \\
\text { porosity of the as } \\
\text { designed material. } \\
\text { Porosity, and therefore, } \\
\text { transport can increase or } \\
\text { decrease as the result of } \\
\text { carbonation. }\end{array}$ \\
\hline $\begin{array}{l}\text { Rebar Corrosion } \\
\text { accelerated by pre- } \\
\text { existing cracks }\end{array}$ & Discrete & $\begin{array}{l}\text { Microcracks } 8 \\
\text { including de-b } \\
\text { rebar surface a } \\
\text { /loss of concre } \\
\text { Typically asso } \\
\text { pre-existing di } \\
\text { that transect th } \\
\text { rebar and/or lo } \\
\text { due to chemic } \\
\text { the concrete. }\end{array}$ & $\begin{array}{l}\text { Microcracks } \\
\text { nding along } \\
\text { d cracking } \\
\text { e cover. } \\
\text { iated with } \\
\text { crete cracks } \\
\text { plane of the } \\
\text { s of cover } \\
\text { attack of }\end{array}$ & Progressive & $\begin{array}{l}\text { Considerable work has } \\
\text { been performed on } \\
\text { predicting damage due to } \\
\text { rebar corrosion in } \\
\text { chloride systems but is } \\
\text { beyond the scope of this } \\
\text { report. }\end{array}$ \\
\hline
\end{tabular}




\subsection{Relationship Between Pore/Crack Size, Saturation and Relative Humidity}

The relationships between pore-opening diameter/crack aperture and degree of saturation of the pores and cracks are important to determining portion of the porosity and size of cracks involved in transporting moisture, gas, and dissolved ions. Moisture and dissolved ions are transported through the water filled or partially filled pores/cracks. Gas, including water vapor, is either dissolved in the liquid phase or transported in the vapor phase (air) in partially filled pores/cracks which have water coated surfaces. (The thickness of the water layer is discussed in Attachment 1, Section 10.) If the influence of the pore solution composition is not ignored, the size of the pores that are filled with water (i.e., saturated) can be approximated by applying the Kelvin Laplace equation provided below and represented graphically in Attachment 1, Figure 1.

$$
\operatorname{Ln}(R H)=\frac{2 \sigma \mathrm{V}_{\mathrm{m}}}{r_{m} R T}
$$

where: $\mathrm{RH}^{1}$ is the relative humidity of air in equilibrium with pore solution, $\sigma$ is the surface tension of pore water (pore solution), $\mathrm{V}_{\mathrm{m}}$ is the molar volume of the pore water (pore solution), $\mathrm{r}_{\mathrm{m}}$ is the average radius of curvature, $\mathrm{R}$ is the universal gas constant, and $\mathrm{T}$ is the absolute temperature. No correction for fluids other than water.

For a concrete (cementitious material) in equilibrium with air at $90 \% \mathrm{RH}$, a pore or crack that is approximately $40 \mathrm{~nm}$ in diameter will be completely filled with water. At 50\% RH the diameter of the largest pore or crack completely filled with water is about 10 times smaller, i.e, 3 or $4 \mathrm{~nm}$. The KelvinLaplace equation is not applicable for determining the condition of concrete pores in equilibrium with lower relative humidity environments because the concept of a meniscus at the air-water interface is probably not valid. Instead, a film of water forms on the pore walls that is between one and five molecules thick. Under extreme drying conditions, this film may be discontinuous.

\subsection{Depth to which concrete is influenced by surface drying}

Cured concrete equilibrates with the environment slowly and the relative humidity in the core of a concrete element is slow to respond to external conditions. Estimating the time required for concrete to equilibrate with surface conditions is important to establishing saturation conditions within a concrete element. At the structural scale the drying process can be assessed using a non-linear diffusion equation were the diffusivity (D) is a function of water content or relative humidity Xi, et al. (1994).

\section{$\frac{\partial H}{\partial \theta}=\mathbb{V D V H}+\frac{\partial H}{\theta_{\alpha}}$}

Where: $H$ is the humidity, $t$ is time, and $\alpha$ is the degree of hydration.

This non-linear diffusion equation was used by Weiss and Langton to simulate the effects of drying using data for a $0.5 \mathrm{w} / \mathrm{c}$ mortar with coefficients of $\left(\alpha_{H}=0.0027, \beta_{H}=3.96\right.$ and $\left.\gamma_{H}=4.685\right)$ fitted to the function described by Xi et al. (1994). See Attachment 1Section 3. Based on this equation, the relative humidities at three different distances from the surface were calculated to provide an example of the time required to approach equilibrium conditions in uncracked material. See Figure 2-1. Three relative

\footnotetext{
1 Relative humidity is the ratio of the partial pressure of water vapor in the air-water mixture to the saturated vapor pressure of water at the prescribed temperature. The relative humidity of air depends on temperature and pressure of the system and takes into account the variation in saturated vapor pressure.
} 
humidity environments (at the surface) were evaluated for a $50 \mathrm{~cm}$ thick concrete wall. The effect of cracking on the equilibration time has not been addressed in the literature and seems best evaluated experimentally. Cracks will probably shorten the equilibration time.

$50 \%$ outer $\mathrm{RH}, 100 \%$ inner $\mathrm{RH}, 100 \%$ initial $\mathrm{RH}$

\begin{tabular}{|c|c|c|c|}
\hline & \multicolumn{3}{|c|}{ RH (\%) } \\
\hline days & $2 \mathrm{~cm}$ & $5 \mathrm{~cm}$ & $20 \mathrm{~cm}$ \\
\hline 30 & 0.991 & 1.000 & 1.000 \\
\hline 365 & 0.923 & 0.985 & 1.000 \\
\hline 3650 & 0.828 & 0.910 & 0.994 \\
\hline 36500 & 0.731 & 0.814 & 0.933 \\
\hline
\end{tabular}

$50 \%$ outer RH, $100 \%$ inner RH, $80 \%$ initial RH

\begin{tabular}{|c|c|c|c|}
\hline & \multicolumn{3}{|c|}{ RH (\%) } \\
\hline days & $2 \mathrm{~cm}$ & $5 \mathrm{~cm}$ & $20 \mathrm{~cm}$ \\
\hline 30 & 0.7997 & 0.8000 & 0.8000 \\
\hline 365 & 0.7856 & 0.7999 & 0.8000 \\
\hline 3650 & 0.7227 & 0.7796 & 0.8000 \\
\hline 36500 & 0.6407 & 0.7111 & 0.8430 \\
\hline
\end{tabular}

$50 \%$ outer RH, $80 \%$ inner RH, 100\% initial RH

\begin{tabular}{|c|c|c|c|}
\hline & \multicolumn{3}{|c|}{ RH (\%) } \\
\hline days & $2 \mathrm{~cm}$ & $5 \mathrm{~cm}$ & $20 \mathrm{~cm}$ \\
\hline 30 & 0.991 & 1.000 & 1.000 \\
\hline 365 & 0.923 & 0.985 & 1.000 \\
\hline 3650 & 0.828 & 0.910 & 0.993 \\
\hline 36500 & 0.715 & 0.794 & 0.891 \\
\hline
\end{tabular}

$50 \%$ outer $\mathrm{RH}, 80 \%$ inner $\mathrm{RH}, 80 \%$ initial $\mathrm{RH}$

\begin{tabular}{|c|c|c|c|}
\hline & \multicolumn{3}{|c|}{ RH (\%) } \\
\hline days & $2 \mathrm{~cm}$ & $5 \mathrm{~cm}$ & $20 \mathrm{~cm}$ \\
\hline 30 & 0.7997 & 0.8000 & 0.8000 \\
\hline 365 & 0.7856 & 0.7999 & 0.8000 \\
\hline 3650 & 0.7227 & 0.7796 & 0.8000 \\
\hline 36500 & 0.6396 & 0.7082 & 0.7896 \\
\hline
\end{tabular}

Figure 2-1. Effect of Drying on a Cured Concrete Wall as a function of Environmental Humidity and Time.

\subsection{Time Required to Saturate Concrete in Soil with $100 \%$ Relative Humidity}

After the concrete is relatively mature, complete saturation is difficult to achieve because it requires the air to diffuse out of the concrete which is a very slow process. This process is dependent on the amount of vapor in concrete that needs to diffuse out of the concrete and the thickness. To provide insight on the time scale involved, an example from Li, et al. (2012) literature is used. Samples $25 \mathrm{~mm}$ (1 in) thick of intact concrete mortar with a water to cement ratio of 0.42 were soaked in water for approximately 250 days. Results indicated that this $25 \mathrm{~mm}$ thick air entrained sample would take up to 6 years to reach approximately $90 \%$ saturation. Transport processes in partially saturated concrete scale as a function of the saturation raised to an exponent power between $7 / 3$ and 5 based on experiments.

\subsection{Relationship Between Rebar Corrosion and Cracking and Spalling}

As rebar corrodes it expands. The expansion can cause cracking. The number of cracks that form as the bar corrodes is dependent on the geometry of the problem. Either one longitudinal crack (directly between the bar and surface) or two longitudinal cracks (forming a V between the surface and bar) generally form as the steel corrodes and expands depending on the geometry of the slab (i.e., bar size, cover depth, and strength of the concrete). The cracking generally occurs between the bar and the surface and does not result in substantial cracking in the core of the reinforced element. In addition, debonding between the rebar and the surrounding concrete is typically associated with rebar corrosion. The de-bonding results in a circumferential crack, centimeters to 10 s of centimeters along the rebar. 
Discrete cracks that penetrate into the concrete (up to and past the rebar) are often the source of corrodents, such as, chloride ions, that contribute to and accelerate rebar corrosion.

\subsection{Methods for Measuring Transport in Partially Saturated Concrete}

Methods for characterizing transport as a function of the degree of saturation in cracked concrete and other cementitious materials include:

1) Electrical conductivity. Electrical conductivity varies as a function of the degree of saturation raised to a power (approximately 4). Preliminary work (Niemuth 2005) showed that depending on the moisture content of the cracks, the conductivity can be very low (if air filled) or high (if fluid filled) when compared with uncracked concrete. As such it may be possible to use the electrical conductivity at different moisture states to determine the influence of the connectivity of the cracks. This should be able to be directly related to other transport processes.

2) Test beds at laboratory and field scale. Experimental configurations can be constructed to investigate relevant aspects and variables related to transport in saturated and partially saturated materials and multiple material systems. Radioactive tracers such as deuterated water/water vapor and oxygen isotopes may be useful in both laboratory and field tests.

3) Percolation rate measurements and similar field techniques for geologic strata and dams can provide non mechanistic information on transport rate of fluids and gas through cracked and intact material.

4) Neutron scattering and imaging techniques may be useful especially when combined with radioisotope tracers for measuring transport in unsaturated concrete. Facilities at NIST, ORNL, and EMPA (Switzerland) are developing capabilities to characterize concrete and other porous materials.

5) Centrifuge methods for applying a whole body driving force to extract pore fluid from porous materials may be applicable to certain sample/crack geometries. The US Army Corps of Engineers Test Laboratory in Vicksburg MS has a large centrifuge for characterizing concrete hydraulic conductivity.

\subsection{CONCLUSIONS}

This report transmits the results of a literature review on transport through cracked concrete which was performed by Professor Jason Weiss, Purdue University per SRR0000678 (RFP-RQ00001029-WY). This review complements the NRC-sponsored literature review and assessment of factors relevant to performance of grouted systems for radioactive waste disposal [1].

Material specific and structure specific measurements are needed to characterize transport in existing SRS concrete structures, cementitious fills and waste forms. Several methods for measuring transport in saturated and unsaturated cracked concrete were provided. This report also provides information for designing and interpreting experimental results. 


\subsection{REFERENCES}

1. SLA-WSTD-00023, Revision 6, SRNL Technical Support to C\&WDA, April 24, 2012.

2. Pabalan, R. T., F. P. Glasser, D. A. Pickett, G. R., Walter, S. Biswas, M. R. Juckett, L. M. Sabido, and J. L. Myers, April 2009. "Review of Literature and Assessment of Factors Relevant to Performance of Grouted Systems for Radioactive Waste Disposal, CNWRA 2009-001, Center for Nuclear Waste Regulatory Analyses San Antonio, TX 78228-0510 (Prepared for the U. S. Nuclear Regulatory Commission Contract NRC NRC-02-07-006).

3. Li, W., Pour-Ghaz, M., Castro, J., and Weiss, W. J., (2012) "Water Absorption and the Critical Degree of Saturation as it relates to Freeze-Thaw Damage in Concrete Pavement Joints,” ASCE Journal of Civil Engineering Materials.

4. Xi, Y., Bazant, Z. P., Molina, L., and Jennings, H., M., (1994) "Moisture Diffusion in Cementitious Materials - Moisture Capacity and Diffusion,” Advanced Cement Based Materials, 1, 258-266 


\title{
ATTACHMENT 1.
}

Transport Through Cracked Porous Media With Emphasis on Concrete

\author{
Jason Weiss, Purdue University
}

April 2012 


\title{
Transport Through Cracked Porous Media with Emphasis on
}

\author{
Concrete and Other Cementitious Barriers Used in
}

\author{
Radioactive Waste Disposal Scenarios
}

Jason Weiss, Purdue University

April 6, 2012

\subsection{SAVANNAH RIVER SITE PERFORMANCE ASSESSMENT NEEDS}

Understanding the transport of moisture, gas, and ions through cracked and uncracked cementitious barrier materials, e.g., concrete, grout, and waste forms, is important to the Savannah River National Laboratory (SRNL) because concrete containment structures are used as engineered barriers at the Savannah River Site (SRS) to enhance the performance ${ }^{a}$ of the onsite LLW disposal facilities. The Department of Energy (DOE) Order $435.1^{\mathrm{b}}$ requires DOE facilities to evaluate release of radionuclides from these facilities over a period of 1000 years after closure. At the SRS, Performance Assessments (PAs) for each of the facilities have been prepared and are updated every five years and modified as needed. Some of the SRS Performance Assessments also have to meet the performance objectives of 10CFR61 over a period of 10,000 years after closure.

The objective of this literature review was to identify previous studies dealing with moisture, gas and ion transport through cracked concrete. It should be noted that while several studies exist that have dealt with transport in cracked concrete this is not a mature field with clearly established protocols. Further, a large portion of the concrete community focuses its efforts primarily on transport in or near saturated conditions. As a result, several of the conditions that are of interest to SRS are unique and not well characterized in concrete literature although literature from the geological field or soils may be available. In addition, the boundary conditions that should be used in the SRS pose their own set of issues.

\footnotetext{
${ }^{a}$ Enhanced performance includes disposing of a higher inventory that would be acceptable if the waste were disposed directly in the ground without and engineered barrier to delay or slow the ingress of water and release of contaminants. It also includes increasing the degree of difficulty or impact of various types of intrusion.

${ }^{\mathrm{b}}$ The DOE Order 435.1 is currently being revised as DOE Order 435.2A.
} 
The information in this report will be used to support the conceptual models and mathematical analysis of transport through aged reinforced concrete containment structures and concrete containment structures affected by chemical degradation. This may provide support on how transport through cracked concrete can be modeled. It is anticipated that in the future, this information may be used to design experiments to test model assumptions.

Reinforced concrete elements are used for the containment structures which have several different designs including: 1) rectangular vaults that are completely filled with incompressible material, 2) rectangular vaults which have steel beam supported roofs ${ }^{a}$ and are not completely filled, 3) cylindrical water tanks constructed of post tensioned vertical reinforced panels on a concrete base slab, 4) cylindrical shells constructed of reinforced shotcrete (Type IV tanks) or poured in placed reinforced concrete (Types I, II, and III high level waste tanks) which are used to support high level waste (HLW) carbon steel tanks, and 5) unreinforced cast in place flowable concrete encapsulating various objects placed on a concrete slab in a soil trench. Some of these containment structures were constructed at grade; some were constructed below natural grade and then backfilled. The $51 \mathrm{HLW}$ tanks in the SRS F- and H-Areas and one of the rectangular intermediate level solid waste vault in E-Area are covered with soil. Concrete vaults 1 and 4 in Z-Area will be buried at a later date and have been at grade for up to about 24 years.

Information required to support methodology for modeling transport through cracks includes:

1. Causes, timing, and characteristics of crack in general and cracks observed and expected for the SRS concrete containment structures.

2. Properties of intact and cracked concrete that impact transport.

3. Properties of the degree of saturation and the impact of transport.

4. Conceptual models for transport through concrete cracked from specific mechanisms.

5. Information on the boundary conditions the tanks are exposed to with specific emphasis on moisture.

6. Potential for crack healing.

This report divides the causes of cracks into those that form before hardening and those that form after hardening. It also categorizes cracks as those that are discrete in location as well as those that form a well distributed crack network.

\footnotetext{
a Z-Area containment structures for the saltstone waste form will be completely filled to the roof prior to closure. However, the E-Area low activity waste vault may not be completely filled with load bearing grout.
} 
Because Saltstone Vaults 1 and 4 have visible cracks and because no repairs to these vaults are currently planned, cracks in the vault walls were assumed in the 2009 Saltstone PA. ${ }^{4}$ It is assumed that visible damage which incurred to the concrete containment structures before hardening and after hardening but before burial will be repaired if determined to impact release of contaminants from the structure. It should also be noted that visible cracking typically represents cracks that are greater than 100 microns in width. (It has been suggested that the human eye can detect cracks of approximately 70 to 100 microns).

Cracking caused by long term deformation due to volume instability (e.g., thermal differentials, shrinkage, or creep), or mechanical forces (e.g., design overload, subsidence, or fatigue) has not been observed. ${ }^{\text {a }}$ However, cracking due to volume instability and mechanical forces during construction and/or filling did occurred in the Saltstone Vaults 1 and 4 . In the buried condition, the majority of these structures will be supported by compacted earth against the outside walls and incompressible waste or waste forms inside the structures ${ }^{b}$. The overburden has been estimated by SRNL to apply a load to the structure of less than $0.69 \mathrm{MPa}(100 \mathrm{psi})$. Consequently, the anticipated damage to the containment structures is expected to result from episodic events (earthquakes) and chemical degradation mechanisms (rebar corrosion that results in expansive corrosion products that thereby crack the concrete, sulfate attack and alkali silica reactions (ASR) both of which result in expansive reaction products that crack the concrete. ${ }^{\mathrm{C}}$

\footnotetext{
a The first saltstone vault has vertical through wall cracks over the entire height of the walls and/or the height of the lifts as the result of thermal differentials during curing. This vault and the second saltstone vault were also damaged due to mechanical loading of the reinforced walls as the result of the roof design. This damage occurred during the early years of operation and SRNL has reported these cracks to be repaired and the design corrected in the new cylindrical tank vault design.

${ }^{\mathrm{b}}$ The Low Activity Waste vault may not be backfilled with incompressible material. Some of the objects encapsulated as components in grout also contain internal voids.

${ }^{\mathrm{c}}$ Freeze thaw cycling is not expected to damage the concrete structures prior to burial because of the mild climate in SC.
} 


\subsection{INFORMATION TO SRS PA MODELING}

Through wall / slab cracks are considered to be typical of cracks that are discrete in space and these cracks will be grouped together regardless of the cause. These cracks may have formed: 1) at an early stage before hardening (e.g., the first saltstone vault), 2) after hardening but before burial (e.g., first and second saltstone vaults), and 3) after burial as the result of mechanical overloads including seismic events and subgrade settling.

Cracks formed as the result of chemical reactions are generally considered distributed and will be grouped into two categories depending on whether the corrosive chemical and detrimental reaction is 1) distributed throughout the matrix or 2) advances into the concrete from one surface. It is worth noting that while some forms of degradation like ASR may be expected to be distributed, the presence of reinforcing steel causes confinement which can typically result in the damage manifesting itself as damage advancing from one surface.

For this discussion on transport through cracks (discontinuities), cracks are defined as having one dimension of at least 40 to 100 micrometers which is in the size range of large unhydrated cement grains and an aspect ratio of $>1: 3$. In other words, the smallest crack that would be differentiated from a cement paste matrix for the purpose of describing transport phenomena would have dimensions of approximately $40 \times 120 \mu \mathrm{m}$.

Concrete can experience porosity and pore structure changes over time that may impact moisture transport into and out of normal intact material. While hydration will tend to reduce the porosity and disconnect the pores, the dissolution of calcium hydroxide or the carbonation of surfaces exposed to the atmosphere will alter the porosity (generally increasing the porosity) and pore structure which in turn may impact moisture transport. This however is heavily influenced by the initial porosity of the concrete (water to cement ratio) and the chemistry of the binder (i.e., whether supplementary cements are used). It is also influenced by the surrounding environment. 


\subsection{MOISTURE TRANSPORT THROUGH UNCRACKED (INTACT) CONCRETE}

Moisture transport through intact, uncracked concrete (no cracks with apertures greater than $40 \mu \mathrm{m}$ ) is dependent on the volume of pores, the connectivity of the pores, and the degree of saturation of the bulk concrete. Transport parameters used to describe moisture transport through saturated intact concrete include: conductivity, permeability and diffusivity. Effective porosity, viscosity and density of the fluid are also frequently used to describe transport. Exhaustive reviews of modeling fluid transport in cementitious materials are available from Hall (1994), Hall and Hoff (2002), Martys (1995), and Luiping et al. (2011). For unsaturated intact concrete, the relative hydraulic conductivity and relative moisture diffusivity are used and are highly dependent on the degree of saturation. ${ }^{a}$

It is important to recognize that the structure of the concrete matrix has large pores that are frequently referred to as capillary pores and smaller pores that are referred to as gel pores. Capillary pores can be thought of as remnants of the original water filled space in the concrete while gel pores develop as a part of the hydrated products. Figure 1a shows a conceptual illustration of the relationship between pore size that remains fluid filled and the relative humidity of the air in the unfilled pore space (assuming the pore fluid is plain water). This may not be exactly the case for the saltstone because the pore fluid is a brine rather than plain water. The pore solution composition for saltstone should be expressly considered in transport models for this material if it has not been (Castro et al. 2008).

\footnotetext{
${ }^{a}$ Moisture diffusivity is a parameter used in some transport codes to describe the combined effect of capillary suction, ionic diffusion, and permeation (darcian flow) [Samson 2009].
} 

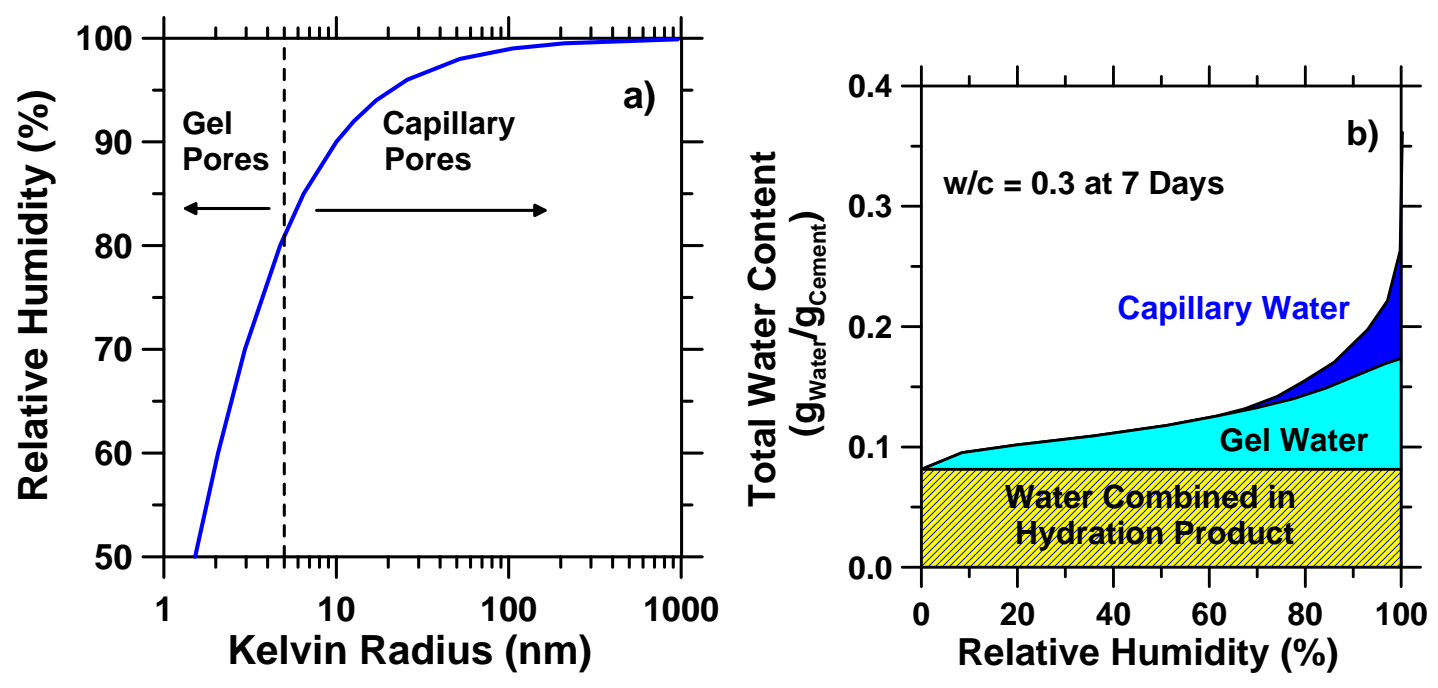

Figure 1: Relation between relative humidity and pore size in cement paste

It can be noticed that as the concrete dries out the largest pores (capillary pores) empty first. Figure $1 \mathrm{~b}$ also shows a desorption isotherm (after Powers 1946) to illustrate the volume of water located in the different size pores at different relative humidities. This illustrates that the largest pores empty first. It should be noted that while transport occurs in both gel and capillary pores, the magnitude to transport in the capillary pores is much higher than that in the smaller gel pores. Further, it is important to note that depending on the amount of cement that has reacted and the water to cement ratio the capillary pores may be connected (perolcated) or disconnected (depercolated). The rate of transport is substantially reduced in depercolated pore systems.

The relationship between the equilibrated relative humidity and the radius of the smallest empty pore is given by the Kelvin-Laplace equation (Equation 1).

$$
\operatorname{Ln}(R H)=\frac{2 \sigma \mathrm{V}_{\mathrm{m}}}{r_{m} R T}
$$

Equation 1

where: $R H$ is the relative humidity, $\sigma$ is the surface tension of water (or alternatively pore solution), $V_{m}$ is the molar volume of water, $r_{m}$ is the average radius of curvature, $R$ is the universal gas constant, and $T$ is the absolute temperature. This equation requires correction when used with fluids other than water to account for ionic species.

The concepts illustrated in Figure 1 can also be extended to cracked concrete to determine what size cracks will be water filled at a particular relative humidity. It can be seen that it is quite probable that in partially saturated 
conditions the cracks in concrete (recall that visible cracks are generally considered to be larger than 100 microns) could be primarily vapor filled with a film of water/pore fluid along the walls of the crack. This film along the walls is can be estimated from absorption theory. It has been suggested that while this thickness changes depending on the relative humidity. At $11 \% \mathrm{RH}$ it is roughly one molecule of water thick and it is tightly bound. As the relative humidity increases, the thickness of the water layers on the pore walls increases. At $50 \%$ $\mathrm{RH}$, the thickness is expected to be on the order of 4 to 5 molecules thick.

The degree of saturation of intact concrete is an important factor in determining transport through the material. For example, it can be generally stated that saturated concrete has a significantly lower gas diffusion rate than partially saturated concrete. This transport rate increases again as the vapor phase becomes percolated and this can occur at high humidities $(\sim 95 \%)$ for concrete with visible cracks.

Construction quality concrete exposed to air is typically in a state that is less than fully saturated. Concrete also typically contains entrained and entrapped air. Excess water that may have been present in the mixture design typically is lost as bleed water through evaporation. Self-desiccation begins shortly after placement. While it is frequently reported that self-dessication is only a problem for low water to cement ratio systems, this is generally referring to its role in volume change. Self-dessication occurs in every mixture irrespective of water to cement ratio if water is not provided by an external source (the water also needs to be able to be transported through the concrete which can be a problem for dense or thick systems). Self-desiccation occurs since water combines with cement to form hydrated reaction products. The hydrated products are smaller in volume than the constituents. The expression of this conditions / property is commonly referred to as chemical shrinkage. As a result, before set, the external volume change occurs and the external volume of the material appears to collapse. However, after set occurs the system cannot shrink completely since the particles impinge on one another and vapor filled spaces in the concrete expand. These vapor filled spaces act like the vapor filled spaces that would develop in drying concrete, however they occur without the need for water loss to the environment or temperature change. The resulting relative humidity of the concrete depends on the size distribution of the pores and the size of the pores that are vapor filled. Further, the stress and internal relative humidity tends to be uniform across the cross section (for a sealed system).

After the concrete is relatively mature complete saturation is difficult to achieve because it requires the air to diffuse out of the concrete which is a very slow process. This process is dependent on the amount of vapor in concrete that 
needs to diffuse out of the concrete and the thickness (in actuality the diffusion rate is related to the thickness squared). To provide some insight on the time scales involved, samples of $25 \mathrm{~mm}$ (1 in) intact concrete mortar with a water to cement ratio of 0.42 were soaked in water for approximately 250 days as shown in Figure 2 ( $\mathrm{Li}$ et al 2012). It can be seen that even after a relatively thin sample is stored in water for a long period of time it is not completely saturated. It should also be noted that the initial slope of these lines generally refers to the absorption of water (the rate of absorption is generally referred to as the sorptivity). The slope at later times refers to the rate of water ingress which appears to be limited by the rate of diffusion of gas out of the pores (commonly referred to as the secondary slope).

On the other hand, structures made with good quality concrete can take a long time to dry (for concrete thickness like those at SRNL this would be in the order of many decades even if constant drying conditions were used). An example is provided in the attached memo. It is generally assumed that at the structural scale the drying process can be assessed using a non-linear diffusion equation were the diffusivity $(D)$ is a function of water content or relative humidity. See Equation 2.

$$
\frac{\partial \pi}{g r}=\nabla D V H+\frac{\partial H}{\partial \sigma}
$$

Equation 2

Where: $H$ is the humidity, $t$ is time, and $\alpha$ is the degree of hydration.

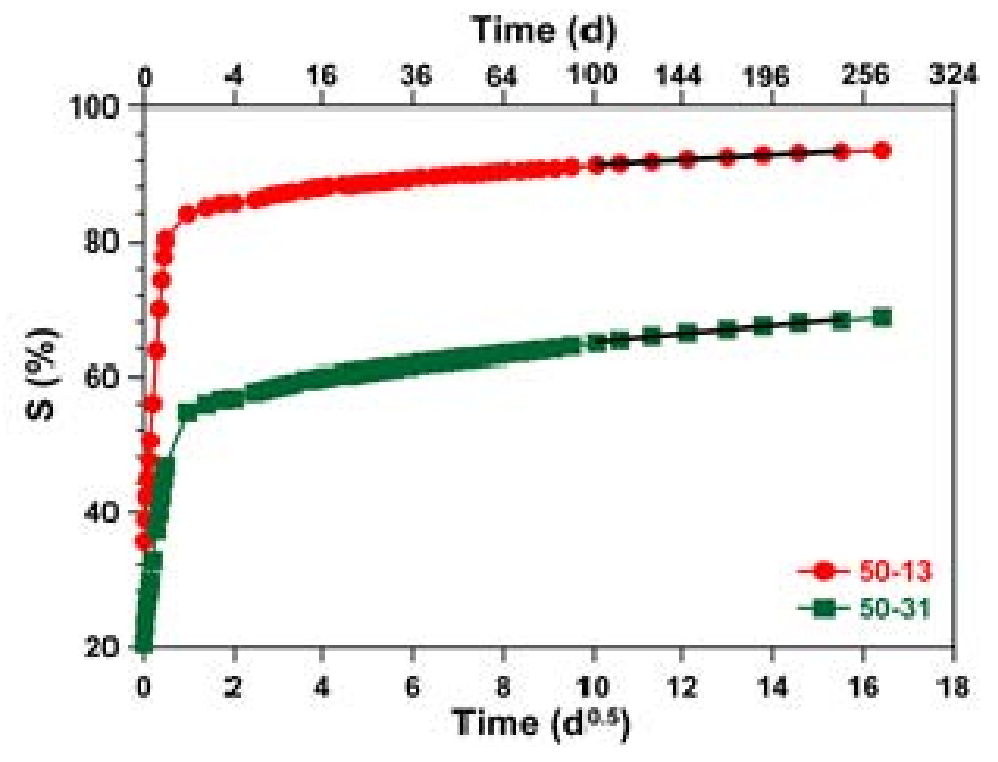

Figure 2: Relation between time and the degree of saturation for concrete dried to $50 \% \mathrm{RH}$ and placed in water. The red line (50-13) refers to concrete with approximately $4 \%$ air by volume and the green line (50-31) refers to concrete with approximately $9 \%$ air by volume ( $\mathrm{Li}$ et al 2012). 
An example of a non-linear diffusion coefficient is shown in Figure 3 (Pour-Ghaz et al. 2010). Other researchers including Bazant and Najjar (1972) and Xi et al (1994) have also use non-linear equations to estimate the effects of water to cement ratio and degree of hydration diffusion coefficients.

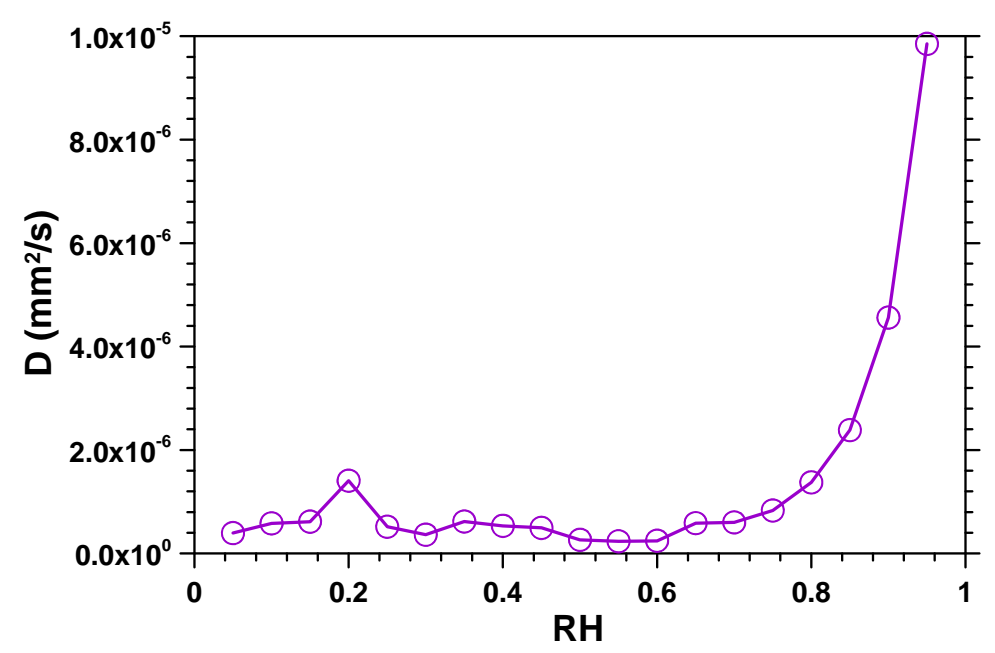

Figure 3: Diffusivity of Cement Paste Sample as a Function of Relative Humidity (Pour-Ghaz et al. 2010).

To provide some context, Figure 4 illustrates experimental evidence of the relative humidities measured in 8 inch $(200 \mathrm{~mm})$ thick concrete slabs over the course of a year in a field exposure site in Indiana. While several different boundary conditions were used in the study, two of the more relevant conditions for the SRS site are a) a vertical wall that was exposed to the atmosphere and allowed to rewet from precipitation and b) a sample that was exposed to the atmosphere but prevented from absorbing additional water. It can be noticed that, as expected, the surface has the greatest fluctuation throughout the course of the year however the measured $\mathrm{RH}$ is consistently above $80 \%$ relative humidity. This implies that the large capillary pores may have lost water however the smaller capillary pores and gel pores remain saturated. The core of the concrete remained at a relatively stable $90 \%$ relative humidity.

By implication, uncracked structures, even submerged in water, will saturate slowly of 10 s to 100 s of years depending on the dimensions of the structure. Structures exposed to ambient conditions in air with periodic rainfall events or in unsaturated soil are likely to remain partially saturated with humidities in the range such as those shown in Figure 4. This implies that some capillary pores will not be filled however the smaller capillaries and gel pores will remain filled. Gas diffusion will be slower in wetter systems than drier systems 
because the pore volume that can transmit gas decreases as the pores fill with water.

For buried structures the degree of saturation in the concrete will depend on the moisture conditions of the soil, the pore structure of the soil, and wetting and drying events. For the case of the vaults containing saltstone it may also be influenced by the equilibrium of the saltstone. While it is generally assumed that water moves from saturated soil to concrete by capillary suction and wicking, this depends on the soil type, depth of the water table, and the moisture/thermal gradients in the concrete. Fine grained soils tend to promote more moisture migration than more coarse grained soils. For concrete slabs on grade, vapor retarding membranes or crushed stone capillary breaks are generally recommended to reduce condensation and moisture movement. Tests can be performed to assess moisture in concrete slabs such as gravimetric methods, ASTM E1907, F1869 or F2170. It is expected that these tests could be modified to provide guidance on moisture movement for the conditions at SRS. Recent $\mathrm{x}$ ray and neutron radiography measurements provide information about temporal and spatial locations of fluid under a variety of conditions.

It is also unclear at the current time what the relative humidity conditions will be inside the tanks at SRS. It is assumed that the tanks will be lower than saturated as they will be filled with grout however depending on the pore solution of the grout the relative humidity can be much lower than the surrounding concrete which, if the vapor barrier fails, could draw water out of the concrete and into the saltstone however additional information would be needed on the relative humidity and pore solution composition of the saltstone material. 


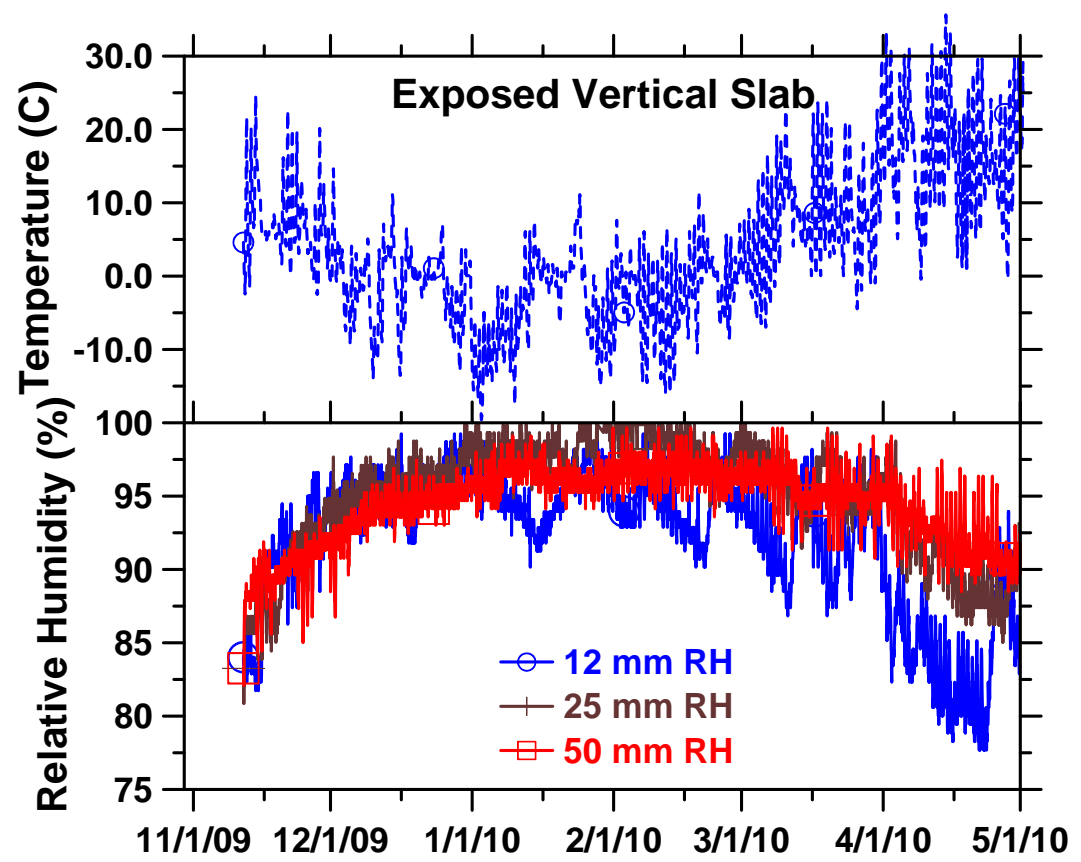

(a)

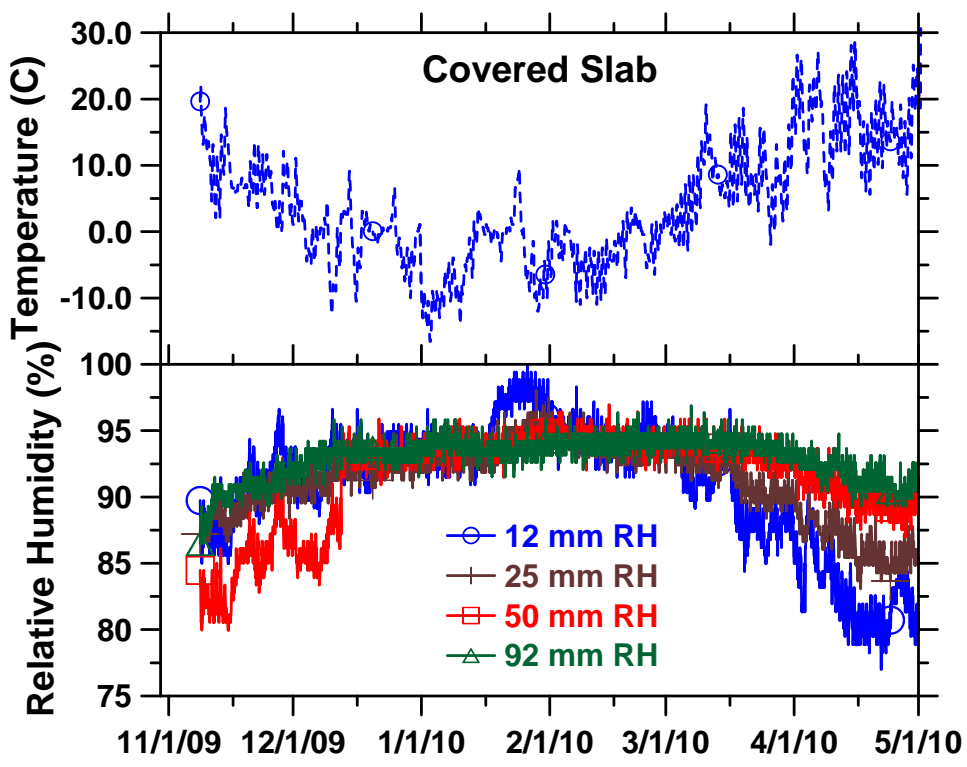

(b)

Figure 4: Relative Humidity Measured in the Concrete in a) an Exposed Vertical Slab and b) a Covered Slab (Dimensions are provided an approximate distance from the nearest exposed surface) 


\subsection{An Overview of Different Types of Cracking}

The remainder of this report discusses the role of cracking on fluid transport. Although it is commonly thought that cracking is caused by mechanical loading, it should be noted that cracking can also be caused by environmental conditions. The cause of the cracking is important as it may have profound implications on the crack morphology which may greatly influence the impact of the crack on overall performance. A brief review of these types of cracks is provided in the following section.

Cracking can occur in concrete elements for several reasons that can primarily be reduced to either mechanical loading or environmental effects. While cracking may be commonly observed in a wide range of concrete elements, it is important to understand that all cracks may have different reasons for occurring. Further, and maybe more important for transport, these cracks can have a different morphology and will influence transport differently.

Cracks can be roughly divided as developing from distress at either early age (before hardening) or later age (after hardening) as shown in Figure 5 (after Weiss 2000). Cracks at early ages and in low strength materials can go around the aggregate, while cracks that occur later or in higher strength materials can either go around the aggregate or fracture the aggregate itself.

While not a complete listing of all the causes for cracking, Figure 5 illustrates that numerous causes for cracking exist. The following section provides a brief overview of the cause for cracking. Additional references on cracking is provided in ACI 224-90R, TRB Circular 2007.

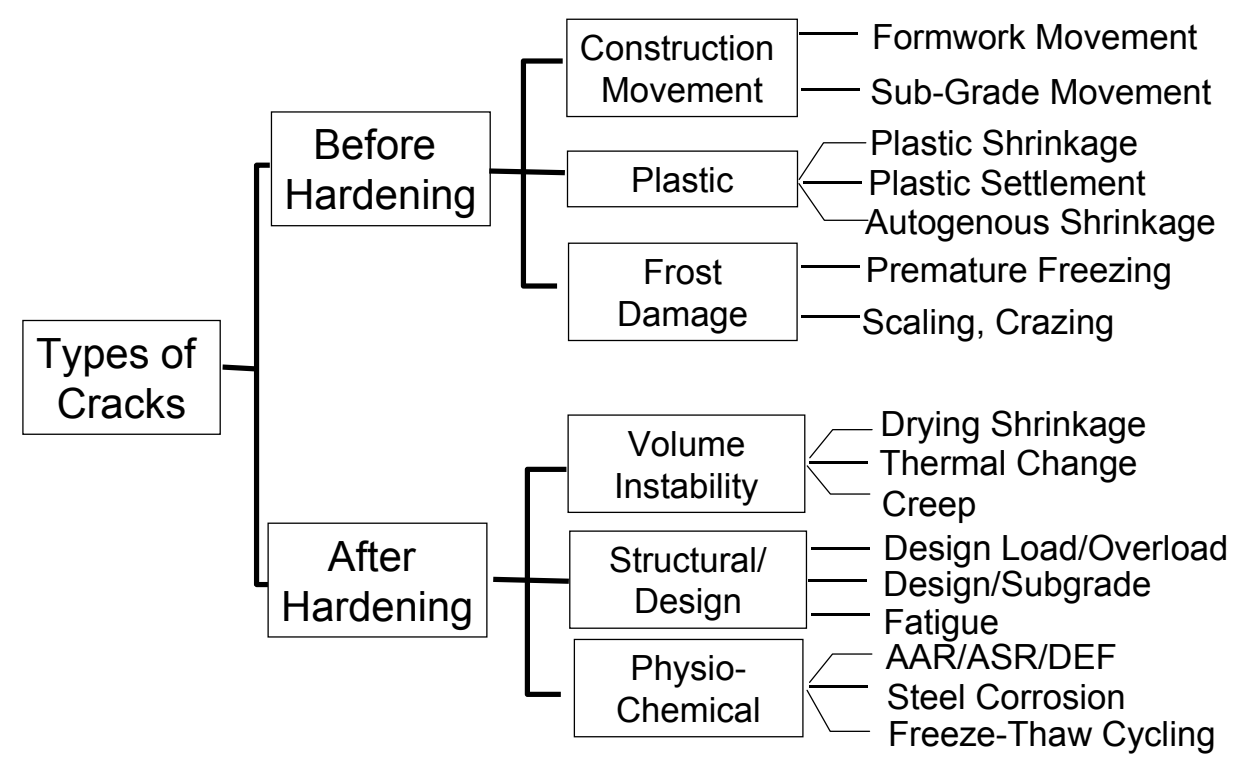

Figure 5: Typical Types of Cracking Observed In Concrete Elements 
Cracks that occur during or shortly after construction are generally referred to as plastic shrinkage, settlement, or construction movement-related cracks. Cracks can also develop at relatively early ages due to the restrained movement due to thermal and hygral shrinkage (i.e., volume change). Cracking can develop in the concrete at later ages due to freezing and thawing, sulfate attack, alkali silica reaction, and reinforcing steel corrosion. The freezing and thawing, alkali silica reaction, and corrosion induced cracking occurs as a result of an internal expansion occurs that is primarily caused by chemical attack of the reinforcing steel, aggregate, or freezing pore water.

It is the premise of this review that cracks can act as conduits that accelerate the ingress of fluids or gas. Although numerous factors influence whether a concrete would be expected to crack due to environmental effects, it can be simply stated that cracking will occur if the stress that develops in response to internal expansion or restraint of a volumetric contraction results in stress that exceeds the strength (or fracture resistance) of the material. The following section describes the main types of cracking that may occur.

\subsection{Mechanical Loading of Unreinforced Concrete}

Concrete is a composite material that is made by binding aggregates together with a cementitious paste. While the independent response of a cement paste and aggregate to an applied load is nearly linear as shown in Figure 6, the response of the composite material, i.e., concrete, is highly non-linear. This nonlinearity can be attributed to the development of small cracks (microcracks) throughout the concrete matrix as load is applied (Hsu et al., 1963). While this is a primary reason for the non-linearity and is generally confirmed with microscopy or acoustic emission measurements, others have suggested that this may be attributed to existence of a weak bond or interfacial transition zone between the aggregate and the paste matrix. While these cracks occur over a wide range of load levels they can be attributed to the development of high locals stresses that occur at the interface of the aggregates and paste (Shah and Slate 1965). These cracks are typically not sufficiently wide as to influence transport substantially. This conclusion is similar to conclusions reported by Pabalan et al (2009).

Even before mechanical loading is applied, concrete is typically thought to develop some micro-cracking due to differential stiffness and movement between the matrix and aggregate (Shah and Slate 1965). It is frequently assumed however that the amount of microcracking that develops at low load levels (less than $30 \%$ of the peak load) is relatively small. This is confirmed with acoustic emission measurements that record very few acoustic events at low load levels (Puri and Weiss 2005). Pabalan et al. (2009) suggest that for unloaded samples 
or samples loaded to less than $30 \%$ of the peak load, discrete interface cracking should not be considered explicitly in transport models because these cracks were probably present in the laboratory samples that were used to measure the transport properties and therefore were included in the measured parameter.

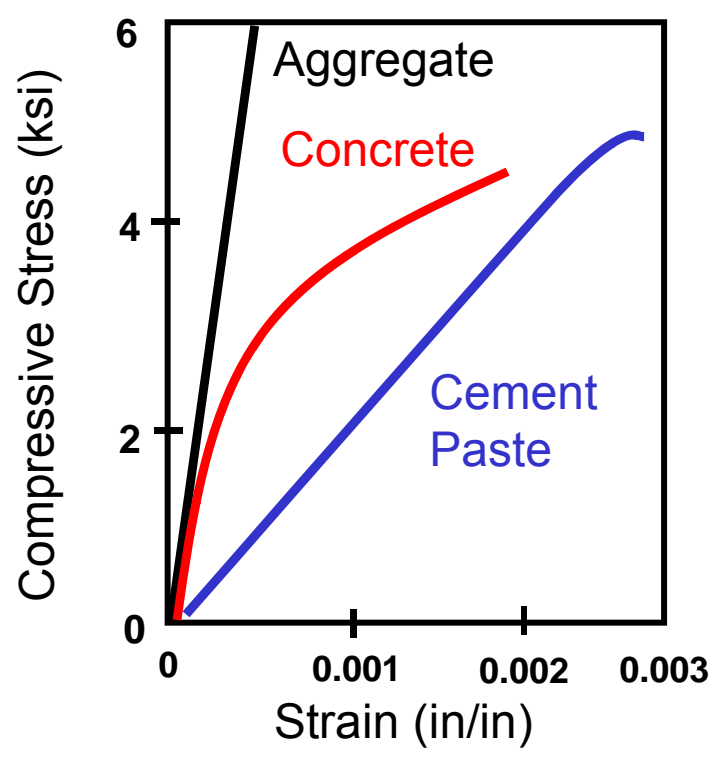

Figure 6: Stress Strain Response of Aggregate Concrete and Cement Paste (After Mindess et al. 2008)

Above a load level of approximately $30-50 \%$ of the peak load, microcracking increases which results in a slight decrease of the stiffness of the concrete. This increase in microcracking is consistent with increased acoustic emission activity. The cracks that occur during this period generally occur at the interface of the matrix and aggregate. While this may be attributed in part to an interfacial transition zone with different properties than the matrix, it can also be attributed to the high level of restraint caused by the aggregate and the differences in elastic properties between the aggregate and matrix. The microcracks that occur up to approximately $50 \%$ of the peak load tend to be relatively small and are disconnected cracks in the material. As a result it is generally believed that these microcracks tend to have a small impact on transport in most materials.

As the load level approaches $75-85 \%$ of the peak, the slope of the loaddisplacement curve begins to show a greater deviation from linearity as the cracks begin to coalesce and localize in one region of the specimen. This cracking can be observed upon inspection under the microscope and acoustic emission measurements also show an increase in activity when the load reaches 
this level. The coalesced crack will eventually become a visible crack at or after the peak load is reached.

Depending on how the specimen is loaded (i.e., load control or displacement control), the crack may result in sudden failure (load control) or it may continue to develop and grow after the peak load is reached (displacement control) resulting in large visible cracks. After the peak load is achieved test specimens demonstrate strain softening behavior which results in a gradual decrease in load carrying capacity with increasing strain. In reinforced concrete elements the crack opening will be controlled by the reinforcing steel.

While many think that the stress-strain response of concrete is a material property, the stress-strain response is dependent on the size of the specimen used in testing. The size dependence of the specimen being evaluated is illustrated in Figure 7. During loading in the pre-peak region of the stress-strain curve, the specimen behaves relatively uniformly with distributed cracking occurring throughout the specimen, and damage is generally assumed to be well distributed throughout the material. However, in the post peak region of the stress-strain curve, the response of concrete can be idealized as two types of materials, 1) the bulk concrete and 2) the damage zone, which behave quite differently from each other (Bazant 1976, Hillerborg et al. 1976; Shah and Jansen, 1993).

A typical model for unloading of these parts has been shown in Figure 7. The bulk region of the sample is generally considered to act as an elastic material or a material that demonstrates some damage due to microcracking but has a linear response during unloading. A damage index may make sense in this region. (The damage index (D) is typically related to the degradation in elastic modulus ( $E$ ) as compared to the original elastic modulus $\left(E_{O}\right)$ as $D=1$ $E / E_{O}$.) The damaged zone can be characterized with both a pre-peak behavior that is similar to that in the bulk region and a stress crack opening type response after the peak is reached. This illustrates the importance of separating the localized region of cracking from the bulk behavior. This also has implications on transport which will be discussed later in this document as transport in the bulk region can be quite different than transport that occurs in the damage zone or localized crack. As such it may be convenient to split material behavior into these two regions.

The same ideas that apply to the response of concrete to compressive loading can be extended to tensile loading. While the size of the localized region in compression is typically related to the diameter of the specimen (Jansen et al 1997; Puri and Weiss 2002), the size of the localized region is smaller for 
specimens loaded in tension or flexure and is approximated as 2 or 3 times the size of the largest aggregate in the concrete (Bazant 1999 and Yang et al 2004). In specimens loaded in tension or flexure, the location of the damage zone corresponds and is limited to the region around the visible crack.

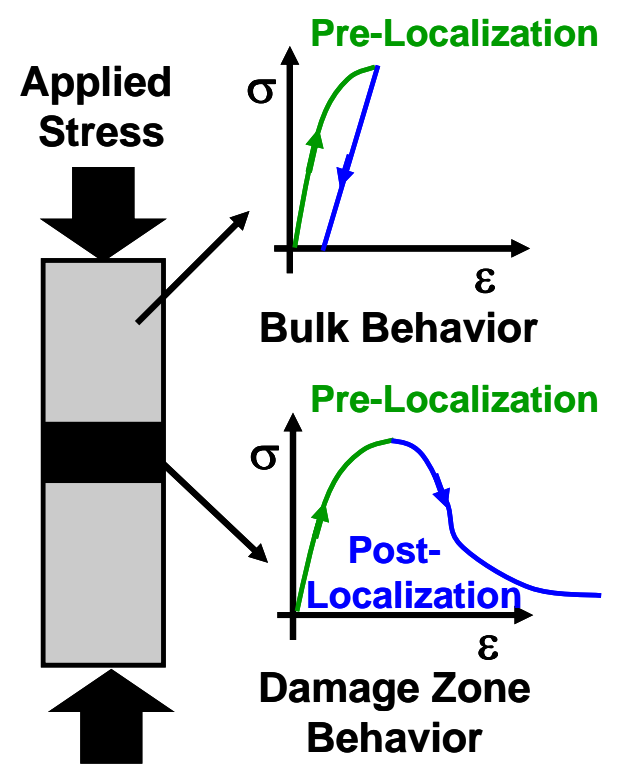

Figure 7: Composite Model for Concrete Response [After Jansen et al. 1997]

Cracks in a structure typically develop at locations of combined highest stresses and weakest planes. This can occur when there is a: 1) reduction in section (thinning), 2) preexisting flaw, or 3 ) area of stress concentration. The study of the development of how cracks develop and propagate in a structure is commonly referred to as fracture mechanics. Over the last four decades significant research has been performed to better understand the fracture processes in concrete. The fracture mechanics approach differs from continuum mechanics approach in that it relates local stress levels (stress intensity) with the existence of a crack and the energy required to grow that crack. Developments in non-linear fracture mechanics research over the last four decades have shown that concrete is a quasi-brittle material which exhibits pre-critical (i.e. pre peak) crack growth (fracture process zone) and strain softening (post-peak stress transfer). Although the subject of fracture mechanics is beyond the scope of this document, several recent references are provided that summarize the main attributes of concrete fracture (Shah et al. 1995; Bazant and Planas 1997; Van Mier 1999).

The process of repeated mechanical loading can also cause crack initiation and evolution in plain concrete. One hypothesis for describing this 
process attributes progressive deterioration to bond failure between the coarse aggregate and the matrix. Another hypothesis attributes fatigue failure in concrete to the coalescence of pre-existing micro-cracks in the matrix, resulting in a single localized macro-crack. For this report a distinction will not be made for cracks made by static or fatigue loading. For further information on fatigue behavior of plain and reinforced concrete the reader is referred to the ACI 215-74 committee report titled "Consideration for Design of Concrete Structures Subjected to Fatigue Loading".

\subsection{Volume Changes Caused by Shrinkage in the Fresh State}

Cracks that develop during or shortly after construction include cracks due to plastic shrinkage, settlement, or construction movements. Plastic shrinkage is generally thought of as being due to capillary stress caused by the rapid evaporation of water from freshly placed concrete ( $\mathrm{ACl} 207)$. It is generally assumed that when the bleed rate exceeds the rate of evaporation the concrete will be safe from plastic shrinkage cracking because a protective layer of water will be present on the surface of the concrete until it gains enough strength to counter the capillary stresses. If the evaporation rate is higher than the bleed rate capillary stresses can develop in the material and lead to cracking (Lura et al. 2007).

It is also important to recognize that there are two other sources of volume change that can occur shortly after placement may lead to cracking 1 ) differential settlement and 2) plastic shrinkage. The assumption that shrinkage is isotropic is violated when associated with differential settlement and plastic shrinkage because the shrinkage occurs preferentially in the vertical direction and near surface horizontal direction, respectively.

Differential settlement can be important for any concrete / grout or waste form that is cast with a difference in cross section or reinforcing steel. The concrete 'settles' in a fresh state as the cement and aggregates are denser than water. As the cement and aggregate settle faster, water is left behind, 'appearing as bleed water' on the surface. When a section, slab, or layer has a uniform thickness and there are no inclusions settlement is more or less uniform. However, if the material is not a uniform thickness or is cast around inclusions (such as reinforcement, blockouts, or forms for a change in section height) the material will experience differential settlement above and next to the inclusion. This results in the development of stress in the freshly placed material that can ultimately lead to cracking (Qi et al 2002, and Kwak et al 2010). 
Settlement as a function of the location of rebar in concrete is illustrated in Figure 8. The y-axis illustrates the amount of settlement at the surface of the concrete shortly after concrete placement, and the x-axis indicates the horizontal distance from the reinforcing bar. Differential settlement is not limited to reinforced concrete and is a common feature over pipes or changes in section depth.

The second type of volume change that can lead to cracking in the fresh state is autogenous shrinkage which occurs in response to chemical shrinkage. While this occurs in all Portland cement based materials, it is important to note that the magnitude of this shrinkage increases substantially as the water to cement ratio is reduced. This type of shrinkage begins to occur as soon as water comes in contact with the cement (Sant et al. 2007).

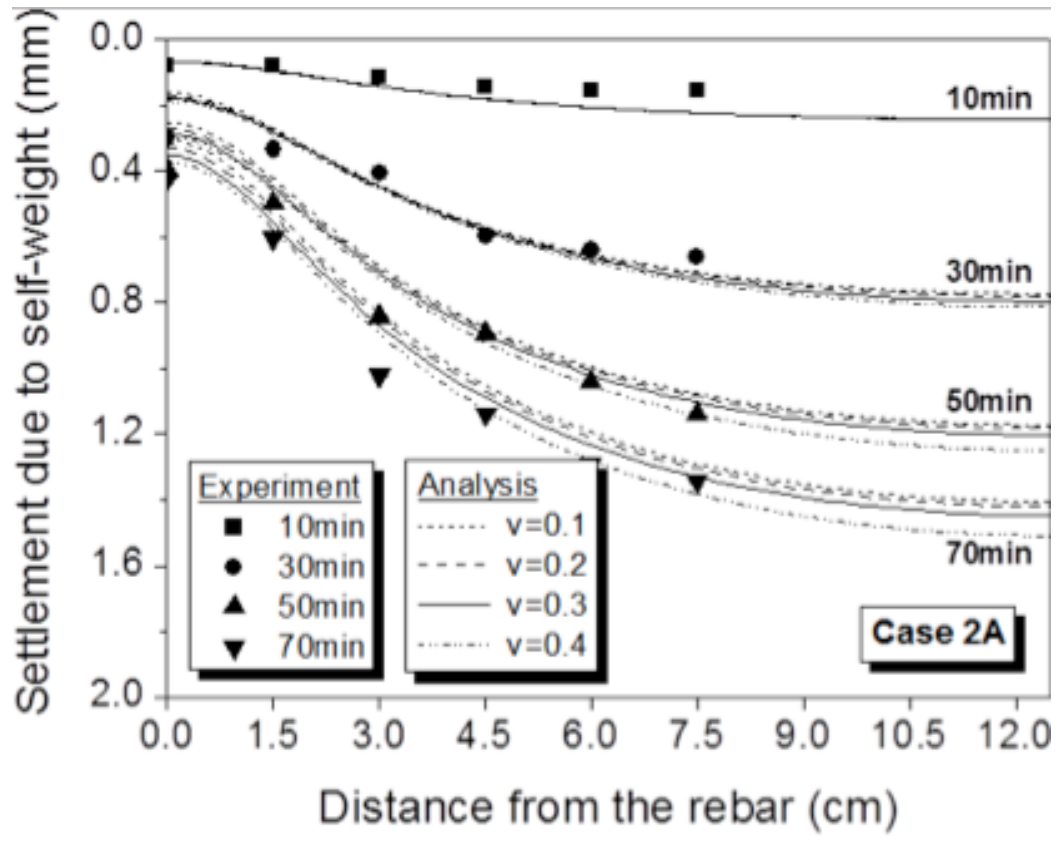

Figure 8: An Example of Differential Settlement over the Surface of the Reinforcing Bar (Kwak et al. 2010)

It is expected that specifications can be developed to substantially reduce plastic cracking in radioactive waste containment structures of the type being built at the SRS. Therefore, they will not be addressed in detail in this review. Standard tests exist to measure the plastic shrinkage cracking tendency (insufficient water at the surface - water evaporation from surface at a faster rate can be compensated for by bleed water) ASTM C 1579 and autogenous shrinkage (insufficient supply of water in the bulk material - self desiccation) with ASTM C 1698. These types of cracks become evident during the first day or two after construction or immediately after the formwork is removed. 
Early age volume changes may be important for the saltstone waste form; however more information on the early age volume changes expected for those materials is needed. For example, if the saltstone material shrinks, a 'gap' could be created along the outer edge of the saltstone that could serve as a fast pathway for moisture and/or air. Also, if the saltsone were restrained during placement it may itself crack thereby altering the diffusion distances assumed in the performance modeling. More detailed characterization of the shrinkage and mechanical properties of this material at early ages per protocols like ASTM C1851 or ASTM C1698 are needed to more fully understand the dimensional stability and potential for cracking.

\subsection{Volume Change Caused Shrinkage in the Hardened State}

Two types of shrinkage (volume change) can occur in hardened concrete due to water related (hygral) effects. They are generally referred to as autogenous shrinkage and drying shrinkage. (Both also occur during the plastic state as previously described.) Drying shrinkage occurs when water is lost from the concrete to the surrounding atmosphere. Autogenous shrinkage is the consequence of chemical reactions (chemical shrinkage) involved in the hydration process. Both autogenous and drying shrinkage occur due to the same mechanics (disjoining pressure and capillary stress associated with the menisci created between vapor filled space/pores and fluid filled space/pores).

The vast majority of the literature over the last century has delt with drying shrinkage. However autogenous shrinkage has been more widely studied in the last two decades due to the increased use of low water/cement, high strength concrete. Valuable information on autogeneous shrinkage in high strength, low water to cement concretes is available in publications like RILEM TC 181.

Two main differences between drying and autogenous shrinkage should be noted.

- First, drying shrinkage occurs when water is lost to the environment which can be a slow process that is dominated by non-linear diffusion (Bazant and Najjar 1972). As such, moisture gradients develop in the material with more shrinkage occurring at the surface of the material than in the core, i.e., surface phenomena. This is not the case with autogenous shrinkage which occurs uniformly across the cross section, i.e., bulk phenonema. Further, unlike drying shrinkage which is related to diffusion, autogenous shrinkage is related conceptually to a combination of pore size distribution and the chemical shrinkage (extent of hydration) that has taken place for a given material. 
- Second, autogenous shrinkage increases as the water to cement ratio decreases or as finer cements (or supplementary material) are used. It is generally assumed to be a consideration for concretes with water to cement ratios below approximately 0.42 , however this is a somewhat arbitrary limit.

Figure 9 illustrates how volumetric changes can result in cracking. If the concrete were unrestrained (able to move freely), it would simply reduce its size and be stress free (assuming the stresses around the aggregate or due to moisture gradients are not considered). However, in most applications movement is restrained, and the concrete is not able to move freely. A concrete wall on a stiff foundation is most restrained along the footing and at corners unless accounted for by design features ( $\mathrm{ACl} 207)$. In this case the foundation would restrict the movement of the wall and the bottom of the wall would be restrained from moving freely and most likely exhibit cracks.

The stresses that are developed due to restraint may or may not lead to cracking. Whether cracking occurs depends on the relationship between the stress and strength. The time-dependent strength development is compared with the time dependent residual stresses that develop in Figure 9a. Cracking can be expected to occur when these two lines intersect (i.e., the stress equals or exceeds the strength). Similarly, it follows that if strength of the concrete is always greater than the developed stresses, no cracking will occur. However, this may not be exactly true for two reasons. First, viscoelasticity can result in stress relaxation (Weiss et al 1998) or reduction. Second sustained loading can result in failure at a lower stress level (Attiogbe et al. 2002).

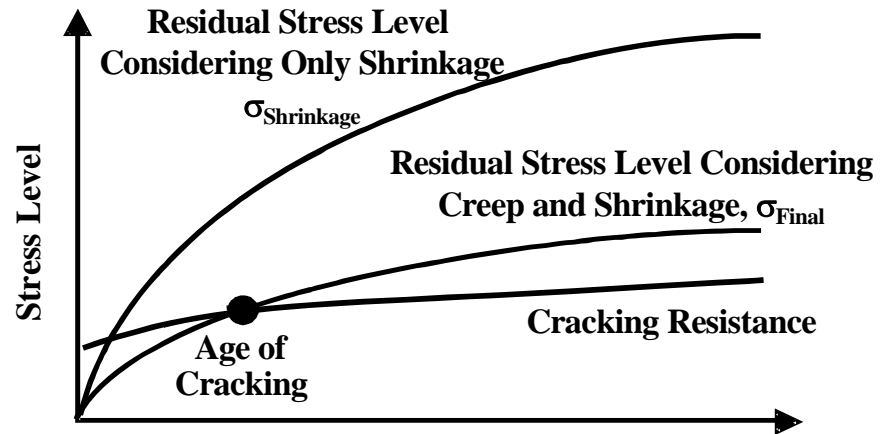

Time Since the Initiation of Drying (Days) (i)

(ii)

(iv)

(v) Stress Relaxation

(vi) Final Stress State

(b)

Figure 9. (a) Stress Development and (b) Conceptual Description of Relaxation (Weiss 1997) 
Figure $9 \mathrm{~b}$ can be used to better understand the role of viscoelasticity. Instead of simply computing the stress that develops directly by multiplying the free shrinkage by the elastic modulus (i.e., Hooke's Law) stress relaxation needs to be considered. Stress relaxation is a visco-elastic response that is similar to creep. However while creep can be thought of as the time dependent deformation due to sustained load stress, relaxation is a term used to describe the reduction in stress under constant deformation.

The dependence of shrinkage cracking on several factors including: 1) free shrinkage (rate and magnitude), 2) time dependent material property development, 3) stress relaxation (creep), 4) strength, 5) structural geometry, and 6) degree of structural restraint (Weiss 1999) is illustrated for a hypothetical specimen in Figure 9b. The specimen has an original length (i) and is exposed to a uniform volumetric strain, i.e., shrinkage (developed across the cross section). If the specimen were unrestrained, the applied shrinkage would cause the specimen to undergo a change in length (shrinkage) of $\Delta \mathrm{L}^{+}$(ii). To maintain the condition of perfect restraint (i.e., no length change) a fictitious load can be envisioned to be applied (iii). However, it should be noted that if the specimen were free to displace under this fictitious loading the length of the specimen would increase (due to creep) by an amount $\Delta \mathrm{L}^{-}$(iv). Again, to maintain perfect restraint (i.e., no length change) an opposing fictitious stress is applied (v) resulting in an overall reduction in shrinkage stress (vi).

\subsection{Volume Change Caused By Temperature Effects}

Concrete temperature rises during the initial hydration however after the first few days the temperature of the concrete is primarily influenced by the ambient temperature. Similar to the stresses that develop when hygral volume changes are restrained (Section 4.3), when temperature changes are restrained stresses can develop and can cause cracking. The coefficient of thermal expansion in the concrete is influenced by the coefficient of thermal expansion of the aggregate since it can occupy approximately $70 \%$ of the total volume of concrete. The coefficient of thermal expansion on concrete is known to cover a relatively wide range and depends on the composition of the aggregate. ACI 207 and RILEM TC 172 provide information on designing mixtures to have a lower susceptibility for thermal cracking.

\subsection{Freezing and Thawing}

Field experience has shown that properly air-entrained concrete with sufficient strength demonstrates sufficient resistance to cycles of freezing and thawing. However, under extremely severe conditions even air entrained 
concrete may suffer damage from cyclic freezing ( $\mathrm{Li}$ et al 2012). Fagerlund (1977) and Li et al (2012) have shown that concrete below a critical limited (approximately 80 to $88 \%$ saturation which varies slightly depending on the composition of the concrete) is resistant to freeze thaw damage while concrete with a degree of saturation over $88 \%$ will exhibit substantial damage even if it is properly air entrained (Figure 10). It should be noted that very little of any concrete reaches complete saturation and air entrainment helps to substantially reduce the degree of concrete saturation. In addition, freeze-thaw damage does occur it happens more uniformly throughout the material and is not limited to a localized region like that typical for mechanically induced loading (Yang et al 2004).

Due to the location of the SRS site a relatively low number of freeze thaw cycles would be expected. During a period of a few years it is unlikely that air entrained concrete would experience freeze thaw damage even in locations like the bottom of the vaults where standing water may be present which could act to increase the degree of saturation for the concrete. However if this is a concern the vaults could be covered or pumped to reduce the potential for standing water since standing water could increase the level of saturation in the concrete.

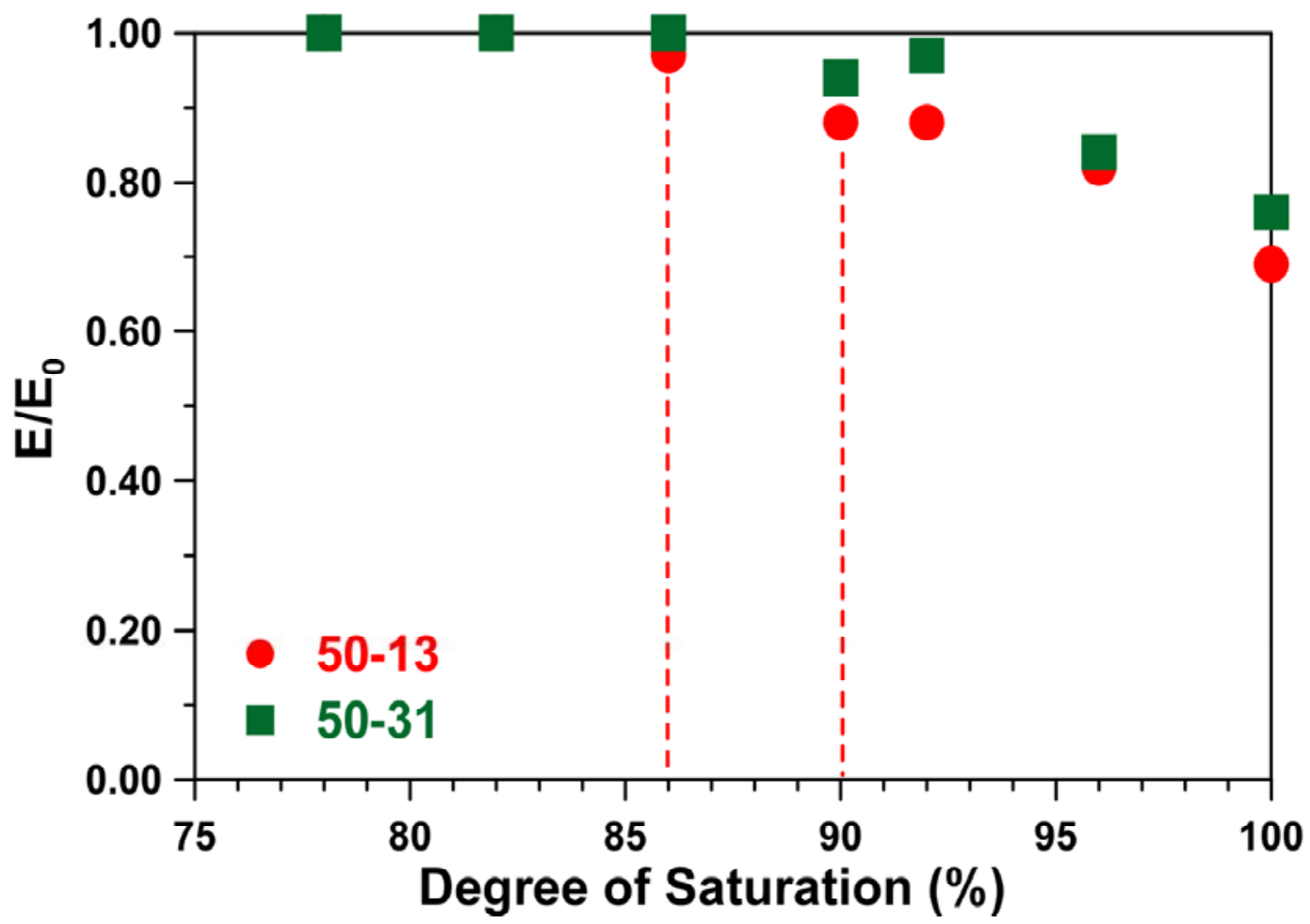

Figure 10: Relationship between Stiffness Degradation (E/E $E_{\circ}$ with $100 \%$ being undamaged) the Degree of Saturation for Non-Air Entrained (Red Circles) and Air Entrained Concrete (Green Squares) (Li et al. 2012) 


\subsection{Corrosion}

Typically, reinforcing steel in concrete is protected from corrosion by the high $\mathrm{pH}$ of the pore solution caused by the calcium hydroxide and the soluble alkalis. Under these high $\mathrm{pH}$ levels corrosion is resisted by the development of a passive layer of ferric oxide that develops on the reinforcing steel. This passive layer prevents corrosion from occurring. If this passive layer breaks down due to carbonation, ingress of oxygen, or the ingress of chloride ions the reinforcing steel will begin to develop active corrosion. For corrosion to initiate, moisture and oxygen must be present.

The corrosion products are expansive in nature and effectively pressurize the concrete around the reinforcing steel. Once sufficient corrosion has occurred splitting cracks typically develop along the rebar-concrete contact and a loss of bond is observed. The thickness of corrosion products required to cause cracking is in proportional to the cover thickness. For concrete with a cover thickness of $40 \mathrm{~mm}$ a corrosion thickness of $50 \mu \mathrm{m}$ is typically sufficient to cause splitting cracks. These cracks frequently propagate to the surface resulting in concrete spalling or loss of bond. Recent research has illustrated that preexisting cracks can accelerate corrosion initiation and propagation (Bentur et al. 1997, Yoon 2002a) while sustained load further accelerates corrosion and can be sufficient to result in creep rupture (Yoon et al. 2000b).

\subsection{Alkali-Aggregate Reaction}

Alkali-aggregate reactivity (AAR) is caused by a reaction between specific aggregates and alkalis that are typically provided by the cement (or supplementary material) or from outside sources, such as deicing salts, ground water, and sea water. If the aggregates are siliceous, the reaction is generally referred to as alkali silica reactivity (ASR). If the aggregates are dolomitic carbonate, the reaction is known as alkali-carbonate reactivity (ACR). The reaction generally causes a portion of the aggregate to dissolve or crack and an expansive gel to form around or in the aggregate which causes internal pressure to develop in the concrete (Stark, 1980). When the pressure is high enough the matrix will crack in a "map" pattern, i.e., typically a well distributed crack network throughout the concrete.

\subsection{Cracking in Reinforced Concrete Elements}

Cracking is generally considered in the design of reinforced concrete elements. Design equations have been developed over the years to limit crack width and location by specifying the amount, distribution, and location of the reinforcing steel. This report is not intended to provide information on design 
procedures such as those outlined in reinforced concrete texts or model codes like $\mathrm{ACl}$ 318. Rather this section is intended to illustrate one important feature of cracks that occur in reinforcing steel, i.e., how cracks that are perpendicular to a reinforcing bar, such as those starting at the surface of a reinforced concrete element loaded in tension or flexure, interact with the reinforcing bar and result in de-bonding along the rebar.

In addition to opening/flaring across the bar, the crack tends to propagate along the bar causing de-bonding. See Figure 11a. The lugs on the reinforcing steel help to provide a mechanical bond with the concrete. However, cracks form along the bar and the bar can separate slightly from the matrix. Figure $11 \mathrm{~b}$ shows experimental results obtained from image correlation by Pease et al. (2010) who examined the role of cracking in reinforced concrete elements.

The primary crack is perpendicular to the surface and is what is frequently focused on when the crack is measured at the surface. However, as loading progresses a secondary crack develops that allows rapid, lateral crack growth (de-bonding) along the bar. Figure $11 \mathrm{~b}$ illustrates experimental measurements from a cracked reinforced concrete element tested in flexure. (The lower face of the beam and the reinforcement are located at the in the center of the image. During loading separation between the concrete and steel contact was observed to extend approximately $0.1 \mathrm{~mm}$ to nearly $50 \mathrm{~mm}$ away from the primary crack. The cracks that crossed over the reinforcing bar (labeled as secondary cracks) were greater in number and narrower than the original crack. Using a specially instrumented rebar Pease et al. (2011) denoted that corrosion occurs along a large segment of the rebar where de-bonding takes. Similar de-bonding and corrosion along rebar in the regions of transverse cracking have been observed by Raoufi and Weiss (2012) for samples where restrained shrinkage cracking had occurred. 


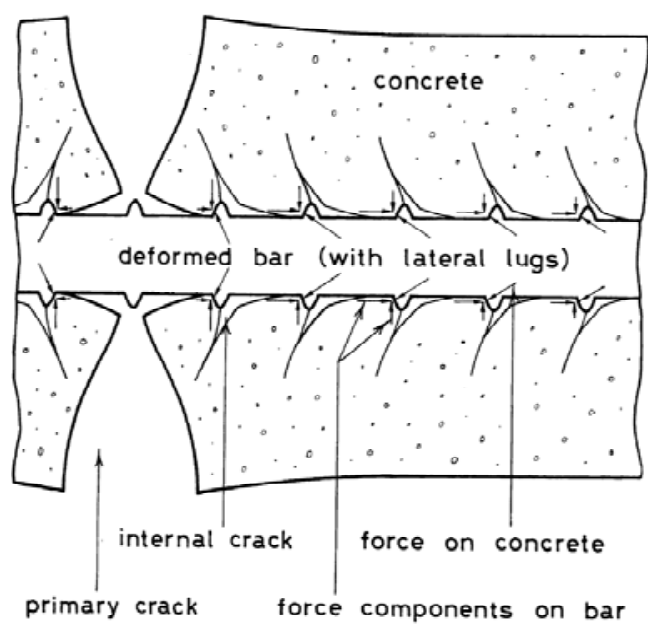

(a)

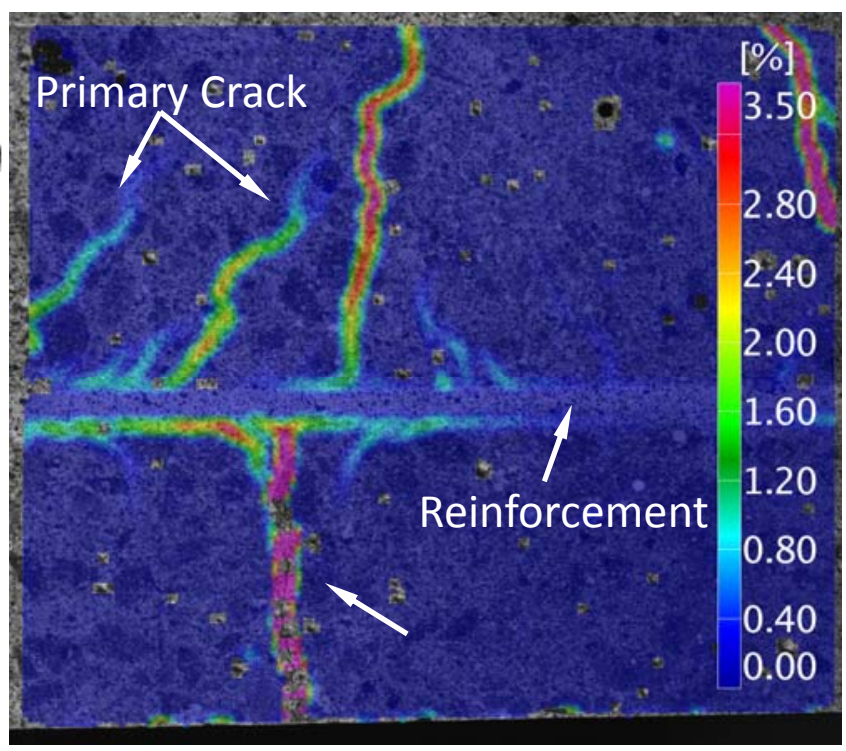

(b)

Figure 11: An Illustration of the Role of Cracking Perpendicular to Reinforcing Steel and the Accompanying De-bonding that Occurs Along the Reinforcing Bar: a) Illustrated conceptually (Goto 1971) and b) Measured Experimentally Using Image Correlation (Pease et al. 2011)

Flexural cracks tend to be larger at the surface and become narrower as one moves from the surface as illustrated for an actual specimen loaded in flexure in Figure 11. Figure 12 illustrates cracking that may occur due to more of a tensile loading condition where the crack is generally uniform in width across the section but narrower at the reinforcing bar due to bonding and pull out of the rebar. Figure 12 also indicates that while chemical degradation processes are typically associated with an advancing front of deterioration from the surface, the crack surfaces provide aggressive chemicals a pathway into the bulk material.

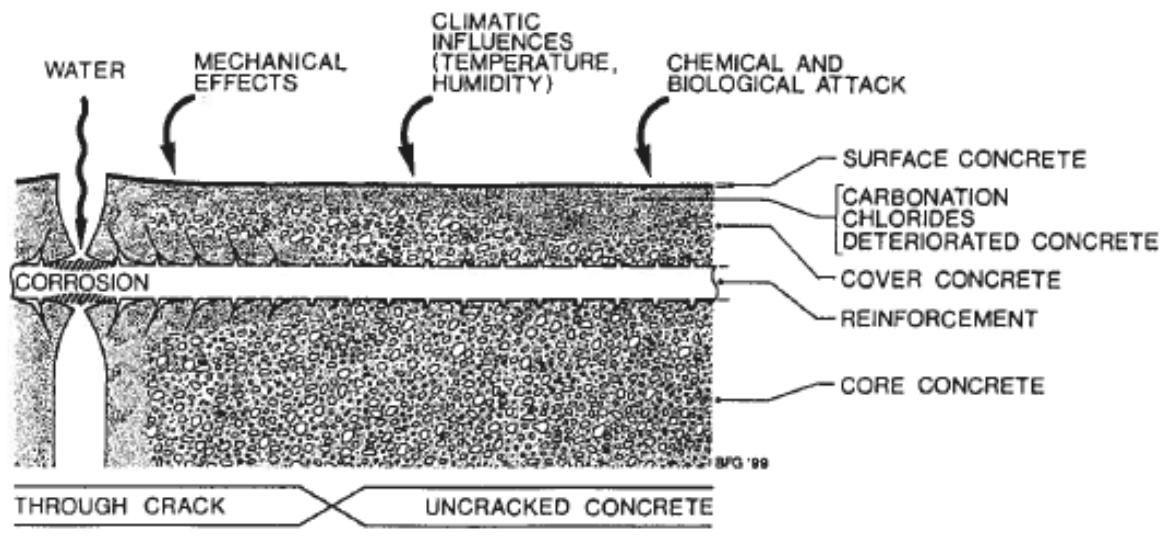

Figure 12: An Illustration of a Through Crack (Bruhwhiller et al. 2003) 


\subsection{Sulfate Attack}

Sulfate attack can be caused by either 1) external or 2) internal sulfate attack. External sulfate attack is caused by contact with water that contains sulfate which is common in seawater and sulfate bearing soils. (Saltstone appears to be a source of sulfate ions. External sulfate attack generally results in an expansive surface skin that leads to cracking. The mechanism for external sulfate attack is complicated and depends on the chemistry of the cement and sulfate solution. Calcium hydroxide can be dissolved at the surface and magnesium from magnesium sulfates can replace the calcium in the calcium silicate hydrates both of which results in loss of strength of the matrix. Formation of gypsum also weakens the matrix. Internal sulfate attack generally occurs as the result of materials incorporated in the concrete at the time of mixing e.g., sulfate rich aggregate or excess gypsum added to the concrete. Delayed ettringite formation can also be thought of as internal sulfate attack. In general external sulfate attack is most severe at the surface. This damaged region appears to consist of damage layers that penetrate from the surface of the concrete. These damage layers consist of a distributed type of cracking where the expansion of the paste causes loss of bond with the aggregate. The damaged material is extensively cracked and has an increased porosity. The damaged layer due to external sulfate attack is so altered that assigning new matrix properties to this layer seems reasonable. It should be noted that sulfate attack requires water as a flux and water (or possibly water vapor) is a key component in some of the expansive reaction products such as ettringinte.

\subsection{Summary}

In summary this section contains a brief overview of different types of cracking that may occur in concrete elements. It was not intended to provide a complete review of all cracking but hopefully does point out that the cause of cracking can have a significant influence on the morphology of the cracks that form. The morphology of the cracks will in turn influence moisture and gas transport. The visible cracks that form due to plastic shrinkage, restrained shrinkage or mechanical loading are generally 'localized in nature'. The cracking that occurs due to moisture gradients, freezing and thawing, and alkali silica reaction are generally more well distributed throughout the matrix. 


\subsection{Defining Different Types of Cracking and the Impact of Cracks on Transport}

Cracks have been proposed by many to increase the ingress of water and aggressive agents in concrete, thereby increasing the susceptibility of concrete to deterioration. On its face this statement seems reasonable and almost obvious; however other researchers have suggested that cracks may have little impact on the rate of transport.

Part of the complexity that drives this apparent divergence in view is how one defines what constitutes a crack in a material. In general, the principal investigator $(\mathrm{PI})$ is of the opinion that this definition is not clearly made in the vast majority of concrete literature. For example, some people view cracking as only cracks that are visible while others include 'microcracking' which is typically only seen when the concrete is examined using high powered optical or scanning electron microscopy. Based on this, it is clear that crack size plays an important role in the discussion. It can also be argued that crack geometry and morphology are important to the discussion. For example, a series of wide connected cracks are expected to have a greater impact than short discontinuous cracks. Further, the moisture contents of the concrete and crack itself are important.

Research by Hearn (1999) that indicated that water permeability was apparently insensitive to load induced cracking while drying shrinkage cracking increased the water permeability by several orders of magnitude. It is believed by the PI that this discrepancy is based on the distribution and orientation of the cracks in the material and the morphology of the cracks. Further it should be noted that discrepancies in the 'role that cracks play' can be caused by the type of testing used in the evaluation process. Some tests measure the global response of the material which is generally more effective in capturing distributed cracking. Other methods capture local behavior which is much more applicable to analysis of a single crack caused by mechanical loading.

In the studies by Hearn (1999), the mechanically induced crack may have introduced very few cracks however the drying crack may have introduced a large network of cracking. As such the PI thinks that it is too generic to simply ask how 'cracks' influence transport because different causes of cracking can result in substantially different crack morphologies.

In this chapter, cracks will be classified as either discrete or distributed depending on morphology. Discrete cracks include localized cracks that are characteristic of plastic shrinkage, restrained shrinkage (thermal and hygral) and 
mechanically loading. Discrete cracks are best described by geometry (width and length) and morphology. Distributed cracks are typically due to damage caused by moisture gradients, freeze-thaw cycling, ASR or ACR. Distributed cracks are described in terms of connectivity in addition to geometry and morphology.

Rules of thumb (guidelines rather than specifications) regarding the widths of cracks that are permissible for different structures have been provided groups like $\mathrm{ACl}$ 224. See Table 1. These suggested crack width limits are based on concerns that cracks can lead to a range of common distress conditions (visible cracking, leakage, corrosion). See Figure 13. Suggestions for crack limits based on the concerns for very long term performance are not addressed by $\mathrm{ACl} 224$.

Table 1: ACI 224 Suggested Crack Width Limits for Different Exposure Conditions

\begin{tabular}{|c|c|c|}
\hline Exposure & \multicolumn{2}{|c|}{ Crack Width } \\
\cline { 2 - 3 } Condition & in & $\mathbf{~ m m}$ \\
\hline Dry Air or Protective Membrane & 0.016 & 0.41 \\
\hline Humidity, Moist Air, Soil & 0.012 & 0.30 \\
\hline Deicing Chemicals & 0.007 & 0.18 \\
\hline Seawater and Seawater Spray, Wetting, Drying & 0.006 & 0.15 \\
\hline Water Retaining Structures & 0.004 & 0.10 \\
\hline
\end{tabular}

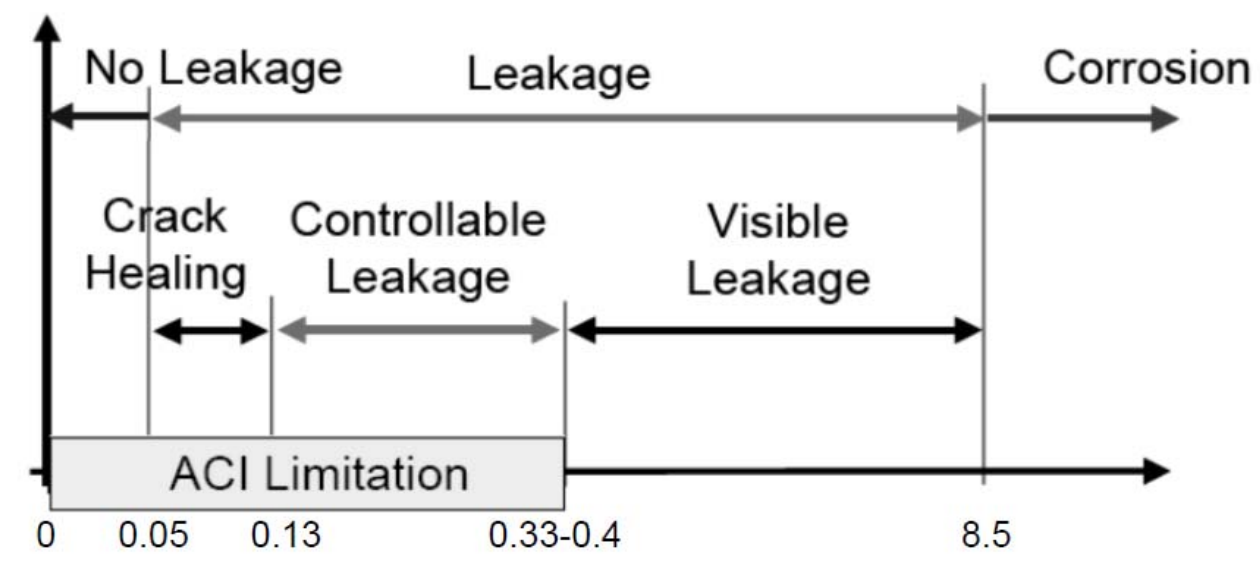

Crack Width $(\mathrm{mm})$

Beginning of
Visible Cracking

Visible Corrosion with Deicers

Figure 13: Relationship between Crack Width and Visible Damage 
It should be noted that field evaluations of crack widths are nearly always performed by measurements on the surface. The shape of the crack can vary significantly through the thickness of the structure with the crack becoming narrower as one moves toward the center of the structure. In addition, the widths of cracks can vary significantly with an average coefficient of variation of approximately 40\% (Leonard 1977, Qi et al 2002).

It is also important to note that while a substantial portion of research has been performed on cracks in unreinforced concrete. In general, crack width is controlled through the design of the reinforcing steel.

\subsection{A Minimum Crack Size to Be Considered a Crack for a Discrete Crack}

The question of how large does a crack need to be to significantly influence moisture and gas transport, i.e., to be considered relevant to this discussion, is common to many fracture mechanics-based failure investigations. In fracture mechanics it is generally assumed that flaws smaller than a specific size are considered as intrinsic to the material, and only flaws larger than a specific size are considered to be 'cracks'. This appears to be a logical and necessary distinction for concrete and can be summarized as: the capillary pores themselves represent voids in a material and 'cracks' should be larger than these voids (larger than the dimensions of the capillary pores).

Assessment of concrete literature indicates that it is common to limit the discussion of cracks to those features having one dimension greater than approximately 100 microns which by coincidence is in the range of large unhydrated cement grains.

One way to distinguish cracks from the presence of other microstructural features in concrete using automatic image analysis system is to consider a measure of the aspect ratio (length to width). Note that disconnected pores generally appear circular in plan-view with a $1: 1$ aspect ratio while cracks can be defined as having a higher aspect ratio, typically $>1: 3$.

Wang et al. (1997) used a falling head permeameter to show a relationship between crack width and the potential increase for water and other aggressive agents to penetrate concrete (Figure 14). In a follow up study, Aldea et al. (1999) showed that even in high-strength concrete that was designed to have a low permeability, after cracking had occurred, the permeability was measured to be nearly identical to cracked normal strength concrete with comparable crack widths. This is important because many of the life-cycle 
models in existence today rate low permeability / high strength concrete mix designs to be substantial better in terms of overall cost and performance. However this may not be justified if cracks develop.

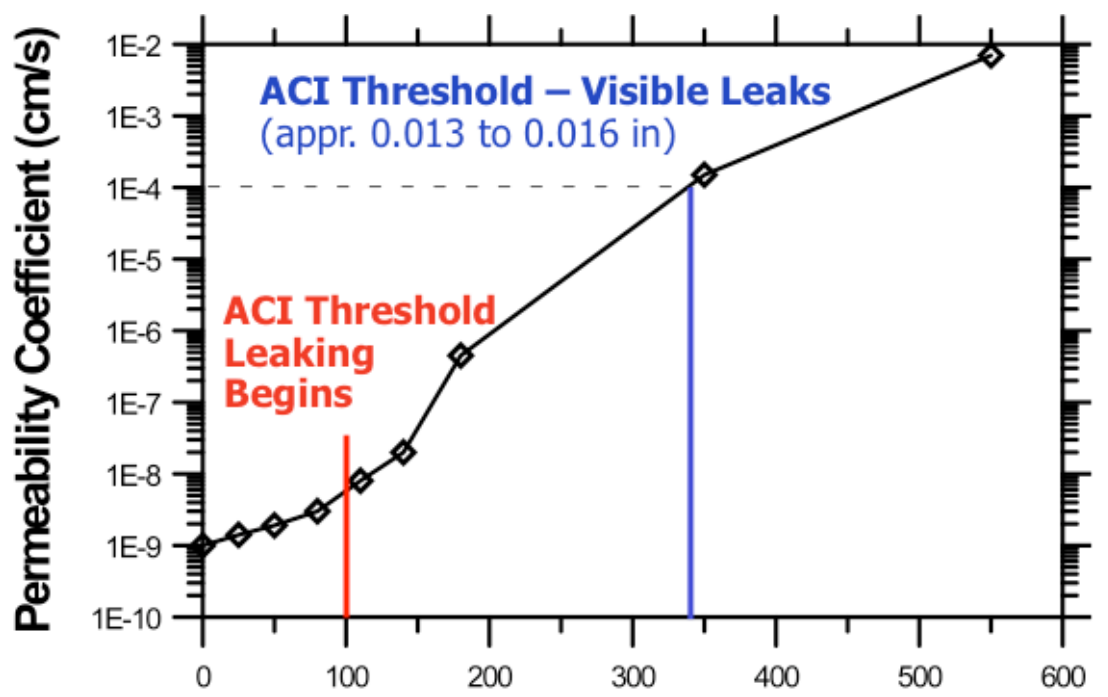

Crack Opening Displacement (microns)

\section{Figure 14: Relationship Between Crack Width (Crack Opening Displacement) and Permeability (after Wang 1997)}

Breyesse et al. (1994) used a specially designed element obtain distributed damage from mechanical loading. The geometry they used was referred to as BIPEDE samples where metal plates were glued on either side of a sample with varying section stiffness to enable cracking to be controlled. In this work they observed an increase in permeability of several orders of magnitude with even relatively small tensile strain ( $50 \mu \varepsilon$ was an approximate increase from $2 \times 10^{-11}$ to $\times 10^{-8}$ ) however they reported that the flow was likely through the discrete cracks and therefore it was misleading to assume this as a distributed property of the material.

It should be noted that during the application of a compressive load the transport properties are typically lower in the direction perpendicular to the loading. A literature review by Breysse and Gerard (1997) identified a substantial number of studies focused on cracking induced by compressive loading. They reported that under compressive loading the transport properties initially decreased due to consolidation however they then began to increase as the cracks began to dilate. Applying these finding to a structural such as a radioactive waste disposal vault suggests that directions of tensile loading are the most significant in terms of inducing crack that will influence fluid transport. 
To investigate the influence of damage due to microcracking, other researchers induced cracks by preloading specimens. Samaha and Hover (1982) did not find significant increases in water penetrability until the load level exceeded $75 \%$ of the peak load (in compression). This appears to indicate that crack coalescence (cracks connecting with each other), rather than microcracking alone, may be required before substantial changes in the moisture transport response occur. This was also observed directly in the studies of Yang et al (2007). Furthermore, it should be mentioned that the permeability tests have typically relied on measurements of the overall system change (i.e., water flow into and out of a specimen, or overall Rapid Chloride Permeability Test results).

\subsection{Distributed Cracking}

Although concrete is generally considered to be a continuum, it is actually a porous material with a wide range of pore sizes. While it may be tempting to focus on treating each crack in the system, there are cases in which it makes sense to treat cracking as a distributed network and to estimate how damage influences the 'average' properties of the concrete. Toward this end one can begin by considering a series of well distributed cracks of a very small width. These microcracks can be considered as being well distributed throughout the material. However they can also be considered to be sufficiently dense so that they can be treated as a homogenous increase in the transport properties of the continuum and expressed as an increase in transport based on bulk material parameter measurements or calculated using dual porosity types of models.

A severely freeze-thaw damaged matrix from concrete that can be considered as showing 'dense cracking' is shown in Figure 15. These images correspond to samples with reductions in stiffness of nearly 15, 54 and $78 \%$. When the stiffness decreased by approximately $20 \%$ the cracks had coalesced. Unlike the case of a mechanically loaded concrete where the majority of damage is localized in a small region, freeze-thaw damage is distributed relatively uniformly throughout the sample (Yang et al. 2004). 


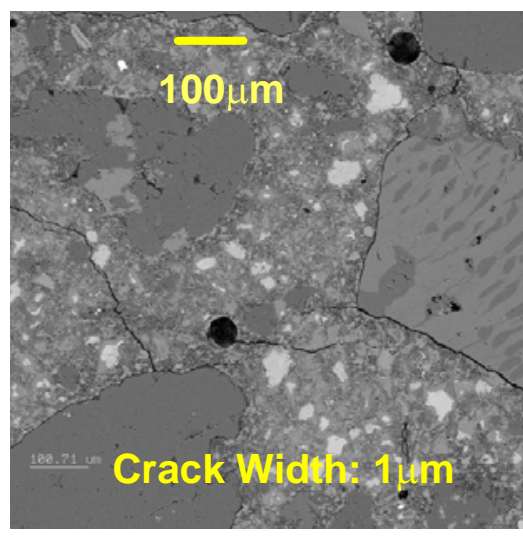

a

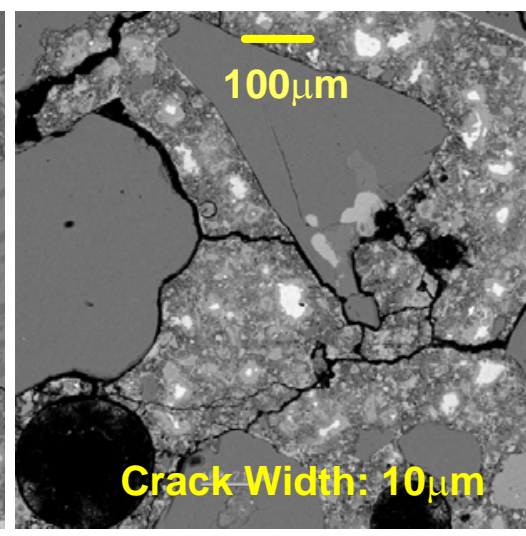

b

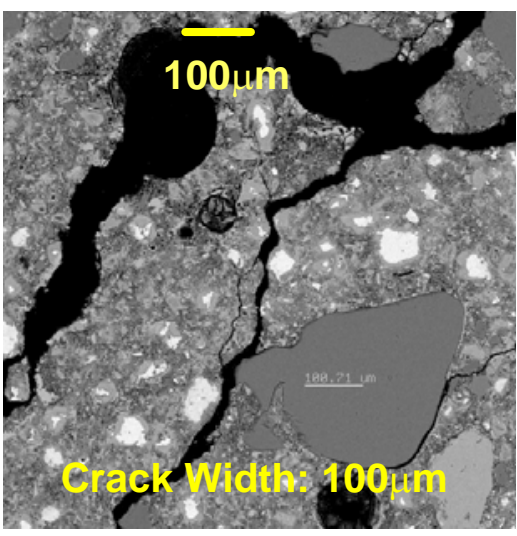

C

Figure 15: Typical crack size and patterns for specimens with hardened air of $4.5 \%$, (a) $E / E_{0}=0.85 ;$ (b) $E / E_{0}=0.46$; and (c) $E / E_{0}=0.22$

To better understand the relationship between crack size and damage level for distributed cracks in the Yang et al. study (2007), refer to the SEM images in Figure 15. For relatively low levels of damage (i.e., $E / E_{0}$ equals to 0.85 ) the crack opening was approximately $1 \mu \mathrm{m}$ and cracks are nearly interconnected. With a decrease in $E / E_{0}$, the number, width, and connectivity of cracks increase. When $E / E_{0}$ is reduced to 0.4 , crack opening is around $10 \mu \mathrm{m}$ and well-connected crack network has been formed. A further decrease in $E / E_{0}$ causes a significant growth in crack width. For example, when the stiffness decreased to $E / E_{0}=0.22$, cracks up to $100 \mu \mathrm{m}$ were observed while the number of cracks and the connectivity of the cracks was very high.

A smeared crack approach can be used for a material that exhibits dense cracking (Yang et al. 2006), and the 'average properties' of the concrete can be changed to account for the cracking. A combination of crack width and crack spacing is needed to justify use of this approach. However, this approach seems reasonable for modeling concrete damaged by freeze-thaw cycling, microcracking due to shrinkage or temperature change, and alkali silica reaction. Use of this approach may require a gradient in damage (or transport properties) as one moves from the surface of the concrete toward the core. This can be potentially be done using a dual porosity model (Papablan 2009). 


\subsection{FLUID TRANSPORT THROUGH CRACKED CONCRETE - DISCRETE CRACKS}

Transport through concrete can be dramatically influenced by the degree of saturation of the concrete which is influenced by exposure conditions. This is also true for the cracks in concrete. The dimensions of the visible cracks in concrete are large when compared with the pores of concrete. Also the cracks are frequently connected to the surface of the concrete. Therefore, fluid can penetrate them rapidly and the transport into and through crack can be more rapid than through the concrete pore structure. As such, it is frequently assumed in moisture and soluble ion transport studies involving infrastructure elements that the cracks are saturated (conservative case).

\subsection{Saturated Concrete with Discrete Saturated Cracks}

Moisture transport through saturated concrete with discrete through wall cracks has been shown to be primarily a function of the crack width regardless of whether this occurs in common construction concrete or high performance concrete. For example, Wang et al. (1997) used split tensile testing as shown in Figure 16 to evaluate the moisture transport through cracks. The LVDT placed across the split cylinder specimen was used not only to measure the width of the crack that opened but also to control the crack growth, thereby, not allowing the crack to propagate in an unstable fashion.

Studies by Wang et al. (1997) and Aldea et al. (1999) used cracked split cylinder tests in a falling head permeameter to show a relationship between crack width and the potential for water to penetrate concrete as shown in Figure 16b. (Also see Figure 14.) It should be noted that interpreting results from these experiments can be complex for two reasons. First, the rate of flow changes considerably immediately after the sample is placed in the permeameter. This change in flow rate may be due to water absorption (samples were probably not sufficiently conditioned/saturated prior to testing) or to crack blocking/healing. The second complication is that the flow rate was related to a measured surface crack width that was measured on the surface of the sample. The crack width can vary from point to point in the sample as well as through thickness and as such only an 'average estimated crack width can be provided'. The geometry shown in Figure 16 may be able to be adapted to study flow under partially saturated conditions. However, the measurement technology would need to be developed further because the current approach relies on the sample being saturated and measuring in flow and out flow. 

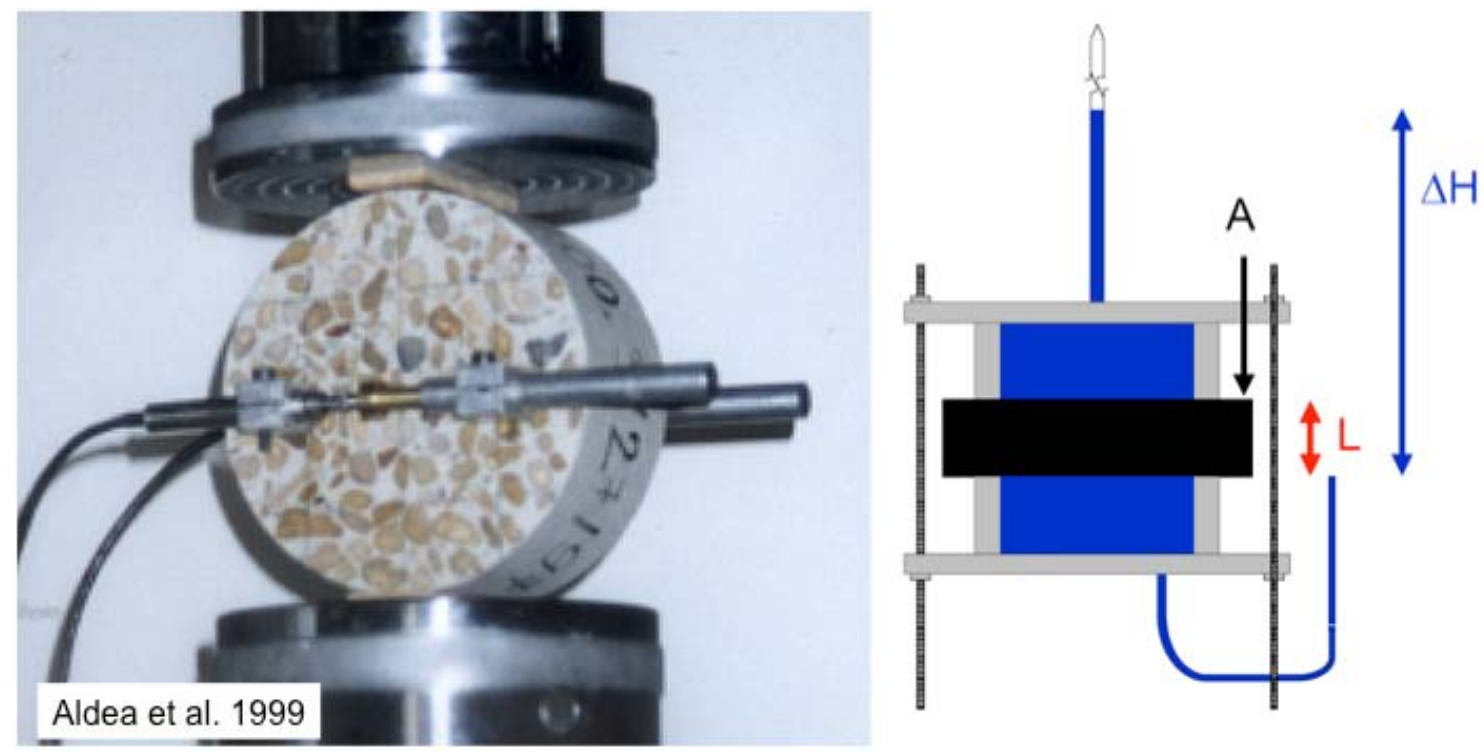

Figure 16: a) Split cylinder specimen tested in closed loop control and b) a falling head permeameter where the split cylinder specimens can be tested.

One approach for calculating moisture flow (Q) through concrete with discrete cracks is to make an assumption of flow through parallel plates. This approach was outlined by Edvarson (1999) who showed that the flow through the crack is related to the width of the crack that forms. This is also reported in several studies on rock.

Edvarsen (1999) suggested that for a single saturated crack a hydraulic conductivity model could be used to describe a crack as a fracture of constant aperture in a porous medium. The fluid flow through a fracture was described using the cubic law for parallel wall fractures. Edvarsen (1999) provided a review of results that indicated how this approach can be modified to account for crack tortuosity or roughness which may be dependent on the nature of the aggregate and the type of binder.

$$
Q=\frac{d w^{3} \Delta \psi}{12 b_{\eta}} \xi
$$

Equation 3

Where: $\Delta \mathrm{p}$ is the pressure gradient, $\mathrm{b}$ is the sample width, $\mathrm{w}$ is the crack width, $\eta$ is the fluid viscosity and $d$ is the length of the flow. The $\xi$ is a factor that is added to the derivation to account for surface roughness, crack blocking and healing. This value can be significant with suggestions it would range from 0.1 to 1.0 . Gerard et al. (1997) made the general assumption that the effective crack width is smaller than the visible crack width. As a result $\xi$ would be 0.5 . To consider 
multiple cracks the flow rate shown in Equation 3 is typically summed as opposed to summing the width.

Reinhart and Joost (2005) showed that flow can be heavily influenced by the temperature of the system as well as by the viscosity of the fluid in the crack. From this type of relationship it is possible to relate the permeability to the square of the crack width. For example, Gerard (1996) used this approach (equation 3) to estimate that the permeability is related to the square of the crack width. Meschkke and Grasberger (2003) refined this estimate using an empirical term that accounted for crack roughness $(A=15)$.

Clarke et al. (1996) used a fixed head permeameter and measured the fluid transport in cracked (machine induced damage) aluminum and identified two flow regimes. The first regime was for cracks with a small width (less than 50 microns) and was believed to be best represented by a system that had tortuous paths of bends and kinks (labeled as bend loss). The second regime was for cracks of larger width (greater than 50 microns) that appeared to follow flow between two parallel plates.

Slowik and Saouma (2000) measured the influence of hydrostatic pressure in a crack on dynamically loaded wedge splitting specimens. The purpose of this test was to compare the rate of crack growth in the pressurized and unpressurized case and to determine whether the pressure could keep up with the crack growth. In slow crack growth the water pressure can develop however in fast crack growths this does not appear to happen.

Research at Purdue and the Danish Technical University examined the potential use of several specimen geometries to measure absorption and diffusion in cracked materials; however the wedge splitting geometry was finally selected. The first benefit of the wedge splitting test is that it enables the parameters that describe the cohesive crack law to be determined. (These parameters are related to the properties of the crack that are generally related to fracture mechanics predictions made using finite element). The second benefit of the wedge splitting test is that it enables transport from a free exterior surface to be more easily separated from the transport in the crack. This can be illustrated in Figure 17 where the transport from an exposed exterior surface into an uncracked concrete and transport into a cracked sample are illustrated. This work was part of a study to measured chloride diffusion and water absorption into a cracked sample (Weiss et al 2005).

Figure $17 a$ shows that in an undamaged concrete, the chloride concentration will be higher near the surface and decrease toward the core. The 
dashed line is intended to indicate the 'chloride front' that would be detected using a method like spraying silver nitrate $\left(\mathrm{AgNO}_{3}\right)$ on a cut surface. If a crack is introduced (Figure 17b), the chloride that penetrates from the crack will interact with the chloride that diffuses into the sample from the exposed surface. Soon after chloride diffusion begins, the effects of the crack can be easily traced with silver nitrate. However over time, the overlapping effects of penetration from the surface and from the crack will occur. Figure 17c shows the chloride ingress profile expected from a test method like the wedge splitting test. The chloride ingress comes primarily from the crack itself, i.e., not from the exposed surface.

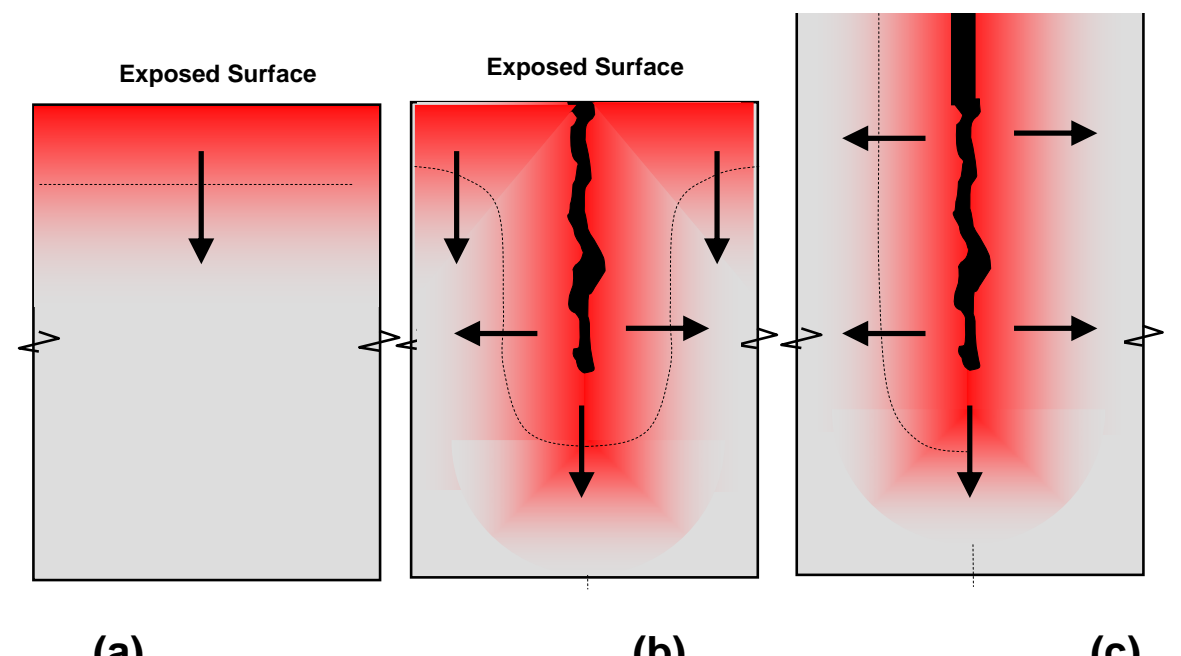

(a)

(b)

(c)

Figure 17: An Illustration of the Effect of Different Sample Geometries on the Chloride Ingress that can Be Measured (a) Uncracked specimen with an Exposed surface, (b) Crack from an Exposed Surface, and c) Wedge and crack Where Chloride is Introduced.

In addition to measuring water absorption, diffusion was assessed using a chloride solution in the crack to determine the depth of ion penetration from the surface of the crack. A $16.5 \% \mathrm{NaCl}$ solution (by mass) was placed in the saw cut and crack of a specimen that was water saturated. The chloride ions were allowed to diffuse into the sample for 21 days. A $0.1 \mathrm{~N}$ silver nitrate $\left(\mathrm{AgNO}_{3}\right)$ solution was sprayed on the surface of the sample shortly after cutting to provide an indication of the depth of chloride penetration. See Figure 18a. The chloride ion penetration profile was calculated as illustrated in Figures $18 \mathrm{~b}$ and $\mathrm{c}$. 


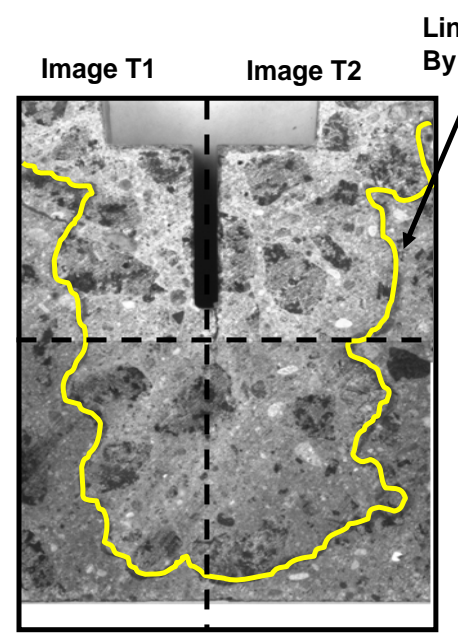

(a)

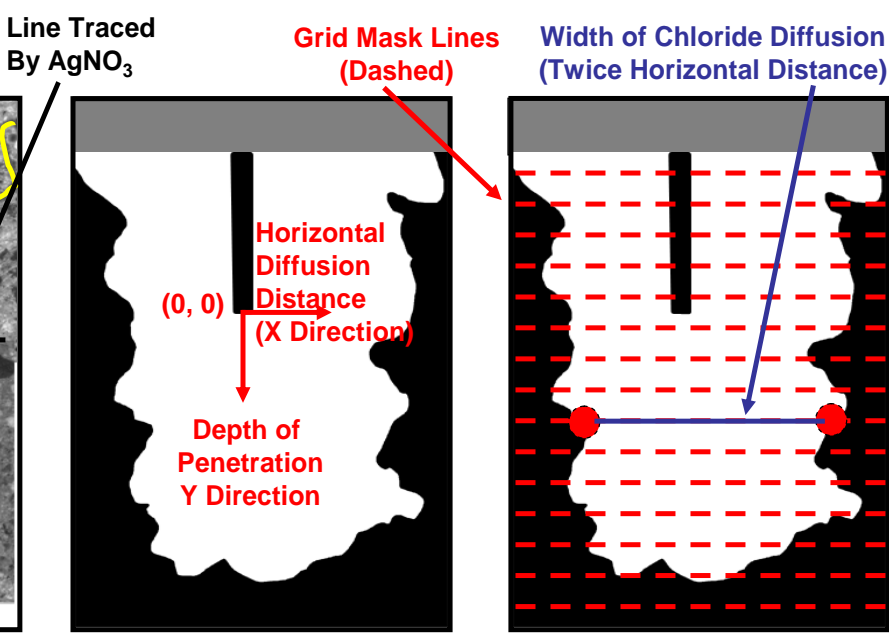

(b)

(c)

Figure 18: a) Sample surface after chloride ingress, b) binary image showing the portion of the sample affected by chloride ingress, and c) an illustration of the imaging approach using a grid mask. (Note the gridlines are not to scale.)

Each plot in Figure 19 shows the average chloride penetration profile depth (y-direction) and width (x-direction or the horizontal diffusion distance) for two samples. Even without a crack, chloride ions penetrate the specimen and build up at the tip of the notch. Diffusion of chloride ions from the notch surfaces results in a $\mathrm{Cl}^{-}$enriched hemi-spherical shape region at the tip of the notch which is consistent with transport from a point source (Hall and Hoff 2004). Samples with no cracking, crack mouth opening displacement $(C M O D=0.0 \mathrm{~mm})$, showed this hemispherical pattern. Very little difference in chloride ingress was observed between uncracked samples and the samples with a small crack mouth opening displacement (CMOD $-0.02 \mathrm{~mm}$ ) with the exception of the mixture with a w/c of 0.30 and $16 \mathrm{~mm} \mathrm{MSA} \mathrm{(maximum} \mathrm{size} \mathrm{aggregate)} \mathrm{and} \mathrm{mortar} \mathrm{mixture}(\mathrm{w} / \mathrm{c}=0.42$ with a $4 \mathrm{~mm} \mathrm{MSA}$ ) which showed a slight increase in chloride penetration. This may be due to the fact that the concretes with a w/c of 0.30 and the mortar mixture are slightly more brittle than the other mixtures. Consequently, the cracks are expected to be less tortuous and to have less distributed micro-cracking at the tip of the crack. 

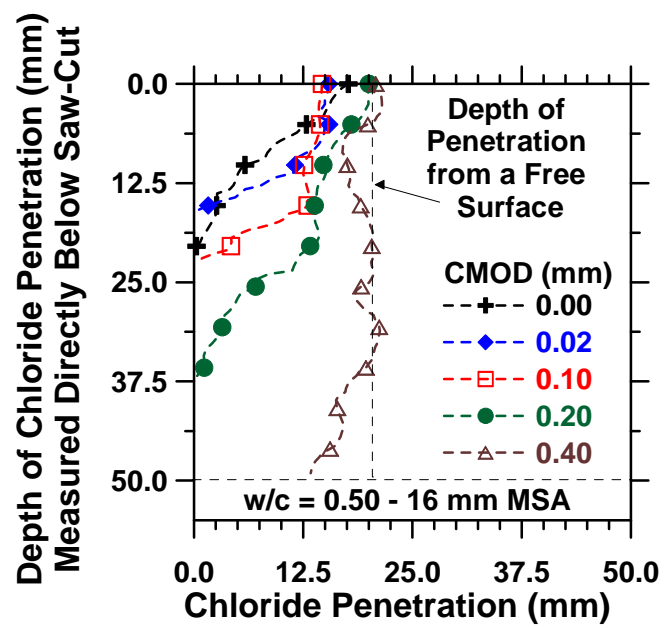

(a)

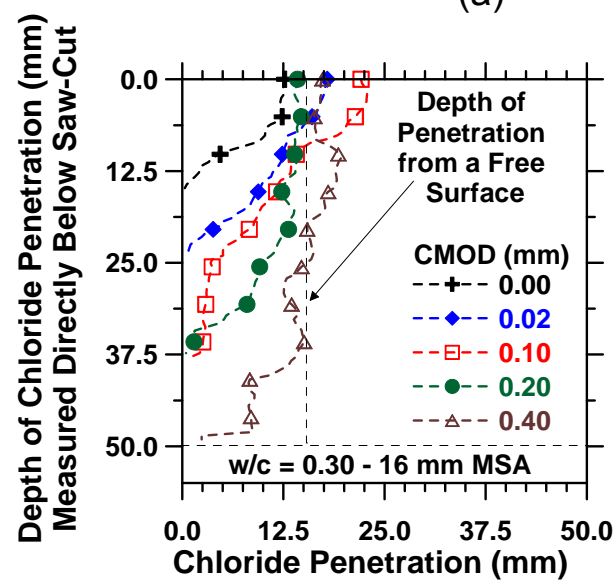

(c)

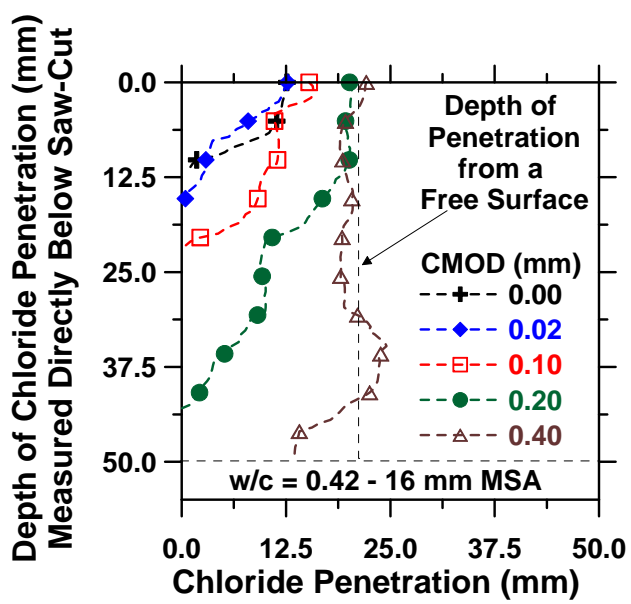

(b)

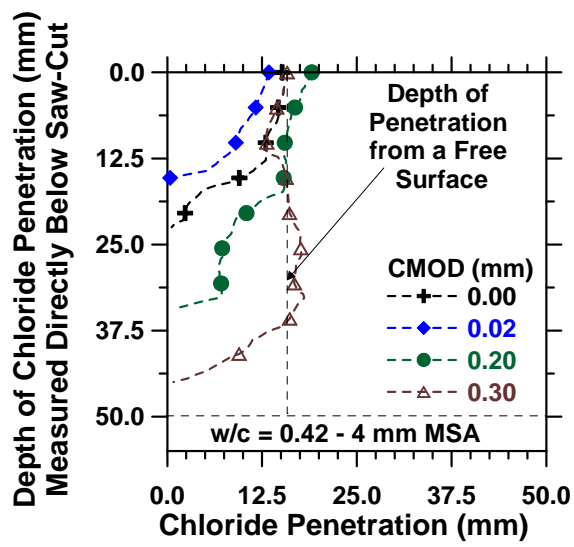

(d)

Figure 19: Width of the Chloride Profiles in Cracked Concrete: a) w/c $=0.50$ with a $16 \mathrm{~mm} \mathrm{MSA}$, b) w/c = 0.42 with a $16 \mathrm{~mm} \mathrm{MSA} \mathrm{a)} \mathrm{w/c}=0.30$ with a 16 $\mathrm{mm}$ MSA a) $w / c=0.42$ with a $4 \mathrm{~mm}$ MSA.

Since each mixture has a different porosity, the $\mathrm{Cl}^{-}$diffusivity will be different for each material. The depth of the chloride diffusion front for each mixture was determined from a slab sample where the depth of chloride ingress could be measured from a free surface on the saw cut face. As expected, samples with a higher water to cement ratio showed a greater depth of chloride ingress. In both the uncracked sample and the samples with small cracks, the horizontal chloride ingress is less than that from a free surface because chloride ions diffused both horizontally and vertically at the base of the saw cut (Pour Ghaz et al 2009).

Samples with larger, tapered crack widths $(\mathrm{CMOD}=0.4$ and $0.6 \mathrm{~mm})$ enable significantly more chloride ingress below the saw-cut. This results in a greater depth of penetration as well as a wider chloride ingress profile. The chloride profile is nearly uniform throughout the effected depth of the specimen. 
This suggests that wider cracks behave as free surfaces. While sufficient data does not exist to define the exact crack width for "free surface behavior", it is clear that by the time the cracks reach a width of $0.4 \mathrm{~mm}$ they behave like free surfaces.

Samples with moderate width cracks (CMOD of 0.1 and $0.2 \mathrm{~mm}$ ) had more ingress than the uncracked sample, but less ingress than the samples with the wide crack widths. The specimens with a CMOD of 0.1 show a slight increase in the penetration depth with the w/c - 0.30-16 mm MSA and w/c - 0.42$4 \mathrm{~mm}$ MSA mixtures. For the sample with a CMOD of $0.2 \mathrm{~mm}$ the crack appears to be open sufficiently wide that the chloride ingress behavior due to the crack is not heavily influenced by the mixture composition but is more influenced by the overall crack geometry.

David et al. (1999) examined the influence of cracking in rock that was produced using two approaches: 1) thermal cracking and 2) mechanically induced loading. They found that the mechanically induced cracks were more anisotropic than the thermally induced cracks. It should be noted however that these specimens were not constrained or restrained in any particular direction which is not what may be typical for reinforced concrete. David et al (1999) used electrical conductivity measurements to determine the formation factor for these materials (A factor that is generally used to describe the porosity and its connectivity in materials). The formation factor decreased as damage was introduced into the samples. They found that the formation factor deviated from a linear relationship when damage was introduced in the material. They also found that conventional permeability measurements also increased with damage however the variability was greater than either acoustic or electrical measurements.

\subsection{Partially Saturated Concrete with Discrete Saturated Cracks}

Several studies have been conducted to quantify how fluid moves from a saturated crack into a partially saturated media. The saturation perimeter (area of the concrete influenced by the crack) around a crack is dependent on the crack size and the properties of the uncracked material. The majority of tests on concrete have examined absorption of solutions containing dissolved chloride ions. Fewer studies, if any have examined the role of cracking on leaching of ions out of the cracked concrete. Some researchers (e.g., Bazant) have studied the influence of cracks on water diffusion in concrete during drying.

The mechanisms of transport through discrete cracks must be resolved and quantified in order to develop rational methods for the determinating input 
values for computer models and for the validating model. One promising experimental approach involves measuring water absorption in cracked concrete with X-ray or neutron radiography methods. X-Ray radiography images of water absorption in a concrete sample over time are shown in Figure 20 (Weiss et al. 2005). The blue contour lines indicate complete saturation. The volume affected by the ingress of water is typically represented as a semi-spherical pattern in the specimens without a crack. A more $V$-shaped pattern is typical of a sample with a crack. Recently these results have been combined with an analytical approach suggested by Wilson (1999) to determine an 'effective initial surface area' of a crack in order to describe the extent to which a crack acts as a free surface. While these results are positive (Figure 21), the aggregate size and crack tortuosity may also play an important role in these measurements.

Neutron and x-ray radiography are important tools that can be also be used to characterize transport in unsaturated conditions because they enable imaging of fluid movement (Sant et al., 2008; Sant and Weiss, 2008; Weiss et al., 2008; Henkensiefken, 2008; Pour-Ghaz et al., 2009; Roels and Carmeliet, 2006). Use of these advanced techniques is especially important in the study of flow through complex geometries, like a saw-cut, that can lead to two-dimensional fluid transport maps (Pour-Ghaz et al., 2009). Work by Poursaee et al. (2010) examined the use of contrasting agents with $x$-ray imaging to measure fluid ingress in unsaturated concrete and movement along fabrics. It should be noted that the viscosity, wetting properties, and surface tension of typical contrasting agents are different than of water and need to be accounted for when interpreting results and extrapolating to water migration in transport models. Recent testing at Purdue University and EMPA (Swiss Federal Laboratories for Materials Testing and Research for Industry, Construction and Commerce) using high contrast neutron imaging provided the ability to resolve water more easily than $\mathrm{x}$ ray measurements. This technique is still under development but appears promising characterizing moisture transport in saturated and unsaturated concrete samples.

Pour-Ghaz et al (2010) examined the role of complex geometries, like saw-cuts, on fluid transport. They used a finite element based code (Hydrus) to simulate unsaturated flow based on solution of Richard's equation. Results of simulations are in good agreement with experimental results (x-ray radiography) and confirm the effects of the geometry of the saw-cut on fluid transport. Recent studies by Li et al. (2012) explored the use of conformal mapping as a method for describing the effects of cracks on moisture transport. 


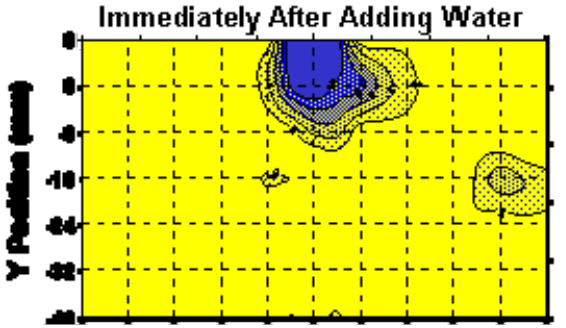

40 Minutes After Adding Water

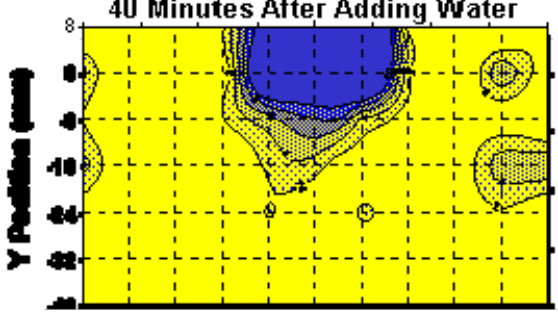

2 Hours After Adding Water

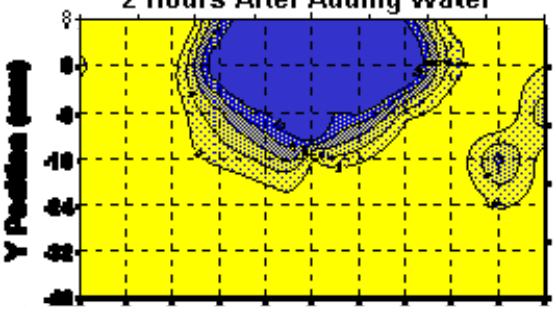

6 Hours After Adding Water

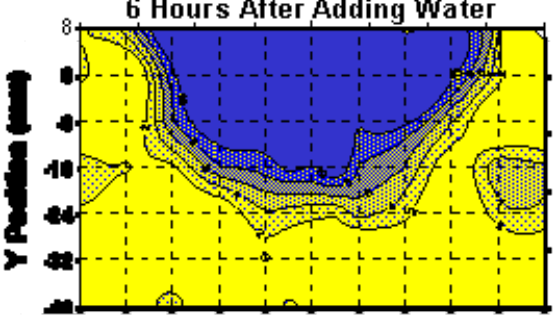

12 Hours After Adding Water

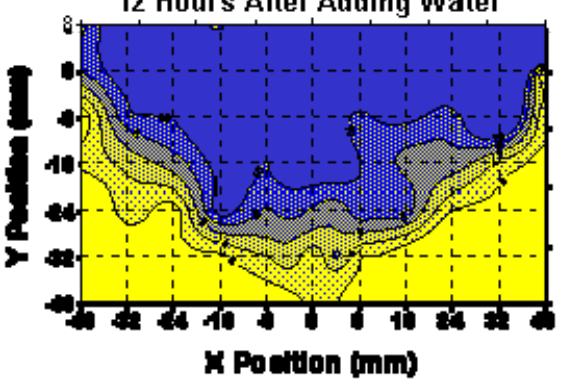

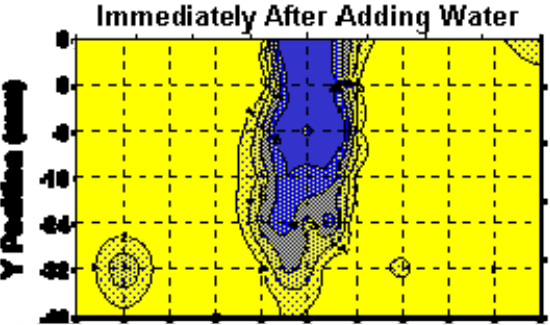

40 Minutes After Adding Water

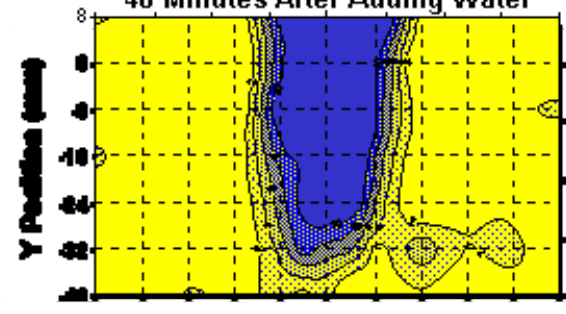

2 Hours After Adding Water

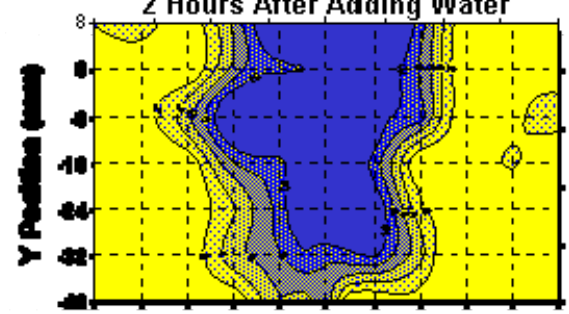

6 Hours After Adding Water

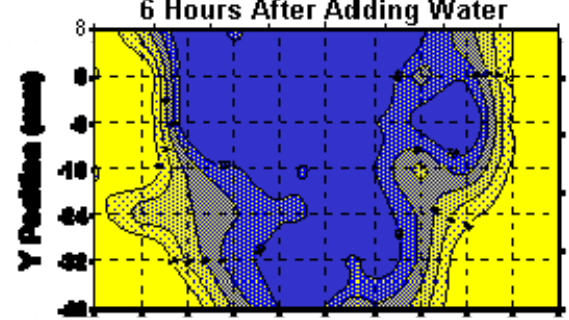

12 Hours After Adding Water

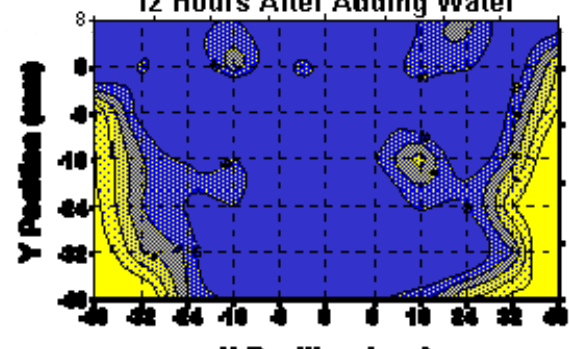

x Pocition (nn)

Normalized Difference in X-Ray Absorption

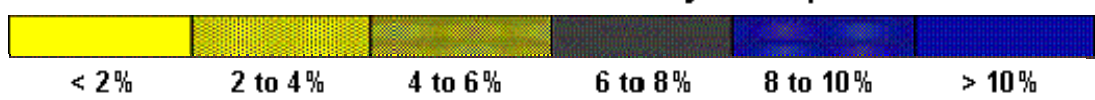

(a)

(b)

Figure 20: Typical plots of the normalized difference in absorption (ABS) around the tip of a sawcut $(0,0)$ for a) uncracked and b) cracked specimens (8 $\mathrm{mm}$ MSA). 


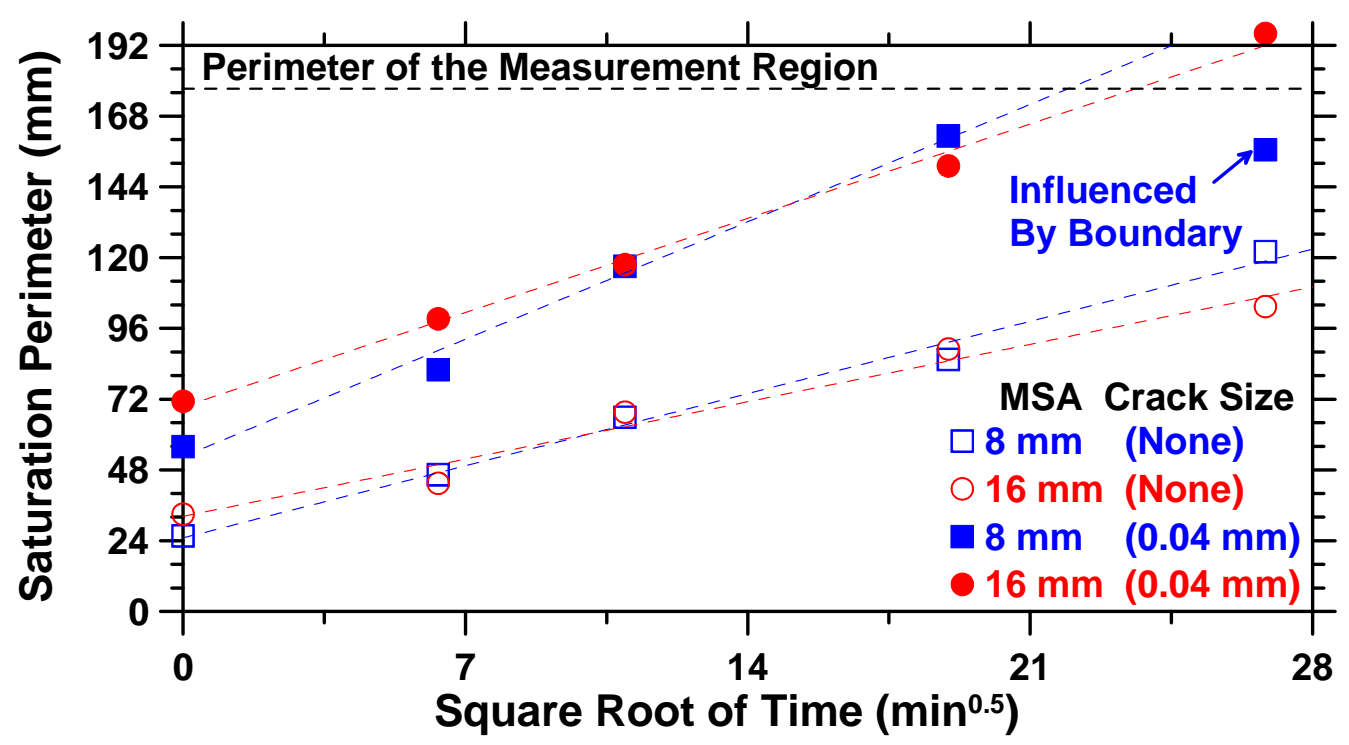

Figure 21: Typical plots of the perimeter of the water saturation area in the wedge splitting test for various concrete samples.

\subsection{Partially Saturated Concrete with Partially Saturated Discrete Cracks}

Or and Tuller (2000) developed a model for flow in partially saturated cracked concrete. This model assumes flow along a fluid film on the walls of the crack. While this appears to be quite plausible, a few items that should be considered with models of this type. First, this model appears to discuss fluid transport and does not explicitly consider gas transport which is a factor for unsaturated conditions. Crack size/aperture is important in determining whether cracks are saturated or partially saturated for a given set of conditions. In addition, crack aperture will impact the moisture gradients (which can be significant) in a concrete element.

Second, it was shown by Rajabipour (2007) that surface conduction (as determined by electrical property measurement) is lower for a cement matrix material than it is for aggregate. The thickness of the film of water on the surface of a crack wall in concrete is generally assumed to be on the order of tens of $\mathrm{nm}$. (See Section 8.) However, very limited work has been performed to confirm this statement. It follows that the thickness of the water film on crack walls for cracks connected to the surface will be controlled by equilibrium with the relative humidity of the environment around the structure. 


\subsection{MOISTURE TRANSPORT THROUGH CRACKED CONCRETE - DISTRIBUTED CRACKS IN AN ADVANCING FRONT OR THROUGH WALL}

\subsection{Saturated Concrete with Saturated Distributed Cracks}

For structural members with visible cracks, the diffusion mechanism becomes less dominant in comparison with other transport mechanisms. This is especially true when the cracks are connected. Consequently, chloride penetration in concrete structures is much more complicated than currently accounted for in available models. Recent research suggests that Fick's second law is not applicable to concrete structural members with crack networks when the crack widths are greater than $0.1 \mathrm{~mm}$.

It is important to recognize that while concrete is generally considered to be a continuum it is actually a porous material with a wide range of pore sizes. While it may be tempting focus on treating each crack in the system independently, there are cases in which it makes sense to treat cracking as a distributed network and to estimate how damage influences the 'average' properties of the concrete.

To account for the role of distributed cracks two approaches are generally taken in terms of modeling. The first approach is to simply increase the transport coefficient (e.g., diffusion coefficient). Fauchet (1991) developed a model using a statistically homogenous cracked medium to determine an effective permeability for the concrete. This approach (developing an effective permeability) has been used by others and a summary of these approaches is provided by Breysse and Gerard (1997). The second approach is to use a 'dual porosity' model where cracks represent one level of porosity while the porosity of the matrix is the second level of porosity (Papablan et al 2009, Pourghaz and Weiss in development).

Some types of damage are related to exposure to aggressive chemicals and advance into the concrete from the exposed surface (external sulfate attack). Other types of damage affect the entire element/sample (alkali silica reaction and freeze-thaw cycling). Hall and Hoff (2002) developed a series of approaches to consider transport in materials with layers that have varying degrees of damage. When multiple damage layers are considered a damage gradient can be approximated.

On the other hand, well distributed cracks with a very small aperture (microcracks) can be well distributed throughout the material. If they are sufficiently dense, they can be treated as a homogenous increase in the transport properties of the continuum. This type of crack pattern can 
substantially increase transport if the cracks are connected with each other and with the surface.

Figure 22a shows a typical network of cracks (dense cracking pattern) caused by relatively severe freeze-thaw damage to a concrete matrix. This image corresponds to a sample with a $60 \%$ reduction in stiffness relative to undamaged material. Unlike the case of a mechanically loaded concrete sample where the majority of damage is localized in a small region, freeze-thaw damage is distributed relatively uniformly throughout the sample (Yang et al 2004). The number of cracks can be correlated to the extent of damage and an increase in the rate and amount of water absorbed. See Figure 23b.

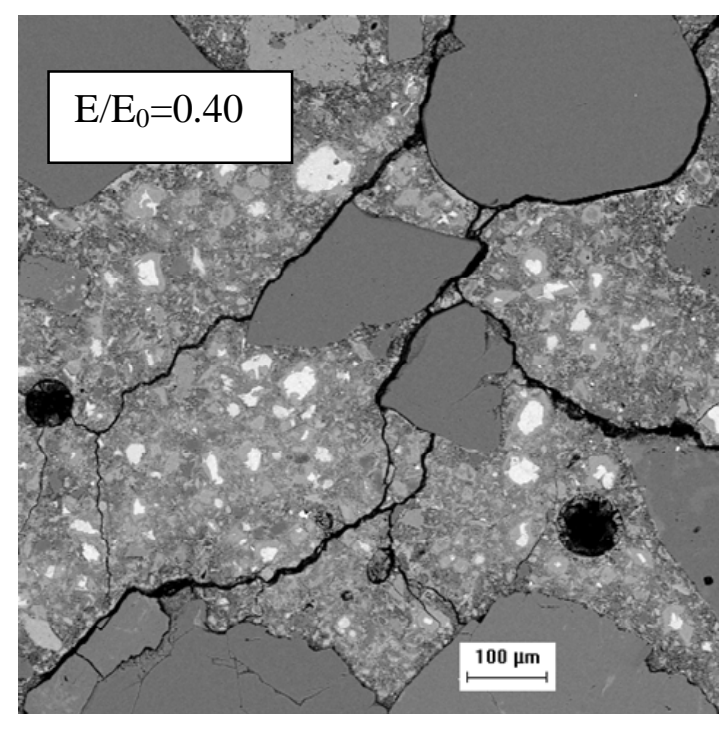

(a)

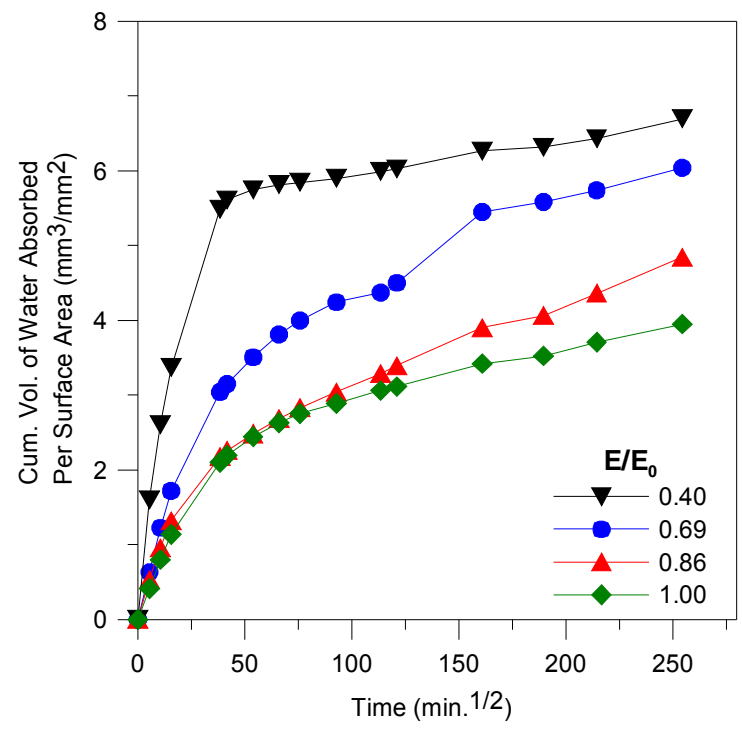

(b)

Figure 22. a) Illustration of the Crack Network in a Heavily Damaged Freeze-Thaw Specimen from a SEM Image and b) the Corresponding Influence on the Rate of Water Absorption: Note $E / E_{0}$ denotes the damage in the specimen with $E$ the elastic modulus in the degraded specimen and $\mathrm{E}_{0}$ the original modulus).

Guse and Hilsdorf [1997] found that surface cracking in high strength concrete is more likely to occur than in normal strength concrete, and showed that these cracks can substantially increase surface permeability, despite having minimal influence on mechanical behavior. Wiens et al. [1997] and Jacobsen et al. [1995] observed that under certain conditions high strength concrete developed a significant number of finely distributed micro-cracks, which accelerated the penetration of deicing salts and freeze-thaw damage near the surface. Fagerlund [1997] speculated that cracks facilitate increased water 
absorption, thereby further accelerating freeze-thaw damage near the surface of concrete.

\subsection{Saturated Concrete with Partially Saturated Distributed Cracks}

Limited testing has been performed on saturated concrete with partially saturated distributed crack networks. However, distributed connected cracks (connected to each other and to the surface) will permit gas transport in similar a similar to what was observed with the discrete cracks. In this case carbonation depths and oxidation fronts are the parameters associated with the chemical and physical damage gradients.

\subsection{Partially Saturated Concrete with Partially Saturated Distributed Cracks}

While very limited testing has been performed to assess the transport properties in unsaturated concrete it would appear reasonable that the transport, although higher for the damaged saturated concrete, would decrease more rapidly for a damaged concrete than an undamaged concrete as the degree of saturation is reduced. This is expected for two reasons. First, if the cracks in the systems are relatively large, they would be among the first 'pores' emptied on drying. As such even slight drying (to $90 \% \mathrm{RH}$ for example) would correspond with a disproportionately large reduction in the degree of saturation. Drying in turn would reduce the connectivity of the pore system as well as the volume of the pore fluid, thereby, decreasing the relative conductivity. While it is believed that relatively little work has been performed to specifically examine transport in partially saturated concrete, the testing the concept via the approach mentioned above may be relatively simple to perform. It may even be possible to estimate this behavior from data obtained in the Yang et al. (2004) studies, however, the available data would need to be further reviewed. 


\subsection{SATURATION AND WATER ABSORPTION IN CRACKED AND UNCRACKED CONCRETE}

For most concrete samples tested, it is generally assumed that the effects of 'gravity' are relatively small when compared with the results of capillary suction in terms of drawing water into the pores of a partially saturated concrete. The water absorption in concrete with distributed damage caused by freezing and thawing was evaluated using three similar but slightly different absorption tests: ponding test, capillary rise, and submerged test (as shown in Figure 23).

Sealed Container

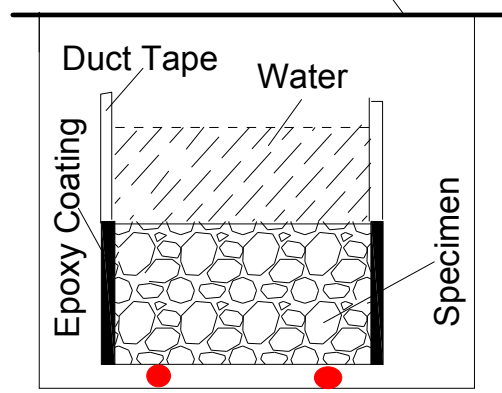

(a) Ponding Test

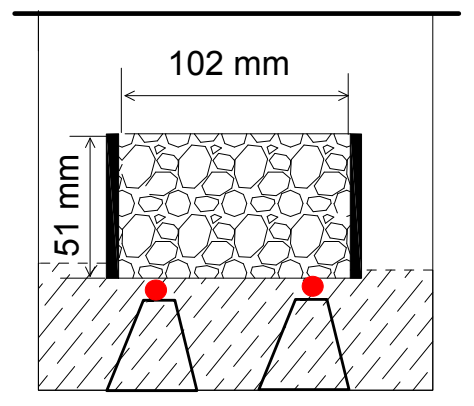

(b) Capillary Rise

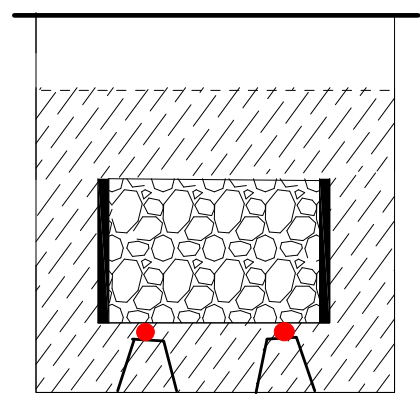

(c) Submerged Test

Figure 23. Water absorption test set up (Yang et al. 2007)

The rate of water transport was found to increase with crack width (i.e., to increase with damage). The submerged test had the lowest initial water absorption, while the ponding test and the capillary rise both had a similar higher absorption. This implies that the trapped air pockets during the submerged test slowed down the rate of water absorption and the diffusion of these air pockets out of the concrete actually appears to be a rate limiting step. This is similar to observations of $\mathrm{Li}$ et al (2012) where air entrained concrete requires substantially longer to saturate than non air entrained concrete.

Crack width, connectivity, as well as crack density greatly contribute to the rate of water absorption in concrete. Gravity was observed to have significant influence on water absorption at high damage levels with a crack width approximately at $10 \mu \mathrm{m}$ or above. It was also observed that air trapping appeared to play a significant role on water transport at high damage levels.

In a study by Yang, et al., 2007, a noticeable increase in crack volume was seen when the relative dynamic modulus decreased to $0.85 \sim 0.75$ due to the formation of microcracks. As $E / E_{0}$ decreased from $0.85 \sim 0.75$ to $0.5 \sim 0.4$ there 
was a slow increase in crack width from approximately $1 \mu \mathrm{m}$ to an average of 10 $\mu \mathrm{m}$ and a corresponding slow increase in volume. When $\mathrm{E}_{\mathrm{E}} \mathrm{E}_{0}$ reached 0.5 0.4, freeze and thaw damage was visible on the sample surface in the form of cracking (Yang et al 2007). When cracks are small, they may behave like equivalent individual capillary pores, in which capillarity controls the water movement; however as crack width increases capillary effects will decrease. Therefore at low damage levels (i.e., $E / E_{0}>0.75$ ), the cracks tend to be relatively small and capillary effects dominate the water absorption. At high damage levels (i.e., $E / E_{0}$ reduces to 0.4 ) capillary effects decreased in the relative magnitude and gravity had noticeably impacts on water transport. See Figure 24.

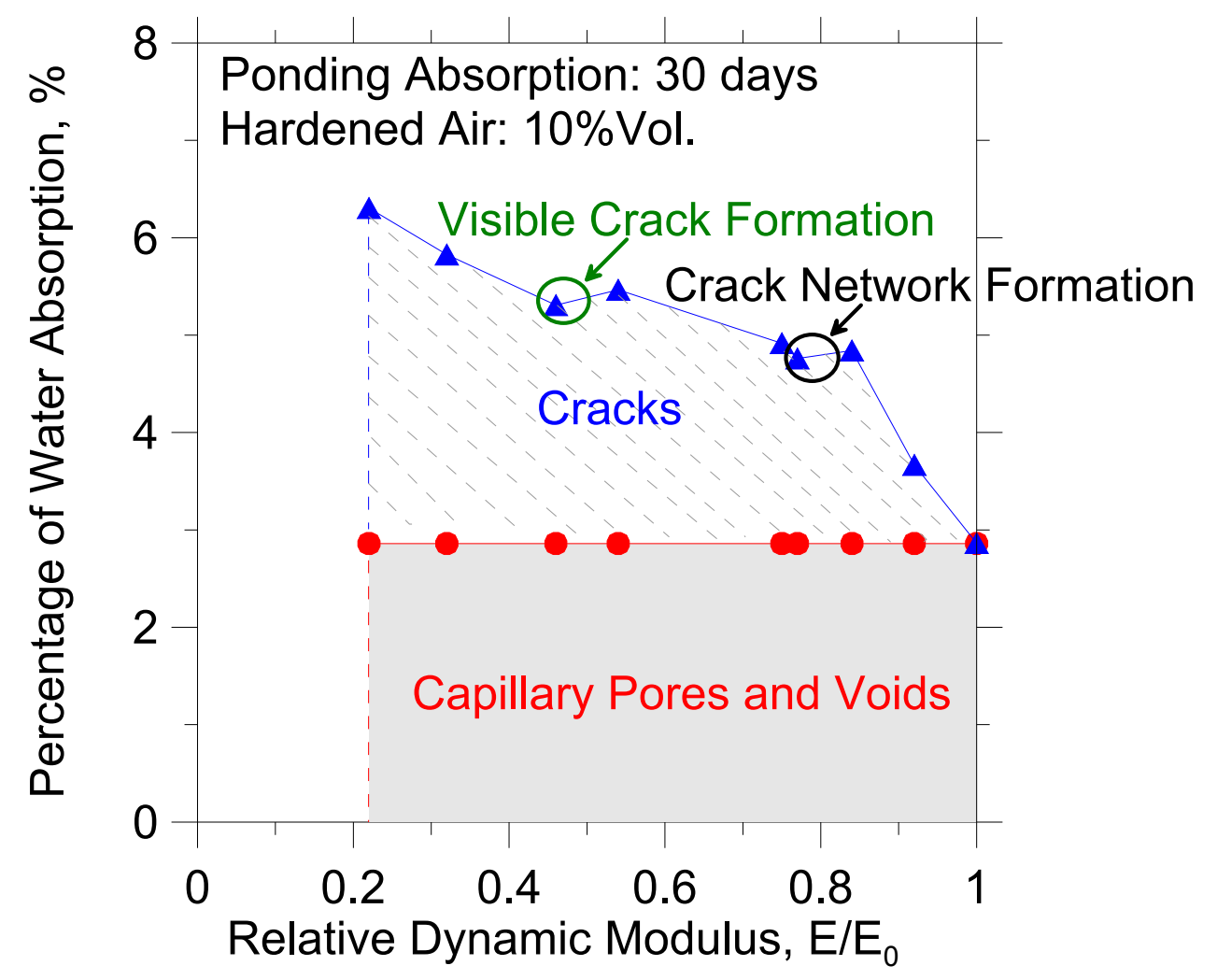

Figure 24: Illustration of water distribution in capillary pores, voids, and cracks (Yang et al 2007). 


\subsection{GAS TRANSPORT THROUGH UNCRACKED (INTACT) CONCRETE}

Gas permeability measurements are sometime used because some researchers feel that gas permeability is easier to measure compared to fluid permeability for high quality concrete. In addition, gas permeability can be related to carbonation rate. Gas permeability may be a rate limiting step with respect to achieving complete saturation in concrete samples (the diffusion of oxygen out of the concrete) or changes in $\mathrm{pH}$ that can lead to rebar corrosion.

Gas permeability of concrete is strongly related to the degree of moisture saturation. As previously mentioned in section 3.0 the Kelvin-Laplace equation can be used to relate the degree of saturation to the 1) size of the pores that remain filled with water, 2) properties of the pore fluid, and 3) pore pressure (i.e., relative humidity). The permeability is lower in samples with a higher degree of saturation because more of the pore volume is occupied with pore fluid. The apparent permeability changes slowly for high levels of saturation. See Figure 25 . However, the permeability changes dramatically as the capillary pores begin to empty. The solid phases and the fluid in the pores block the flow of the percolating gas.

Gas permeation through concrete violates some Darcy Law assumptions because the small pore size and because laminar flow does not occur (Abbas et al 1999). As such, the permeability varies with pressure. The permeability is typically related to the Hagen-Poiseuille expression. An approach can be used (which is believed to have been first introduced by Klinkerberg) where an intrinsic permeability is calculated from the apparent permeability. An approach to account for this is presented by Abbas et al (1999).

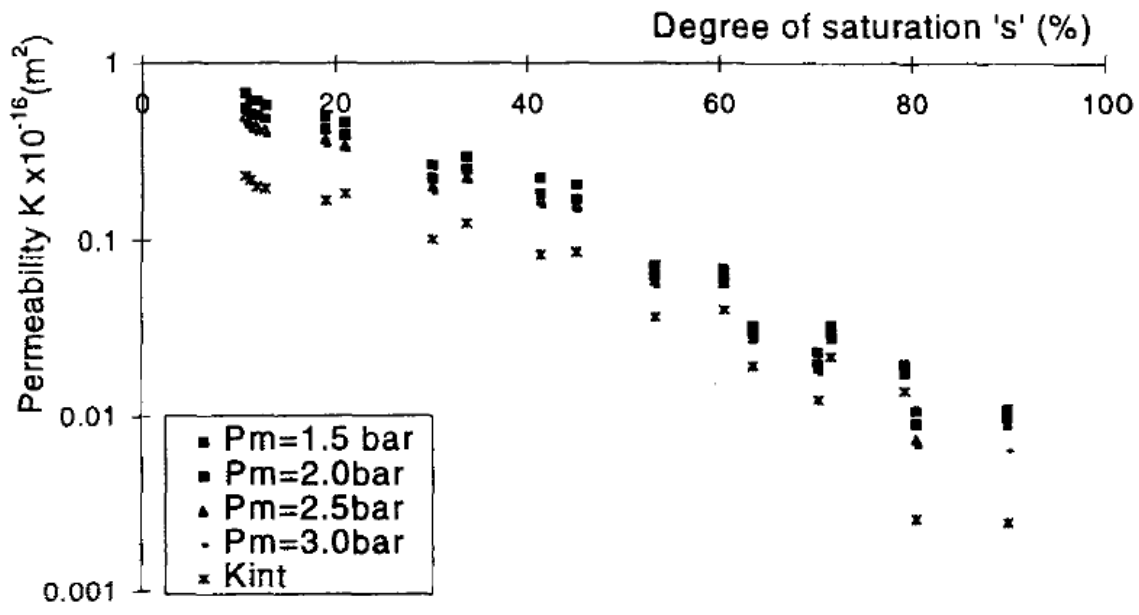

Figure 25: The Relationship between Permeability (Intrinsic) and the Degree of Saturation. 


\subsection{GAS TRANSPORT THROUGH CRACKED CONCRETE}

Studies on gas transport in cracked concrete are very limited. Some of the studies on larger specimens (e.g., performed the University of San Diego by Hutchinson and co-workers) did not contain information on the saturation and specific morphology of the cracks did. It is assumed that visible cracks would be unsaturated as they were tested in air and the relative humidity in the air probably did not support saturated cracks. As such it is difficult to bring that information into a materials model at a materials length scale. However, this information is presented due the size of the samples and relevance of the research as well as the general trends.

\subsection{Saturated and Partially Saturated Concrete with Saturated Discrete Cracks}

As mentioned in Section 9, gas permeability is dramatically influenced by the degree of saturation. In cases where discrete cracks in the system are saturated, gas transport through the cracks would be expected to be relatively low compared to transport through unsaturated cracks. If the concrete is partially saturated and the cracks are saturated water would be absorbed into the bulk concrete from the cracks. If the source of fluid is not sufficient the cracks would become partially saturated. Two conditions that may result in saturated cracks are 1) the concrete has an ample supply of water and gravity or capillary action enable the crack to remain saturated and 2) the fluid in the system contains sufficient salts such that it is stable at a lower relative humidity (Spragg, et al., 2010).

\subsection{Partially Saturated Concrete with Partially Saturated Discrete Cracks}

The Kelvin-Laplace equation can be used to determine the size (approximate radius) of pores or cracks that will remain saturated at different relative humidities. Even at relatively high humidity levels, the crack size that remains full is of the order of $100 \mathrm{~nm}$ in width as shown in Figure 26. However by the time the relative humidity decrease to $90 \%$ the crack size that remains full is of the order of $40 \mathrm{~nm}$. In addition, a film of water can be expected to remain on the surfaces of the crack walls during the drying if the pore is not completely filled due to absorption (Adamson 1997). The thickness of this water layer is dependent on several factors including, most notably, the relative humidity and the electrical charge on the walls of the cracks and pores (Haggymassy et al. 1969) as shown in Figure 27 (Rajabipour 2007). The thickness of this water layer is on the order of $2 \mathrm{~nm}$. It should be noted that hysteresis effects would need to be considered in a wetting and drying environment. 


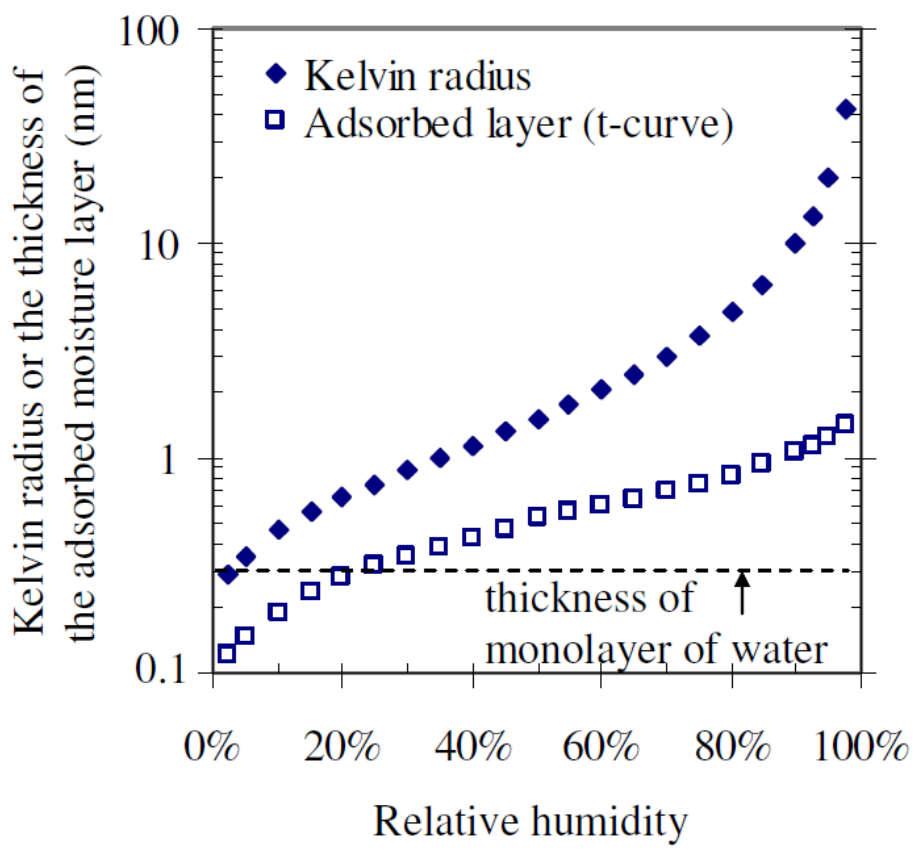

Figure 27: An Estimate of the Crack Widths that would Remain Water Filled for Different Relative Humidities and the Thickness of the Absorbed Water Layer.

Ujike et al. (1990) conducted a series of gas permeability experiments on reinforced concrete tested in tension and related the relative air permeability to the stress in the reinforcing bar (an indirect measure of damage due to cracking) and the depth of cover over the rebar. Greiner and Ramm (1995) noted that permeability was approximately 30 percent lower in reinforced concrete than it was in plain concrete for the same crack width. It can be speculated that this may be due to increased crack tortuosity and variation in crack width at the reinforcement caused by the rebar.

To better understand the role of cracking on gas permeability of concrete Hutchinson and Soppe (1997) conducted a series of evaluations (both numerical and computational) on full scale concrete shear walls. They assessed the role of cracking on the gas permeability of concrete (air flow in concrete) using air pressure decay methods for the majority of the tests. However a steady state test method was employed when the cracks changed the permeability to a point where readings were too high to measure using the conventional approach. They also provided a review of several numerical procedures that have been used to assess gas flow through cracked concrete.

The results of the Hutchinson and Soppe study indicate that lightly reinforced concrete elements are more permeable due to the larger crack widths that form in response to loading. The results appear to indicate that cracked low 
strength concrete $(20 \mathrm{MPa})$ is more permeable than cracked higher strength concrete (approx. $42 \mathrm{MPa}$ ). While this makes sense for undamaged concrete it is not immediately clear why this would hold for cracked concrete given that other studies indicate that cracks in lower strength concrete are more tortuous and therefore less permeably than cracks in high strength concrete. In the Hutchinson-Soppe study, the cracked concrete had a permeability was several of orders of magnitude greater than the uncracked concrete. While the work is quite interesting, limited details were provided on the sample moisture properties or the geometry of the cracks (1997).

Several approaches have been taken to assess the gas permeability of reinforced concrete on a structural level. However several of these studies do not explicitly consider either the geometry of the crack or the degree of saturation in the concrete. It appears that generally when the geometry of the crack is considered some form of Poiseuille's law is appropriate for describing the gas flow. Generally it is assumed that there are two crack faces and some factor is generally added to account for friction and/or tortuosity. When detailed information on the crack network is not available, permeability is related to some global damage indicator rather than to some physical crack geometry.

For example, Wang et al. (2004) summarized many of these approaches in their study that examined the flow through cracked reinforced concrete walls containing shear cracks. They intentionally do not consider the geometry of the crack since there is no method to measure crack patterns and because this would not be known by the designer or evaluator of that structure. In addition, if the samples were in the laboratory condition, as appears to be the case, the cracks would be partially saturated with a relatively thin film of water along the surface of the crack while the remainder of the crack would have been unsaturated.

After review of the literature, Gerard et al (1997) recommended that the flow of a compressible fluid through a crack could be related to crack features using Equation 4.

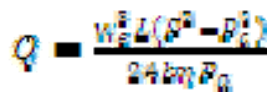

Equation 4

Where: $w_{e}$ is the equivalent crack width that is generally $1 / 3$ to $1 / 4$ the actual crack with, $P$ is the pressure, $P_{a}$ is the atmospheric pressure, $\eta$ is the fluid viscosity. And if an incompressible fluid is used this equation can be written as

$$
Q=\frac{w_{F}^{2} L\left(F-E_{h} Z\right.}{12 \ln }
$$


It was assumed that, when other information is not available, the critical crack width can be assumed to be greater than 40 microns and cracks less than 200 microns will self-heal when they have sufficient access to water.

\subsection{Saturated and Partially Saturated Concrete with Saturated and Partially Distributed Cracks}

Very little work is reported on assessing the gas permeability on distributed crack networks. This is somewhat understandable because many of the causes of distributed cracking require the presence of water for the damage to progress (e.g., ASR, Freeze-Thaw). As mentioned earlier, when crack networks are saturated with water or with other materials (such as gel in the case of ASR damage) the gas permeability will be low.

Further, as previously mentioned, some types of damage are are characterized by distributed cracks occur on an exposed surface and progress into the element. This results in a progressive or layered damage front that advances into the concrete from an exposed surface. As such it may be reasonable to assume that the damaged regions have little physical influence on gas permeation and gas flow rate will be limited by the undamaged concrete. 


\subsection{Crack Healing}

In the last five years a substantial amount of research has been conducted on the potential for concrete to be 'self-healing'. Strictly speaking, healing implies that the concrete would reduce the impact of cracking through chemical reactions that occur 1) in the cement matrix, 2) from a material placed in the concrete to fill cracks after they occur (e.g., an epoxy capsule), and/or 3) from bacteria placed in the concrete to fill the crack with biological products. These 'self-healing' concretes are being reviewed by an active committee in RILEM (report expected within 12 months). This report will focus on conventional healing technologies and as appropriate will address the role of crack repairs.

The topic of self-healing through hydration reactions has been studied for over a century with LaChatlier providing discussion of this as early as the 1880's. Work by Abrams in 1913, Turner in 1937, and Lauer and Slate (1952) provided substantial insights into the potential for self-healing to occur. Unreacted calcium silicate (either $\mathrm{C}_{2} \mathrm{~S}$ or $\mathrm{C}_{3} \mathrm{~S}$ ) is present in the majority of the concrete. This material has the potential to react to form hydration products when it encounters water. It is possible that these hydrated products could form in cracks. Based on this idea alone it is possible for some healing to occur in conventional concrete. However, other aspects should be considered when it comes to healing and have been the source of much of the debate on how much self-healing in concrete actually occurs.

There are several chemical, physical and mechanical processes that should be considered. For example, the behavior specifically associated with the term healing should be discussed. In the literature, many investigators have historically used this term to describe a wide range of changes that take place in cracked concrete over time. Bouge and Neville independently suggested that healing was due to the continued reaction of unhydrated cement. This however needs to be viewed in light of certain geometric realities. Researchers at NIST used a computer model (Chemhyd3d) to simulate the continued hydration that could be expected to occur when a crack was present in a water saturated concrete with unhydrated cement present. This modeling study indicated that the volume of unreacted cement was only sufficient to fill in a crack that was on the order of less than 10 microns wide. As such this does not appear to be a plausible mechanism for healing cracks of reasonable width if one is speaking only of the continued hydration of unhydrated cement.

Healing does occur more readily in specimens that have sufficient moisture in the crack and it occurs more easily in samples where the crack faces are 'pressed together' during the healing process. More healing is observed in 
younger concrete which could be explained by more unhydrated cement. Slate (1965) noted that water was essential for healing to occur. Samples stored in water showed a recovery of approximately $85 \%$ of strength while samples in 'lab air' had almost no strength increase. Neville (1996) noted that smaller cracks heal faster than larger cracks.

Other researchers have suggested other mechanisms for the beneficial behavior referred to as 'healing'. First it should be noted that in the presence of water the many of the hydrated phases in the matrices of hydrated Portland cement and blended cement concretes tend to swell. Slate (1965) noted that calcium carbonate precipitation (or calcium hydroxide precipitation) can also occur which can create a solid, though weaker particle, that could fill the crack, provide some strength, and reduce moisture and gas transport. A relationship was noted between the percentage of the crack covered with calcium carbonate and calcium hydroxide crystals and the strength that was recovered. He also observed that material may be washed into or accumulate in cracks which 'block the crack' thereby filling them with debris. This was also mentioned by Edvarson (1999) and is consistent with several other researchers who have observed that even when the cracks were 'healed' the cracks act as a weak plane for further fracturing to occur (Jawad and Haddad 1992).

Work by Edvardson (1999), Yoon et al. (2000), and Geiker et al (2006) demonstrated that cracks that were being opened or opened and closed showed substantially less healing than cracks present in an unloaded state.

Gerard et al (1997) assumed that, when other information is not available, that cracks less than 200 microns will self-heal when they have sufficient access to water. 


\subsection{SUMMARY AND IMPLICATIONS}

The performance of a concrete element as a containment device is related to its ability to 1) impede, or greatly reduce, the transport of one or more of the following: contaminants, moisture and gas and 2) prevent inadvertent intrusion. This is especially true for cementitious barriers for nuclear applications which are designed to limit radionuclide release. A recent report has stated that "at the present time, performance and risk assessment do not fully incorporate the effectiveness of engineered barriers because the processes that influence performance are coupled and complicated" (Langston and Kosson 2009). As such additional information is needed to quantify the performance of these barriers. Cracking is one area that provides a substantial complication.

This report provides a review of the literature on concrete cracking. The vast majority of the research performed on transport in concrete considers uncracked samples/material. Further, the research that does consider cracking in relation to durability generally assumes that both the concrete and cracks are saturated. This report provides information about concrete saturation which can be applied to modeling transport rates. However, it is noted that there is a lack of existing models with sufficient validation for modeling transport in cracked concrete elements, especially when saturation level is varied.

Potential causes for crack formation in concrete are identified in this report. The cracks can be grouped into two primary categories for convenience with respect to transport modeling. As such the cracks can be treated as either being discrete (localized cracks) or distributed cracks.

Discrete Cracks - These cracks are caused by mechanical loading, restrained volume change, and/or expansive reactions associated with steel rebar corrosion. Discrete crack (localized damage) analysis and modeling typically considers the crack geometry explicitly and lends itself to models based on fracture mechanics. Discrete cracks are frequently modeled as parallel plates for transport and fracture mechanics modeling. Corrections are generally provided for roughness. A dual porosity approach is one approach used for modeling discrete cracks through a porous matrix.

Distributed Cracks - These cracks are characterized as a crack network caused by alkali silica reaction, freeze-thaw, shrinkage gradients or sulfate attack. Distributed damage lends itself to being described by damage mechanics models. A smeared crack approach is applicable to modeling where the transport properties of the concrete are increased in regions of 
the structural element. The distributed crack networks can be represented by new representative 'effective material transport properties'. Use of a layered conceptual model with layers representing different extents of damage is very useful in modeling the effect of distributed cracking originating from an exposed surface on transport through concrete elements.

Cracks in concrete tend to have a higher probability of occurring 1) early in the life of the concrete (mainly due to volume change), 2) after a period of time when damage processes begin to be expressed as deterioration (mainly due to alkali silica reaction, sulfate attack, or freeze-thaw; or 3) after a discrete event (e.g., earthquake loading). This is frequently discussed as a bathtub type of probability of cracking where if the concrete makes it though early age (the first few weeks/months) without cracking it will remain crack free for decades until cracks related to chemical (physical) attack occur. It would be anticipated that the majority of early age cracking can be avoided through proper design. 


\subsection{References}

Abbas, A., Carcasses, M., and Olivier, J. P., (1999) "Gas Permeability of Concrete in Relation to Its Degree of Saturation," Materials and Structures, Vol. 32, pp. 3-8

ACl 224-90R, "'Control of Cracking in Concrete Structures", American Concrete Institute, Farmington Hills, Michigan, 1990

Adamson, A. W., (1990) "Physical Chemistry of Surfaces, $5^{\text {th }}$ Edition" John Wiley and Sons

Attiogbe, E.K., Weiss, W. J., and See, H. T., (2004) "A Look At The Rate of Stress Versus Time of Cracking Relationship Observed In The Restrained Ring Test," Advances in Concrete Through Science and Engineering, Northwestern University, Evanston, IL, March 22-24, 2004 (on CD)

Aldea, C. M., Shah, S. P., \& Karr, A. (1999) Effect of cracking on water and chloride permeability of concrete. Journal of Materials in Civil Engineering, 11(3), 181-187. doi: 10.1061/(asce)0899-1561(1999)11:3(181)

Alfaiate, J., Moonen, P., Sluys, L. J., \& Carmeliet, J. (2010) On the use of strong discontinuity formulations for the modeling of preferential moisture uptake in fractured porous media. Computer Methods in Applied Mechanics and Engineering, 199(45-48), 2828-2839. doi: 10.1016/j.cma.2010.05.004

Bachmat, Y. \& Bear, J. (1986) MACROSCOPIC MODELING OF TRANSPORT PHENOMENA IN POROUS-MEDIA .1. THE CONTINUUM APPROACH. Transport in Porous Media, 1(3), 213-240. doi: 10.1007/bf00238181

Banthia, N., \& Bhargava, A. (2007) Permeability of stressed concrete and role of fiber reinforcement. ACI Materials Journal, 104(1), 70-76.

Bazant, Z. P. and Najjar, L. J., (1971) "Drying of Concrete as a Non-linear Diffusion Problem," Cement and Concrete Research, Vol. 1, pp 461-473

Bazant, Z. P. and Najjar, L. J., (1972) "Nonlinear water diffusion in nonsaturated concrete," Maeriaux et Constructions, Vol. 5, No. 5, pp. 3-20 
Bažant, Z.P. (1976) "Instability, ductility, and size effect in strain-softening concrete," J. Engng. Mech. Div., Am. Soc. Civil Engrs., 102 (EM2) (1976), pp. 331-344 (disc. pps.: 103, 357-358, 775-777, 104, 501-502)

Bažant and Oh, 1983Z.P. Bažant, B.-H. Oh (1983) "Crack band theory for fracture of concrete," Materials and Structures (RILEM, Paris), 16 (1983), pp. $155-177$

Bazant, Z. P., and Najjar, L. J., (1972) "Nonlinear water diffusion in nonsaturated concrete," Materials and Structures, 1972, vol 5, no 20, pp. 3-20

Bazant, Z. P., and Planas, J., (1998) "Fracture and Size Effect in Concrete and Other Quasi-Brittle Materials", CRC Press, Boca Raton.

Bazant, Z., and and Pijaudier-Cabot, G., (1989) "Measurement of Characteristic Length in of Nonlocal Continuum," Journal of ASCE Engineering Mechanics, 115, 4, 755-767

Bazant, Z. P., Sener, S., \& Kim, J. K. (1987). Effect of Cracking on Drying Permeability and Diffusivity of Concrete. ACl Materials Journal, 84(5), 351-357.

Bear, J., \& Bachmat, Y. (1986). Macroscopic Modeling of Transport Phenomena in Media. 2. Applications to Mass Momentum and Energy Transport, Transport in Porous Media, 1(3), 241-269. doi: 10.1007/bf00238182

Bentur, A., S. Diamond, and N. Berke. (1997). Steel Corrosion in Concrete. London: Chapman \& Hall.

Bear J., Dynamics of Fluids in Porous media, Dover Publications Inc, New York, USA, 1988.

Berkowitz, B., Bear, J., \& Braester, C. (1988). Continuum Models for Contaminant Transport in Fractured Porous Formations. Water Resources Research, 24(8), 1225-1236. doi: 10.1029/WR024i008p01225

Boulfiza, M., Sakai, K., Banthia, N., \& Yoshida, H. (2003). Prediction of chloride ions ingress in uncracked and cracked concrete. Aci Materials Journal, 100(1), 38-48. 
Breysse, D., and Gerard, B., (1997) "Transport of Fluids in Cracked Materials," Chapter 4, RILEM Report 16 - Penetration and Permeability of Concrete, Barriers to Organic and Contaminating Liquids, Ed. H. W. Reinhardt

Breyesse, D., Gerard, B, and Lasne, N., (1994) "An Experimental Device to Study Cracking and deterioration of Concrete," $3^{\text {rd }}$ CANMET/ACI International Conference on Durability of Concrete Nice

Carmeliet, J., Delerue, J. F., Vandersteen, K., \& Roels, S. (2004). Threedimensional liquid transport in concrete cracks. International Journal for Numerical and Analytical Methods in Geomechanics, 28(7-8), 671-687. doi: 10.1002/nag.373

Castro, J., Lura, P., Rajabipour, F., Henkensiefken, R., and Weiss, W. J., (2010) "Internal Curing: A Discussion of the Role of Pore Solution on Relative Humidity Measurements and the Desorption of Lightweight Aggregate," ACI SP

Castro, J. Bentz, D., and Weiss, W. J., (2011) "Effect of Sample Conditioning on the Water Absorption of Concrete," Cement \& Concrete Composites 33 (2011) 805-813

Chen, D., \& Mahadevan, S. (2007). Cracking analysis of plain concrete under coupled heat transfer and moisture transport processes. Journal of Structural Engineering-Asce, 133(3), 400-410. doi: 10.1061/(asce)07339445(2007)133:3(400)

Clarke, J. V., Bainbridge, H., Beck, S.B.M., and Yates, J. R., (1996) "Measurement of Fluid Flow Rates Through Cracks," International Journal of Pressure Vessels and Piping, 71, pp. 71-75

Concrete Repair Manual, International Concrete Repair Institute and American Concrete Institute, 1999

David, C., Menendez, B., and Darot, M., (1999) "Influence of Stress-Induced and Thermal Cracking on Physical Properties of Microstructure of La Peyratte Granite," International Journal of Rock Mechanics and Mining Society, 36, pp. 433-448

Doughty, C. (1999a). Investigation of conceptual and numerical approaches for evaluating moisture, gas, chemical, and heat transport in fractured 
unsaturated rock. Journal of Contaminant Hydrology, 38(1-3), 69-106. doi: 10.1016/s0169-7722(99)00012-1

Doughty, C. (1999b). Investigation of conceptual and numerical approaches for evaluating moisture, gas, chemical, and heat transport in fractured unsaturated rock. Journal of Contaminant Hydrology, 38(1-3), 69-106. doi: 10.1016/s0169-7722(99)00012-1

Edvardson, C., "Water Permeability and Autogenous Healing of Cracks in Concrete," ACI Materials Journal, Vol. 96, No. 4, pp. 448-455 (1999)

Emmons, P. H., "Concrete Repair and maintenance Illustrated," (c) 1993 RH Means

Fagerlund, G., "The International Cooperative Test of the Critical Degree of Saturation Method of Assessing the Freeze/Thaw Resistance of Concrete," Materials and Structures, Vol. 10, No. 58, 1977, p231-253

Fagerlund, G. (1997b), "On the service life of concrete exposed to frost action," Freeze and thaw durability of concrete, J. Marchand, M. Pigeon and M. Setzer, eds., E\&FN Spon, London, UK, 23-41'

Finsterle, S. (2000). Using the continuum approach to model unsaturated flow in fractured rock. Water Resources Research, 36(8), 2055-2066. doi: 10.1029/2000wr900122

Flach, G. P., Jordan, J. M., and Whiteside, T., (2009) "Numerical Flow and Transport Simulations Supporting the Saltstone Disposal Facility Performance Assessment," SRNL-STI-2009-00115, Revision 1

Garboczi, E. J. (1990). PERMEABILITY, DIFFUSIVITY, AND MICROSTRUCTURAL PARAMETERS - A CRITICAL-REVIEW. Cement and Concrete Research, 20(4), 591-601. doi: 10.1016/00088846(90)90101-3

Ge, S. M. (1997). A governing equation for fluid flow in rough fractures. Water Resources Research, 33(1), 53-61. doi: 10.1029/96wr02588

Gerard, B., Reinhardt, H. W., and Breysee, D., (1997) "Chapter 8 - Measured Transport in Cracked Concrete," RILEM report 16 - Penetration and 
Permeability of Concrete - Barriers to Organic and Contaminating Liquid," Ed Reinhardt H.. W.,, E and FN Spoon, pp. 265-324

Gerard, B., \& Marchand, J. (2000). Influence of cracking on the diffusion properties of cement-based materials - Part I: Influence of continuous cracks on the steady-state regime. Cement and Concrete Research, 30(1), 37-43. doi: 10.1016/s0008-8846(99)00201-x

Gowripalan, N., Sirivivatnanon, V., \& Lim, C. C. (2000). Chloride diffusivity of concrete cracked in flexure. Cement and Concrete Research, 30(5), 725730. doi: 10.1016/s0008-8846(00)00216-7

Goto, Y., (1971) "Cracks Formed in Concrete Around Deformed Tension Bars," American Concrete Institute, pp. 244-251

Greiner, U., and Ramm, W., (1995) "Air Leakage Characteristics in Cracked Concrete, SMIRT 11, Transactions Voume H, Japan, pp. 181-186

Guse, U., and Hisdorf, K., 'Surface Cracking of High-Strength Concrete Reduction by Optimization of Curing', Self-Desiccation and Its Importance in Concrete Tech., Persson, B., Fagerlund, G., (editors), Lund, Sweden, pp. 239-249, (1997)

Hao, T., Zhang, P., \& Su, B. (2010). ON-SITE PERMEABILITY TEST OF PRESTRESSED CONCRETE CONTAINMENT OF NUCLEAR POWER STATIONS.

Haggymassy, J., Brunauer, S., and Mikhail, S.H., (1969) "Pore Structure Analysis by Water Vapor Adsorption," Journal of Colloid and Interface Science, Vol., 29, No. 3, pp 485-491

Hall, C., (1994) "Barrier Performance of Concrete: A Review of Fluid Transport Theory," TC 146 Report Tightness of Concrete with Respect to Fluids, 27, pp. 291-306

Hall, C., and Hoff, W. D., (2002) "Water Transport in Brick, Stone, and Concrete," Spon Press, London and New York

Hamilton, C. H., Hutchinson, T. C., Pardoen, G. C., Salmon, M . W., and Wang, T., (2004) "Gas and Aerosol Leakage Rate Through Reinforced Concrete 
Shear Walls: Experimental Study," $13^{\text {th }}$ World Conference on Earthquake Engineering, Paper 2484

Hearn N., Effect of shrinkage and load-induced cracking on water permeability of concrete, ACI Material Journal, March-April, 234-240, 1999.

Hedenblad, G. (1989, Nov 28-30). DETERMINATION OF WATER-VAPOR PERMEABILITY IN CONCRETE UNDER HIGH MOISTURE CONDITIONS. Paper presented at the Symp on Pore Structure and Permeability of Cementitious Materials / Symp on Fly Ash and Coal Conversion by-Products, Boston, Ma.

Hedenblad, G. (1991, Sep). DETERMINATION OF WATER-VAPOR PERMEABILITY IN CONCRETE, CEMENT MORTAR AND CEMENT PASTE. Paper presented at the 21st Symp of the International Centre for Heat and Mass Transfer: Heat and Mass Transfer in Building Materials and Structures, Dubrovnik, Yugoslavia.

Hillerborg, A., Modwer, M., and Peterson, P. E. (1976) "Analysis of Crack Formation and Crack Growth in Concrete by Means of Fracture Mechanics and Finite Elements", Cement and Concrete Research, Vol. 6, pp. 773-782

Hsu, T.T.C, Slate, F. O., Struman, G. M., and Winter, G., (1963), "Microcracking of Plain Concrete and the Shape of the Stress Strain Curve", Journal of the American Concrete Institute, Vol. 60, pp. 209-224

Hutchinson, T., and Soppe, T. E., (2011) "Experimentally Measured Permeability of Uncracked and Cracked Concrete Composites," Journal of Materials in Civil Engineering, doi:10.1061/(ASCE)MT.1943-5533.0000406

Ishida, T., Iqbal, P. O. N., \& Anh, H. T. L. (2009). Modeling of chloride diffusivity coupled with non-linear binding capacity in sound and cracked concrete. Cement and Concrete Research, 39(10), 913-923. doi: 10.1016/j.cemconres.2009.07.014

Ismail, M., Toumi, A., Francois, R., \& Gagne, R. (2004). Effect of crack opening on the local diffusion of chloride in inert materials. Cement and Concrete Research, 34(4), 711-716. doi: 10.1016/j.cemconres.2003.10.025

Jacobsen, S., Marchand, J., \& Boisvert, L. (1996). Effect of cracking and healing 
on chloride transport in OPC concrete. Cement and Concrete Research, 26(6), 869-881. doi: 10.1016/0008-8846(96)00072-5

Jang, S. Y., Kim, B. S., \& Oh, B. H. (2011). Effect of crack width on chloride diffusion coefficients of concrete by steady-state migration tests. Cement and Concrete Research, 41(1), 9-19. doi: 10.1016/j.cemconres.2010.08.018

Jansen, D.C., and Shah, S.P., (1997), "Effect of length on compressive strain softening of concrete", Journal of Engineering Mechanics, Vol. 123, No.1, pp 25-35

Jansen, D. C., Shah, S. P., and Rossow, E. C., (1995) "Stress-Strain Results of Concrete From Circumferential Strain Feedback Control Testing" ACl Materials Journal, July/August, Vol. 92, No. 4, pp. 419-428

Jawad, Y. and Haddad, R., (1992) "Effect of Early Overloading of Concrete on Strength at Later Ages," Cement and Concrete Research, Vol. 22, pp. 927-936

Kari, O.-P. J., \& Puttonen, J. A. (2009, Mar 30-Apr 02). MODELLING THE DURABILITY OF CONCRETE FOR NUCLEAR WASTE DISPOSAL FACILITIES. Paper presented at the RILEM Workshop on Long-Term Performance of Cementitious Barriers and Reinforced Concrete in Nuclear Power Plants, Cadarache, FRANCE.

Kim, J. G., \& Deo, M. D. (2000). Finite element, discrete-fracture model for multiphase flow in porous media. AICHE Journal, 46(6), 1120-1130. doi: 10.1002/aic.690460604

Kayir, H., and Weiss, W. J., (2002) "A Fundamental Look At Settlement In Fresh Systems: Role Of Mixing Time And High Range Water Reducers," First North American Conference on Self-Consolidating Concrete, November, Chicago, IL

Küter, A., Geiker, M.R., Olesen, J.F., Stang, H., Dauberschmidt, C., Raupach, M., Chloride ingress of concrete cracks under cyclic loading, Proceedings of the ConMAT Conference, Vancouver (Canada), 2005. 
Kwak, H. G., Ha, S. J., and Weiss, W. J., (2010) "Experimental and Numerical Quantification of Plastic Settlement in Cementitious Systems," ASCE Journal of Engineering Materials

Kwicklis, E. M., \& Healy, R. W. (1993). NUMERICAL INVESTIGATION OF STEADY LIQUID WATER-FLOW IN A VARIABLY SATURATED FRACTURE NETWORK. Water Resources Research, 29(12), 4091-4102. doi: 10.1029/93wr02348

Langston, C., and Kosson, D., (2009) "Review of Mechanistic Understanding and Modeling and Uncertainty Analysis Methods for Predicting Cementitious Barrier Performance," CBP-TR-2009-002

Lauer, K. R., and Slate, F. O., (1952) "Autogenous Healing of Cement Paste", American Concrete Institute, V27, no. 10 pp. 52-63

Leonardt, F. (1977) "Crack Control in Concrete Structures," IABSE

Leepach, M., and Li, V., (2005) "Water Permeability of Cracked Cementitious Composites," ICF Conference

Li, W., Pour-Ghaz, M., Castro, J., and Weiss, W. J., (2012) "Water Absorption and the Critical Degree of Saturation as it relates to Freeze-Thaw Damage in Concrete Pavement Joints," ASCE Journal of Civil Engineering Materials

Liu, H. H., \& Bodvarsson, G. S. (2001). Constitutive relations for unsaturated flow in a fracture network. Journal of Hydrology, 252(1-4), 116-125. doi: 10.1016/s0022-1694(01)00449-8

Liu, H. H., Doughty, C., \& Bodvarsson, G. S. (1998). An active fracture model for unsaturated flow and transport in fractured rocks. Water Resources Research, 34(10), 2633-2646. doi: 10.1029/98wr02040

Liu, H. H., Haukwa, C. B., Ahlers, C. F., Bodvarsson, G. S., Flint, A. L., \& Guertal, W. B. (2003). Modeling flow and transport in unsaturated fractured rock: an evaluation of the continuum approach. Journal of Contaminant Hydrology, 62-3, 173-188. doi: 10.1016/s01697722(02)00170-5 
Luiping, T., Nilsson, L-O., and Basheer, P.A.M., (2012) "Resistance of Concrete to Chloride Ingress: Testing and Modeling," E and FN Spon, London

Lura, P., Pease, B., Mazzotta, G., Rajabipour, F., and Weiss, W. J., (2007) "Influence of Shrinkage-Reducing Admixtures on Evaporation, Settlement, and Plastic Shrinkage Cracking," American Concrete Institute Materials Journal, Vol. 104, No. 2, pp. 187-194

Machida A., Win P.P., Modeling of chloride distribution in cracked reinforced concrete, Proceedings of the ConMAT Conference, Vancouver (Canada), 2005.

Martys, N., (1995) "Diffusion in Partially Saturated Porous Media," Materials and Structures, Vol 32., pp 552-562

Martys, N.S., (1995) Survey of Concrete Transport Properties and Their Measurement," National Institute of Standards and Technology Internal Report 5592.

Mindess, Sidney, and Young, J. Francis. 1981. Concrete, Prentice-Hall, Englewood Cliffs, NJ.

Mills, R. H. (1985). MASS-TRANSFER OF WATER-VAPOR THROUGH CONCRETE. Cement and Concrete Research, 15(1), 74-82. doi: 10.1016/0008-8846(85)90010-9

Mnahoncakova, E., Jirickova, M., \& Cerny, R. (2006). Properties of high performance concrete: the effect of cracks. High Performance Structures and Materials III, 85, 409-417. doi: 10.2495/hpsm06040

Naus, D. J. (2009). The management of aging in nuclear power plant concrete structures. Jom, 61(7), 35-41. doi: 10.1007/s11837-009-0100-0

Niklasch, C., \& Herrmann, N. (2009). Nonlinear fluid-structure interaction calculation of the leakage behaviour of cracked concrete walls. Nuclear Engineering and Design, 239(9), 1628-1640. doi: 10.1016/j.nucengdes.2008.09.001

Nishimura, T., \& Raman, V. (2010). Corrosion behavior of reinforcing steel in concrete for nuclear facilities exposed in high chloride and low $\mathrm{pH}$ environment. Journal of Nuclear Materials, 397(1-3), 101-108. doi: 
10.1016/j.jnucmat.2009.12.015

Nordqvist, A. W., Tsang, Y. W., Tsang, C. F., Dverstorp, B., \& Andersson, J. (1992). A VARIABLE APERTURE FRACTURE NETWORK MODEL FOR FLOW AND TRANSPORT IN FRACTURED ROCKS. Water Resources Research, 28(6), 1703-1713. doi: 10.1029/92wr00216

Or, D., and Tuller, M., (1999) 'Liquid retention and Interfacial Area in Variably Saturated Porous Media: Upscaling from Single-Pore to Sample Scale Models," Water Resources Research, Vol 35, No. 12. pp. 3591-3605

Or, D., and Tuller, M., (2000) 'Flow in Unsaturated Fractured Porous Media: Hydraulic Conductivity of Rough Surfaces," Water Resources Research, Vol. 36, No. 5. pp. 1165-1177

Østergaard, L. 'Early-Age Fracture Mechanics and Cracking of Concrete Experiments and Modelling'. Ph.D. Thesis, (BYG•DTU Department of Civil Engineering, Technical University of Denmark, 2003.

Ozbay, E., Gesoglu, M., \& Guneyisi, E. (2011). Transport properties based multiobjective mix proportioning optimization of high performance concretes. Materials and Structures, 44(1), 139-154. doi: 10.1617/s11527-010-96157

Pan, T., \& Wang, L. (2011). Finite-Element Analysis of Chemical Transport and Reinforcement Corrosion-Induced Cracking in Variably Saturated Heterogeneous Concrete. Journal of Engineering Mechanics-Asce, 137(5), 334-345. doi: 10.1061/(asce)em.1943-7889.0000232

Pabalan, R. T., Glasser, F. P, Picket, D. A., Walter, G. R., Biswas, S., Juckett, M.R., Sabido, L. M., and Myers, J. L. (2009) "Review of Literature and Assessment of Factors Relevant to Performance of Grouted Systems of Radioactive Waste Disposal," US Nuclear Regulatory Commission, NRC 02-07-006

Paulsson-Tralla, J., \& Silfwerbrand, J. (2002). Estimation of chloride ingress in uncracked and cracked concrete using measured surface concentrations. ACl Materials Journal, 99(1), 27-36.

Persoff, P., \& Pruess, K. (1995). 2-PHASE FLOW VISUALIZATION AND RELATIVE PERMEABILITY MEASUREMENT IN NATURAL ROUGH- 
WALLED ROCK FRACTURES. Water Resources Research, 31(5), 11751186. doi: $10.1029 / 95 w r 00171$

Pease, B.J., Geiker, M. R., Stang, H. R, and Weiss, W. J., (2006) "Cracking Behavior of Reinforced Concrete Beams Under Service Loads," Advances in Concrete through Science and Engineering, RILEM Quebec abstract $p$. 281 (electronic proceedings pp. 11)

Pease, B. J., Couch, J. B., Geiker, M. R., Stang, H., and Weiss, W. J., (2009) 'Quantifying Moisture Movement in Cracked Concrete Using X-Ray Absorption," International RILEM Conference on Concrete Durability and Service Life Planning 'ConcreteLife '09', Haifa, Israel (2009)

Pease, B., Skoček, J., Geiker, M. R., Stang, H., and Weiss, W. J., (2007) "The Wedge Splitting Test: Influence of Aggregate Size and Water-to-Cement Ratio," Workshop on Transport Mechanisms in Cracked Concrete, pp. 111-122

Pease, B. J., Geiker, M., Stang, H., and Weiss, W. J., (2010) "Development of an Instrumented Rebar for Assessment of Corrosion in Cracked Reinforced Concrete," Journal of Materials and Structures

Picandet, V., Khelidj, A., and Bellegou, H., (2009) "Crack Effects on Gas and Water Permeability of Concetes," Cement and Concrete Research, 39, pp., 537-547

Pour-Ghaz, M., Castro, J. E., Rajabipour, F., and Weiss, W. J., (2009) 'Measurement and Modeling Fluid Transport in Cracked Concrete," International RILEM Conference on Concrete Durability and Service Life Planning 'ConcreteLife '09', Haifa, Israel (2009)

Pour-Ghaz, M., Rajabipour, F., Couch, J.B, and Weiss, J., (2010) "Numerical and Experimental Assessment of Unsaturated Fluid Transport in Saw-Cut (Notched) Concrete Elements," ACI Special Publication

Pourasee, A., Peled, A., Weiss, W. J., (2011) "Fluid Transport in Cracked Fabric Reinforced Cement Based Composites," ASCE Journal of Civil Engineering Materials, 23, 895; doi:10.1061/(ASCE)MT.19435533.0000247 
Powers, T.C., (1968), "The properties of fresh concrete", John Wiley and Sons, pp 533-652, New York.

Pruess, K. (1999). A mechanistic model for water seepage through thick unsaturated zones in fractured rocks of low matrix permeability. Water Resources Research, 35(4), 1039-1051. doi: 10.1029/1998wr900100

Pruess, K., \& Tsang, Y. W. (1990). ON 2-PHASE RELATIVE PERMEABILITY AND CAPILLARY-PRESSURE OF ROUGH-WALLED ROCK FRACTURES. Water Resources Research, 26(9), 1915-1926. doi: 10.1029/90wr00724

Puri, S., and Weiss, W. J., (2003) "Assessing Damage Localization In Concrete Cylinders Tested In Compression," The Seventh International Symposium On Brittle Matrix Composite, 13-15 October 2003, Editors A Brandt, V. Li, and Marshall, BMC 07, Woodhead Publishers, pp. 111-120

Puri, S., and Weiss, W. J., (2005) "Assessment of Localized Damage in Concrete Using Acoustic Emission" Journal of Engineering Materials, ASCE,

Rajabipour, F., Schmit, T., and Weiss, W. J., (2006) "'Linking Health Monitoring in Concrete Structures with Durability Performance Simulations', American Society of Civil Engineers Structures Congress, St. Louis, Missouri, St. Louis MO, (electronic proceedings, pp. 10)

Rajabipour, F., and Weiss, J., (2008) "Parameters Affecting the Measurements of Embedded Electrical Sensors for Concrete Health Monitoring Applications," American Concrete Institute Special Publication 252, CD

Reinhardt, H. W., Sosoro, M., \& Zhu, X. F. (1998a). Cracked and repaired concrete subject to fluid penetration. Materials and Structures, 31(206), 74-83. doi: 10.1007/bf02486468

Reinhardt, H. W., Sosoro, M., \& Zhu, X. F. (1998b). Cracked and repaired concrete subject to fluid penetration. Materials and Structures, 31(206), 74-83. doi: $10.1007 / \mathrm{bf02486468}$

Reinhardt H.W., Jooss M., Permeability and self-healing of cracked concrete as a function of temperature and crack width, Cement and Concrete Research, vol. 33, p. 981-985, 2003. 
Rodriguez O.G. and Hooton R. D., Influence of Cracks on Chloride Ingress into Concrete, ACI Materials Journal, vol. 100, no. 2, March-April 2003, 120126.

Roels, S., Vandersteen, K., \& Cameliet, J. (2003). Measuring and simulating moisture uptake in a fractured porous medium. Advances in Water Resources, 26(3), 237-246. doi: 10.1016/s0309-1708(02)00185-9

Saito M., Minoru O., Hiroshi I., Chloride Permeability of Concrete Subjected to Freeze-Thaw Damage, Cement and Concrete Composites, vol. 16, pp. 233-239, 1994.

Saito M., Chloride Permeability of Concrete under static and repeated compressive loading, Cement and Concrete Research, vol. 25, no. 4, p. 803-808, 1995.

Samaha H.R., Hover K.C., Influence of Microcracking on the Mass Transport Properties of Concrete, ACl Materials Journal, vol.89, no.4, pp. 416-424, 1992.

Samson E., Marchand J., Snyder K.A., Beaudoin J.J., Modeling ion and fluid transport in unsaturated cement systems in isothermal conditions, Cement and Concrete Research, vol.35, p.141-153, 2005.

Sant, G., and Weiss, W. J., (2009) "Using X-Ray Absorption to Assess Moisture Movement in Cement-Based Materials," Journal of ASTM International, July, Volume 6, Issue 9, 15 pages

Sant,, G., Eberhardt, A., Bentz, D., and Weiss, J., (2009) "The Influence of Shrinkage-Reducing Admixtures (SRAs) on Moisture Absorption in Cementitious Materials at Early-Ages" ASCE Journal of Civil Engineering Materials

Schie I, A., Weiss, W. J., Shane, J. D., Berke, N. S., Mason, T.O., and Shah, S. P., (2000) "Assessing the Moisture Profile of Drying Concrete Using Impedance Spectroscopy," Concrete Science and Engineering, Vol. 2, pp. 106-116

Shah, S. P., Weiss, W.J., and Yang, W., (1998) "Shrinkage Cracking-Can It Be Prevented?" Concrete International, Vol. 20, No. 4, pp. 51-55 (Selected by Editors) 
Shah, S. P., Swartz, S. E., and Ouyang, C., "Fracture Mechanics of Concrete," John Wiley @ 1995 Shah, S. P., Wang, K., \& Weiss, W. J. (2000). Is high strength concrete durable? Concrete Technology for a Sustainable Development in the 21st Century, 102-114.

Song, H.-W., \& Kwon, S.-J. (2007). Permeability characteristics of carbonated concrete considering capillary pore structure. Cement and Concrete Research, 37(6), 909-915. doi: 10.1016/j.cemconres.2007.03.011

Su, G. W., Geller, J. T., Pruess, K., \& Wen, F. (1999). Experimental studies of water seepage and intermittent flow in unsaturated, rough-walled fractures. Water Resources Research, 35(4), 1019-1037. doi: 10.1029/1998wr900127

Slate, F.O., and Hover, K.C., (1984), "Microcracking in concrete", Fracture Mechanics of Concrete, pp 137-160

Slowik, V., and Saouma, V. E., (2000) "Water Pressure in Propagating Concrete Cracks," ASCE Journal of Structural Engineering, Vol. 126, No. 2, pp. 235242

Smadi M. M. and Slate F.O., Microcracking of high and normal strength concretes under short-and long-term loadings, ACl Materials Journal, March-April 1989, No. 86 (2), 117-126

Snyder K.A. and J.W. Bullard, "Effect of Continued Hydration on the Transport Properties of Cracks Through Portland Cement Pastes in a Saturated Environment: A Microstructural Model Study," NISTIR 7265 , National Institute of Standards and Technology, August 2005.

Spragg, R., Castro, J., Li, W., Pour-Ghaz, M., Huang, P., and Weiss, W. J., (2011) "Wetting and Drying of Concrete in the Presence of Deicing Salt Solutions", Cement and Concrete Composites, Volume 33, Issue 5, May, Pages 535-542

Spragg, R., Castro, J., Nantung, T., Paredes, M., and Weiss, W. J., "Variability Analysis of the Bulk Resistivity of Concrete Measured Using Cylinders," (Submitted to JAI, November 2011)

Stark, D.C., (1980), "Alkali-Silica Reactivity: Some recommendations", Journal of Cement, Concrete, and Aggregates, Vol. 2, No. 2, pp 92-94 
Takayama, H., Nonomura, M., Masuda, Y., Nakayama, T., Takahashi, M., \& Kojima, Y. (2007, May 05-10). Study on cracks control of tunnel lining concrete at an early age. Paper presented at the 33rd ITA-AITES World Tunnel Congress, Prague, CZECH REPUBLIC.

Torrijos, M. C., Giaccio, G., and Zerbino, R., (2010) "Internal Cracking and Transport in Damaged Concrete," Materials and Structures, Vol 43, pp 109-121

Tokunaga, T. K., \& Wan, J. M. (1997). Water film flow along fracture surfaces of porous rock. Water Resources Research, 33(6), 1287-1295. doi: 10.1029/97wr00473

Ujike, I., Nagataki, S., Sato, R., and Ishikawa, K., (1990) "Influence of Internal Cracking formed around deformed tension bar on air permeability of concrete," Transactions of the Japan Concrete Institute, Vol 12, pp 207214

1.0 Van Mier., (1999)., Towards an Universal Theory for Fracture of Concrete, Chapter 1: Mechanics of Material Failure, in : Mechanics of Quasi-Brittle Materials and Structures, G. Pijaudier-Cabot, Z.Bittnar and B. Gerard (eds.), HERMES Science Publication, Paris, pp. $17-30$

Wang, J. S. Y., \& Narasimhan, T. N. (1985). HYDROLOGIC MECHANISMS GOVERNING FLUID-FLOW IN A PARTIALLY SATURATED, FRACTURED, POROUS-MEDIUM. Water Resources Research, 21(12), 1861-1874. doi: 10.1029/WR021i012p01861

Wang, K. J., Jansen, D. C., Shah, S. P., \& Karr, A. F. (1997). Permeability study of cracked concrete. Cement and Concrete Research, 27(3), 381-393. doi: 10.1016/s0008-8846(97)00031-8

Wang, T., and Hutchinson, T., (2005) "Gas Leakage Rate through Reinforced Concrete Shear Walls: Numerical Study," Nuclear Design and Engineering, 235, pp. 2346-2260

Wang, T., Hutchinson, T.C., Hamilton, C. H., Pardoen, G. C., and Salmon, M. W., (2004) "Gas Leakage Through Reinforced Concrete Shear Walls: Numerical Study," $13^{\text {th }}$ World Conference on Earthquake Engineering, Paper 34 
Wang, X.-Y., \& Lee, H.-S. (2008). Analysis of Chloride Diffusion in Cracked Concrete. Advances in Fracture and Damage Mechanics Vii, 385-387, 661-664.

Weiss, J., Geiker, M., and Hansen, K., (in preparation) Using X-Ray Absorption to Detect Fluid Ingress in Cracked Concrete

Weiss, Olek, and Nantung (2000) Interaction Between Micro-Cracking, Cracking and Reduced Durability in Concrete: Developing Methods for Considering Cumulative Damage in Life-Cycle Modeling, INDOT JTRP Project Proposal

Weiss, W. J., Yang, W., and Shah, S. P., (1998) "Shrinkage Cracking of Restrained Concrete Slabs." Journal of Engineering Mechanics Division, American Society of Civil Engineering, Vol. 124, No. 7, pp. 765-774

Weiss, W. J, Yang, W., and Shah, S. P., (2000) "Influence of Specimen Size and Geometry on Shrinkage Cracking." Journal of Engineering Mechanics Division, American Society of Civil Engineering, Vol. 126, No. 1, pp. 93101

Weiss W. J., Radlinska A., Paradis F., Niemuth M., and Sant G., (2007) 'Cracks in Concrete: an Overview of an Approach to Assess Their Development, Their Physical Features, and Their Impact on Durability', RILEM Workshop: Transport Mech. In Cracked Conc., Ghent (2007)

Weiss, W. J., Lura, P., Rajabipour, F., and Sant, G., (2008) "Performance Of Shrinkage Reducing Admixtures At Different Humidities And At Early Ages," American Concrete Institute Materials Journal, Vol. 105, no. 5, pp. 478-486

Weyers, R. E., Conway Jr, J. C., \& Cady, P. D. (1982). Photoelastic analysis of rigid inclusions in fresh concrete. Cement and Concrete Research, 12(4), 475-484. doi: 10.1016/0008-8846(82)90062-x

Wiens, U., Meng, B., Schroeder, P., and Schiessl, P. (1997), "Micro-cracking in high-performance concrete- from model to the effect on concrete properties," Self-desiccation and its importance on concrete technology, B. Persson and G. Fagerlund, eds., Lund, Sweden, 193-208

Win, P. P., Watanabe, M., \& Machida, A. (2004). Penetration profile of chloride 
ion in cracked reinforced concrete. Cement and Concrete Research, 34(7), 1073-1079. doi: 10.1016/j.cemconres.2003.11.020

Witherspoon, P. A., Wang, J. S. Y., Iwai, K., \& Gale, J. E. (1980). VALIDITY OF CUBIC LAW FOR FLUID-FLOW IN A DEFORMABLE ROCK FRACTURE. Water Resources Research, 16(6), 1016-1024. doi: 10.1029/WR016i006p01016

Xi, Y., Bazant, Z. P., Molina, L., and Jennings, H., M., (1994) "Moisture Diffusion in Cementitious Materials - Moisture Capacity and Diffusion," Advanced Cement Based Materials, 1, 258-266

Yang, Z., Weiss, W.J., Olek, J., and Nantung, T., (2005a) "Assessing Damage, Sorptivity, Air Content and Strength of PCCP in Indiana" 8th International Conference on Concrete Pavements, pp. 128-148

Yang, Z., Weiss, W. J., and Olek, J., (2005b) "Using Acoustic Emission For The Detection Of Damage Caused By Tensile Loading And Its Impact On The Freeze-Thaw Resistance Of Concrete," CONMAT 2005

Yang, Z., Weiss, W. and Olek, J. (2005c), "Interaction Between Micro-Cracking, Cracking, and Reduced Durability of Concrete: Developing Methods for Quantifying the Influence of Cumulative Damage in Life-Cycle Modeling", Final Report, FHWA/IN/JTRP-2004/10, Joint Transportation Research Program

Yang , Z., Weiss, J., and Olek, J., (2006) "Water Transport in Concrete Damaged by Tensile Loading and Freeze-Thaw Cycling," ASCE Journal of Civil Engineering Materials

Yang, Z., Weiss, J., and Olek, J., (2007) "Water Absorption in Partially Saturated Fracture Concrete," Workshop on Transport Mechanisms in Cracked Concrete, RILEM Week, Ghent, Belgium

Yoon, S., Wang, K., Weiss, W. J., and Shah, S. P. (2000a) "The Interaction between Loading, Corrosion, and Serviceability of Reinforced Concrete." American Concrete Institute Materials Journal, Vol. 97, no. 6, NovemberDecember, pp. 637-644 
Yoon, D. J., Weiss, W. J., and Shah, S. P., (2000b) "Detecting the Extent of Corrosion with Acoustic Emission," Transportation Research Record 1698, pp. $54-60$

Yoon, D.-J., Weiss, W. J., and Shah, S. P., (2000c) "Assessing Corrosion Damage in Reinforced Concrete Beams Using Acoustic Emission." Journal of Engineering Mechanics Division, American Society of Civil Engineering, 126(3), 273-283

Yoon, I.-S., \& Schlangen, E. (2010). Long/Short Term Experimental Study on Chloride Penetration in Cracked Concrete. Advances in Fracture and Damage Mechanics Viii, 417-418, 765-768.

Yoon, I.-S., Schlangen, E., de Rooij, M. R., \& van Breugel, K. (2007). The effect of cracks on chloride penetration into concrete. Advances in Fracture and Damage Mechanics VI, 348-349, 769-772.

Zhou, Y., M. D. Cohen, and W. L. Dolch (1994), "Effect of external loads on the frost-resistant properties of mortar with and without silica fume," $\mathrm{ACl}$ Material Journal, 91(6), 595-601

Zhou, X., Zheng, J., Mao, K., \& Soc, I. C. (2007). Application of modified back propagation algorithm to the prediction of the chloride ion concentration in cracked concrete. ICNC 2007: Third International Conference on Natural Computation, Vol 3, Proceedings, 257-261. 


\section{Distribution:}

H. H. Burns, 773-43A - Rm.227

B. T. Butcher, 773-43A - Rm.212

T. W. Coffield, 705-1C

L. B. Collard, 773-43A - Rm.207

D. A. Crowley, 773-43A - Rm.216

S. D. Fink, 773-A

G. P. Flach, 773-42A

K. M. Fox, 999-W

B. J. Giddings, 786-5A

C. C. Herman, 999-W

C. A. Langton, 773-43A

S. L. Marra, 773-A

B. A. Martin, 705-1C

A. M. Murray, 773-A

F. M. Pennebaker, 773-42A

K. H. Rosenberger, 705-1C

F. M. Smith, 705-1C

W. R. Wilmarth, 773-A

(1 file copy \& 1 electronic copy), 773-43A Rm.213 